\title{
THIRD PARTY CITIZEN REACTIONS TO INTERVENTIONS IN A GENOCIDE: THE INFLUENCE OF THE SOCIAL CATEGORIZATION OF VICTIMS AND THE NORM OF A RESPONSIBILITY TO PROTECT
}

\author{
By \\ Andrena Pierre
}

\begin{abstract}
A thesis submitted to
the Faculty of Graduate Studies and Postdoctoral Affairs

in partial fulfillment of the requirements of the degree of

Doctor of Philosophy

in

Psychology
\end{abstract}

\author{
Carleton University \\ Ottawa, Canada
}

(C) 2013 Andrena Pierre 


\begin{abstract}
Groups involved in ongoing genocidal conflicts within a nation may appeal to third nations, who are neither perpetrators nor victims, as potential allies. The present research investigated social psychological factors that influence citizens of a third party country (Canada) to support and participate in actions to intervene in an ongoing genocidal conflict in a distant region of the world (Darfur). Study $1(n=135)$ examined the influence of social categorization (decategorization, outgroup and common ingroup) on participants' endorsement of prosocial actions, as well as the mediating role of psychological antecedents, including perception of complicity in the genocide due to inaction, perception that the ingroup could be held accountable for their inaction, and guilt (for the situation of the victims and for the ingroup's inaction). The results suggested that framing the plight of victims of genocide in terms of the victimization of particular individuals might be more effective in eliciting appraisals and emotions that encourage support for intervention. Study $2(n=100)$ built on the results of Study 1 to explore whether the influence of recategorization of the victims as humans (relative to outgroup members) on endorsement of prosocial actions and its antecedents was moderated by individuals' evaluation of human beings (humanity-esteem). The moderation hypothesis was not supported; however, portraying the victims as a part of a common humanity was associated with greater feelings of guilt for the victims' plight. In addition, the more participants held humans in high esteem, the more likely they were to endorse government intervention. Study $3(n=321)$ assessed whether the relations among complicity, feelings of guilt and prosocial actions were altered when competing norms that prescribed action against genocide were made salient (i.e., the norm of a
\end{abstract}


responsibility to protect versus the norm of non-intervention in a sovereign country). It appears that people were more likely to comply with norms that prescribed demanding actions, such as the protection of others, only when there were no alternative norms that provided an escape from such obligations. The implications of these findings for citizen support for international interventions in conflict regions are discussed. 


\section{Acknowledgements}

I would like to acknowledge the contribution of several individuals and organizations that have made the completion of this doctoral thesis possible. First, I would like to acknowledge the doctoral scholarships that were awarded to me by the Canadian Institutes of Health Research (CIHR; 200710CGD-188128-159950) and by Carleton University. I would also like to thank the participants in my studies for their time. A special thanks goes to member of my advisory committee, Dr. Kim Matheson, my supervisor, for her time, her assistance, her guidance, and continued insightful research input throughout the whole course of my doctoral studies; Dr. Hymie Anisman, whose input was instrumental in helping me frame the first study of this thesis; and Dr. Michael Wohl, for sharing with me research tools as well as input and documents that were important for the design of the second study of this thesis.

Second, I would like to thank members of the administration team of Carleton University, namely Etelle Bourassa who provided me with unexpected and important help in several occasions; and June Callender and Juliet Kayanja who always had the right words of encouragement at the right moment. Special thanks go to Jessica Palladina for her administrative support. I would also like to thank my colleague Tracey Cronin, for her statistical help and our research discussions regarding the studies presented here. Additionally, I would like to thank my officemates Robyn McQuaid and Opal McInnis for their support.

Third, I would like to thank my professional family from McGill University who continued to support me and keep me connected with the research and clinical interventions that are conducted at the Jewish General Hospital. Along this line, I would 
like to particularly thank Marc Renaud, who during my first years of undergraduate studies started to call me Dr. Pierre before I even envisioned myself with this social identity.

Of course, I could not have completed this $\mathrm{PhD}$ without the support, the listening abilities, and the encouragement of family members and close friends: Daniela, Germaine, Daniel, Jude, Catherine, Erllynne, Antoine, Lily, Ademola, Amatoritsero, Berthony, Jean-François, Claude, Don, to name a few. I also would like to acknowledge the support of the newest arrivals in my life, the Mak family, in particular Jon, Gerrit and Ron.

Finally, this thesis is the fruit of a long journey, but most of all, it is the fruit of love, faith and resilience. So, to my very special, loving, faithful, and resilient family, who has been with me in every step of this long journey, when I will receive my diploma, I will remember that I owe it to you. 


\section{Table of Contents}

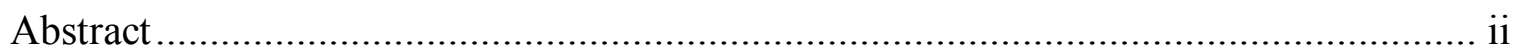

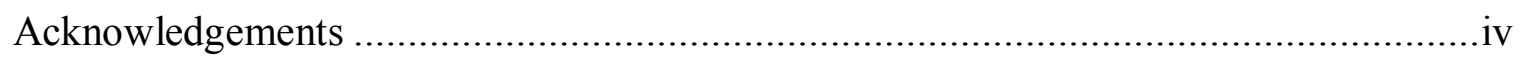

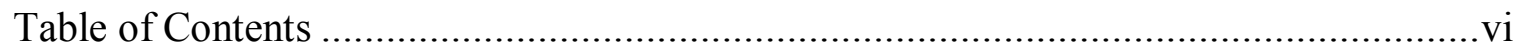

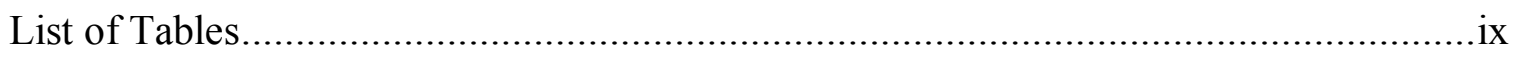

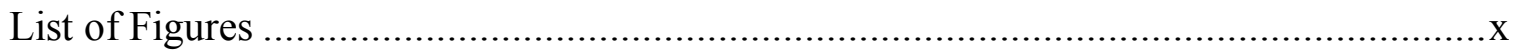

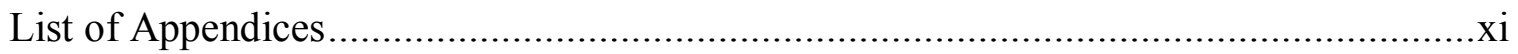

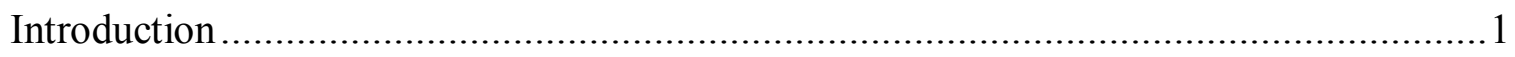

Chapter 1: Theoretical Background...........................................11

The Impact of Categorization, Re- and De-Categorization on Reactions to a

Genocide............................................................. 11

National Complicity............................................... 15

National Accountability ............................................ 17

Guilt............................................................. 17

Prosocial Actions.......................................................20

Overview of the Present Research.....................................21

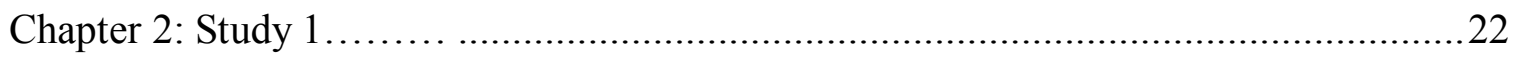

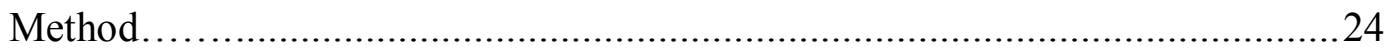

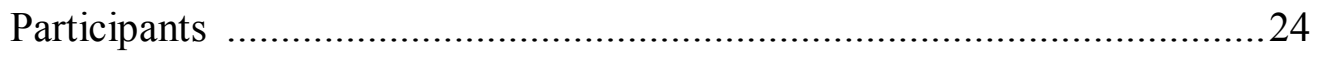

Procedure ................................................................................. 25

Measures................................................................................ 27

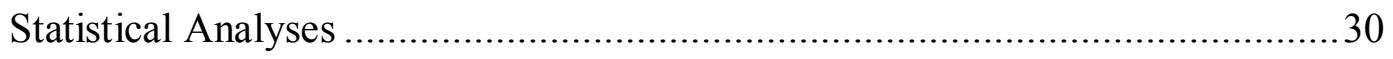

Results............................................................ 32 


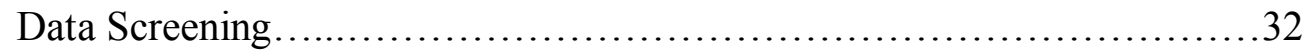

Preliminary Analyses.............................................32

Main Analyses.................................................... 35

Discussion.......................................................... 41

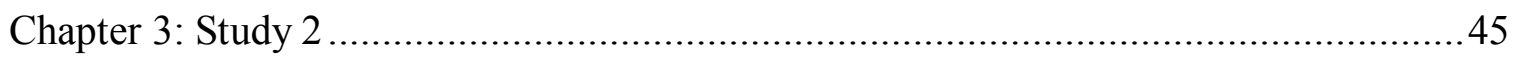

Present Investigation...............................................48

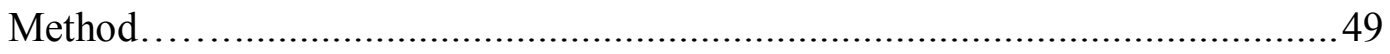

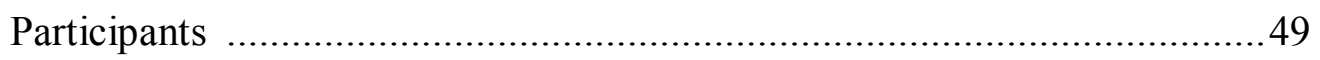

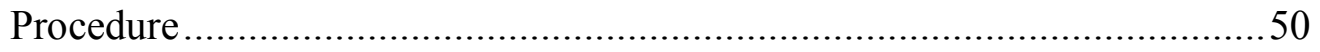

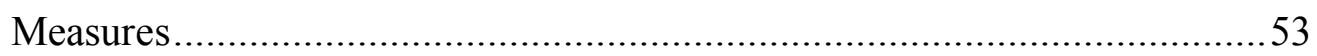

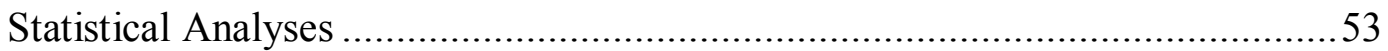

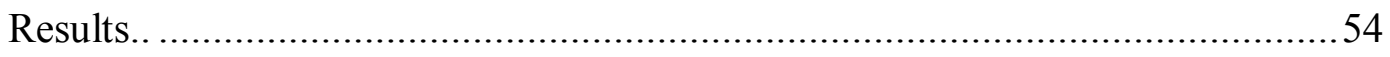

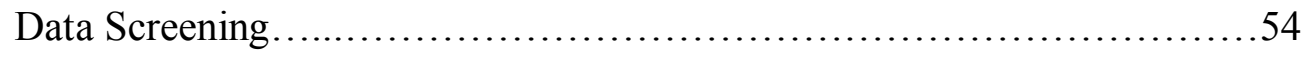

Preliminary Analyses............................................55

Main Analyses.................................................56

Discussion.......................................................61

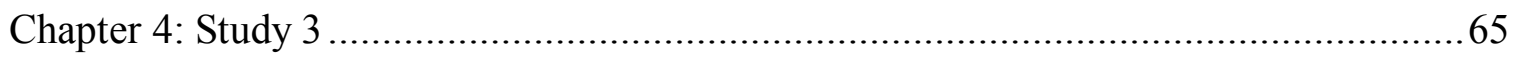

Responsibility to Protect............................................65

Normative Behaviors............................................67

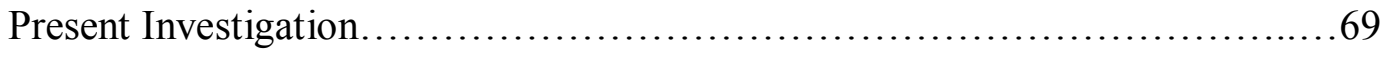

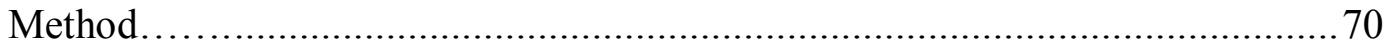

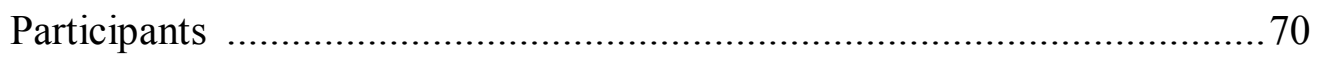

Procedure .............................................................................. 71 
Measures.

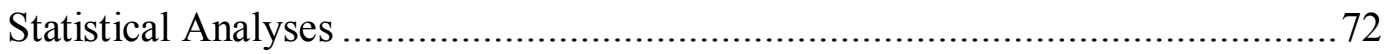

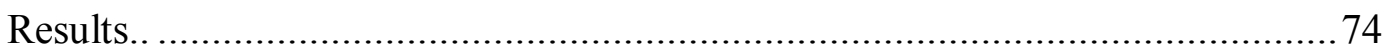

Data Screening............................................... 74

Preliminary Analyses........................................... 74

Main Analyses.................................................. 75

Discussion....................................................... 81

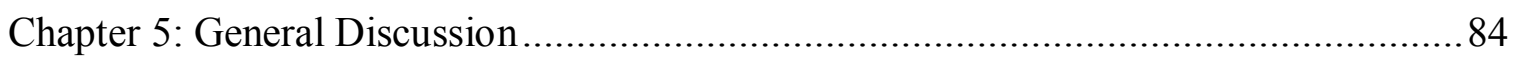

Limitations....................................................93

Future Directions..................................................... 96

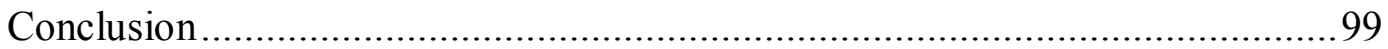

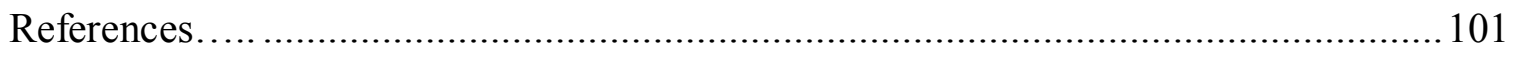




\section{List of Tables}

Table 2.1. Correlations Among the Main Variables in the Study .................................34

Table 3.1. Descriptive Statistics (Means and Standard Deviations) for the Common

Ingroup and the Outgroup Categorizations and the Total Sample...............57

Table 3.2. Item-total Reliabilities and Bivariate Correlations Among the Main

Variables......................................................... 58

Table 3.3. Regression Coefficients for Moderation Model .........................................59

Table 4.1. Item-total Reliabilities and Bivariate Correlations Among the Main

Variables

.76 


\section{List of Figures}

Figure 0.1 . Explanatory model of the process by which social categorization and norms influence endorsement of actions through the mediation of appraisals and emotions........................................................... 10

Figure 2.1. Standardized beta $(\beta)$ estimates of the model of prosocial actions against genocide relating levels of categorization, complicity in the genocide, ingroup accountability, guilt for the situation of the victims, guilt for the inaction of Canada, and endorsement of government intervention and collective action

Figure 4.1. Predictive path model linking norms, perceived complicity in the genocide, guilt (about the situation in Darfur and for the inaction of Canada) and endorsements of government intervention and collective action 


\section{List of Appendices}

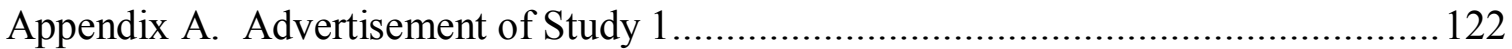

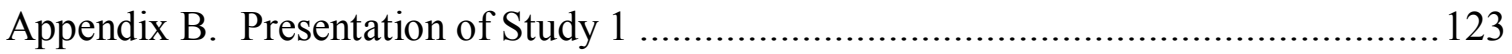

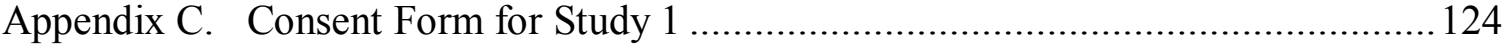

Appendix D. Socio-demographic Characteristics and Engagement with Current News................................................................. 126

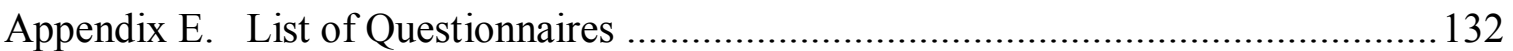

Appendix F. Manipulation of the Levels of Social Categorization............................. 134

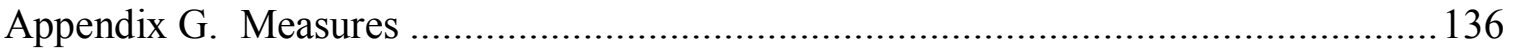

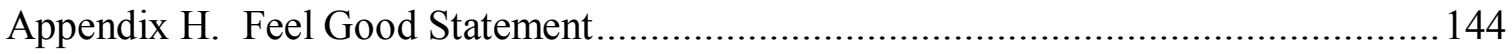

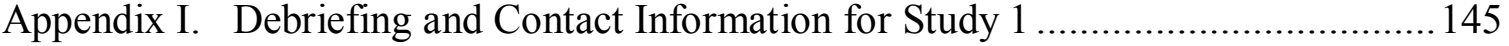

Appendix J. Announcement for Recruitment for Study 2 .................................. 148

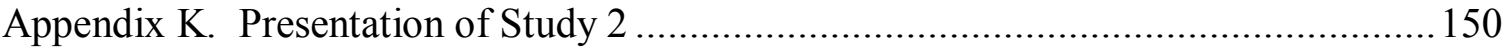

Appendix L. Informed Consent Form for Study 2 ............................................. 151

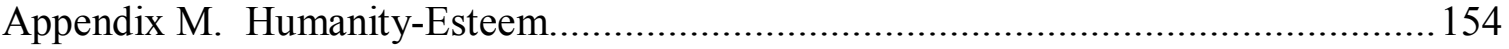

Appendix N. Manipulation of Levels of Social Categorization for Study 2 ............... 155

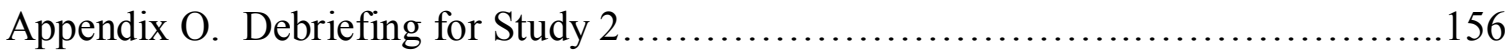

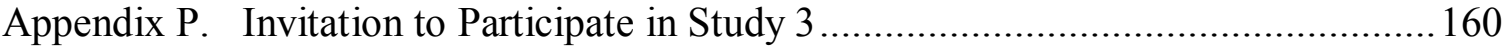

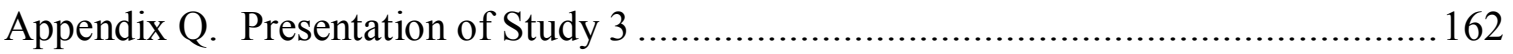

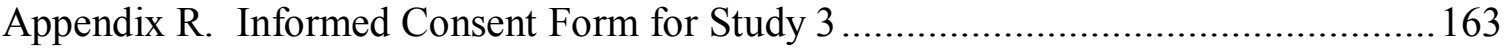

Appendix S. Debriefing and Contact Information for Study 3 ............................. 165

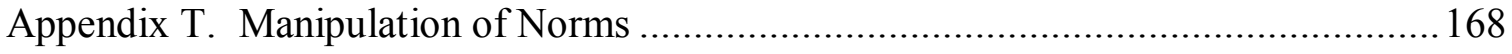




\section{Third Party Citizen Reactions to Intervention in a Genocide: The Influence of the Social Categorization of Victims and the Norm of a Responsibility to Protect}

"We have all been bystanders to genocide. The crucial question is why" (Power, 2003).

The above epigraph is a sentiment expressed by Samantha Power, a former Balkan war correspondent and founding executive director of Harvard's Carr Center for Human Rights Policy, in view of the failure of American leaders and citizens to prevent or stop genocides (i.e., acts committed with the intent to decimate a group) during the twentieth century. Still, in the twenty-first century, the delayed international response to the recent Darfur genocide (LeBor, 2006) illustrates a continued passive complicity in genocide, but also fosters the need to discover what would influence individuals to take action against ongoing genocide. Conflicts of varying degrees between groups are expected to increase due to globalization, overpopulation, discrimination and aspirations for self-determination (Staub, Pearlman, Gurbin, \& Hagengimana, 2005). When groups are involved in ongoing genocidal conflicts they may appeal to third parties, who are neither perpetrators nor victims, as potential allies (Nolte \& Aust, 2009; Simon \& Klandermans, 2001). The intervention of third parties can influence the course of these conflicts in one way or the other. Notwithstanding, some states may have sufficient influence or authority to pressure states that are perpetrating wrongdoing to find a peaceful solution to the conflict (Wettstein, 2010).

Of particular relevance, the ways the victims are portrayed to members of third party groups as well as norms that prescribe intervention against genocide are expected to influence actions against genocide. In this respect, prosocial actions on behalf of victims of genocide can be publicly mobilized (Reicher, Cassidy, Wolpert, Hopkins, \& Levine, 
2006) and public mobilization usually influences government policies and actions (Louis, 2009; McGarty, Bliuc, Thomas, \& Bongiorno, 2009; Montreal Institute for Genocide and Human Rights Studies [MIGS], 2009). It was the focus of the present research to understand social psychological factors that might influence transnational bystander citizens, who form a third party to national and international conflicts, to support an agenda for their own country to intervene in the face of genocide occurring in other global regions.

The Convention of the Prevention and Punishment of the Crime of Genocide, adopted in December 1948 by the United Nations (UN), considers genocide to be an international crime that needs to be prevented and punished. It defines genocide as any of the following acts committed with intent to destroy, in whole or in part, a national, ethnical, racial, or religious group: a) killing members of the group; b) causing serious bodily and mental harm to members of the group; c) deliberately inflicting on the group conditions of life calculated to bring about its physical destruction in whole or in part; d) imposing measures intended to prevent births within the group; e) forcibly transferring children of the group to another group (Convention on the Prevention and Punishment of the Crime of Genocide, 1948). The Darfur conflict was ongoing at the time of data collection for the preparation of this thesis and this conflict meets most of the criteria of genocide (LeBor, 2006). Moreover, the international inaction toward this conflict is largely covered in the political literature (Badescu \& Berghom, 2009; Booker, 2008; Slim, 2004; Williams \& Bellamy, 2005). Therefore, it provided fertile grounds for research on mobilization of action against genocide. 
It is worthwhile to provide a short account of this conflict for contextual purposes. The Darfur genocide started in April $2003^{1}$ when tribes of settled farmers, who identify as African, accused the Arab government of their country, Sudan, of ethnic discrimination and of ignoring the economical development of the province of Darfur. They asked for greater rights and an equitable share of resources. Following their unmet request, they started to rebel against the government, who in response, sponsored an Arab militia, the Janjaweed (meaning devil on horseback), who raped, starved, destroyed infrastructures, forced the displacement of millions of Africans, and mass murdered hundreds of thousands of others (Booker, 2008; Slim, 2004). By spring 2004, the international community was quite aware of the plight of the Darfur victims, but failed to act in time to stop the mass killing (Badescu \& Bergholm, 2009; LeBor, 2006).

Logically, given that the Darfur conflict meets most of the criteria of genocide (LeBor, 2006) and in line with the responsibility to act against genocide (Glanville, 2012), one would have expected the international community to act quickly to stop the genocide after their failure to prevent it (Williams \& Bellamy, 2005). Instead, influential states have remained silent mainly because of socio-political and economic reasons, including concerns over stigma of colonialism and moral imperialism (Wettstein, 2010). Western intervention might be interpreted as another assault of the West on Arabs and Muslims particularly because the Sudanese government declared the conflict an internal

\footnotetext{
${ }^{1}$ By the beginning of 2004, external observers started to ask whether it is "ethnic cleansing" and "genocide" in Darfur (see http://www.un.org/News/dh/dev/scripts/darfur_formatted.htm). On September 9, 2004, the US administration qualified the conflict as "genocide" (Slim, 2004). In keeping with the scholarly literature on this conflict, the terms conflict and genocide, as in the Darfur conflict or the Darfur genocide, are used interchangeably in this thesis to refer to this particular conflict.
} 
matter and refused foreign interference based on the international principle of nonintervention in a sovereign country (Badescu $\&$ Bergholm, 2009). Further, whereas influential countries, including Russia and China, could have implemented economic sanctions on Sudan, they remained silent to avoid possible drawbacks for their own national economies (Badescu \& Bergholm, 2009; LeBor, 2006).

Certainly, at the macro level (i.e., the state), one could argue that this delayed intervention was mainly motivated by socio-political and economic considerations (Badescu \& Bergholm, 2009; LeBor, 2006). However, even in instances where sociopolitical and economic concerns prevented leaders of states from intervening, there is reason to think that social psychological factors might have motivated citizens of influential states to collectively pressure their government to take action against genocide. Specifically, drawing on the literature on bystander and the rescue of Jews during World War II (WWII), there is reason to think that at the micro level (i.e., citizens), bystanders' willingness to support interventions against the genocide of European Jews was influenced by social psychological processes underlying intergroup relations (Kroneberg, Yaish, \& Stocke, 2010; Levine, Cassidy, Brazier, \& Reicher, 2002; Monroe, 1991, 2008; Yzerbyt \& Demoulin, 2010).

One important determinant of prosocial actions toward victims of genocide is the way the victims are portrayed to members of a third party group that has the possibility to favorably intervene on their behalf. People tend to automatically categorize other individuals on the basis of physical similarity, proximity, or shared fate because it enables them to quickly evaluate and make conclusions about incoming information (Campbell, 1958; Dovidio, Gaertner, Shnabel, Saguy, \& Johnson, 2010). For instance, 
qualitative research revealed that during WWII, a large number of Bulgarians engaged in collective action (e.g., letters to deputies) against the deportation of Jews from Bulgaria because they embraced the inclusion of Jews in their identity as Bulgarians, perceiving them to share the same national feelings, values, norms and interests as them (Reicher et al., 2006). Certainly, bystanders are more likely to help victims who are members of their own group (ingroup) in comparison to victims who belong to another group (outgroup; Dovidio \& Gaertner, 2010; Levine et al., 2002; Reicher et al., 2006). However, this ingroup favoritism diminishes when outgroup members are de-categorized, that is, when they are presented as individuals rather than group members (Brewer \& Miller, 1984; Miller, 2002; Wilder, 1978). Hence, it can be expected that members of third nation party would endorse greater collective action on behalf of the victims and support greater government intervention against genocide when victims are either de-categorized or recategorized into a common group, for example citizens of the world, that is inclusive of members of third nation party.

The processes by which salience of a particular social categorization can influence actions against genocide remain to be explored. It is well documented that how people categorize victims of harm not only influences their behavior toward victims, but also their appraisals and emotions toward the situation (Dumont, Yzerbyt, Wigboldus, \& Gordijn, 2003; Gordijn, Wigboldus, \& Yzerbyt, 2001; Gordijn, Yzerbyt, Wigboldus, \& Dumont, 2006; Kuppens \& Yzerbyt, 2012). Genocide is a vicarious emotion-eliciting event (Lickel, Schmader, \& Barquissau, 2004). It has been suggested that narratives of genocide might directly evoke emotions that can lead to helping the victims (Slovic, 2007). Emotions can also be derived from how individuals appraise their role and that of 
members of their group in a particular situation (Cehajic-Clancy, Effron, Halperin, Liberman, \& Ross, 2011; Zimmerman, Abrams, Doosje, \& Manstead, 2011). In this regard, members of groups who perpetrated harm against members of another group can blame themselves for the harm doing, as well as acknowledge that others could hold their group responsible for such harm (Cehajic-Clancy et al., 2011; Lickel et al., 2004;

Zimmerman et al., 2011). These studies have primarily been conducted among members of groups that were the perpetrators of the harmful actions. However, because of the universal responsibility to act against genocide (Arbour, 2008), group members who are not direct perpetrators of genocide could perceive themselves as complicit in the genocide because of their inaction, and that they could be held to account for their failure to act against the genocide.

It is suggested that the way third party members interpret their role with respect to the genocide will greatly determine their emotional and subsequent behavioral responses. Guilt is an unpleasant emotion that is evoked when people perceive that they (personal guilt) or members of their group (collective guilt) are responsible for wrongdoing or could be perceived by others as such (Beaumeister, Stillwell, \& Heatherton, 1994; Wohl, Branscombe, \& Klar, 2006). When people feel guilty they perform actions aimed to alleviate the psychological distress caused by the feelings of guilt (Baumeister, Vohs, DeWall, \& Zhang, 2007). For instance, when Dutch citizens learned that Dutch UN soldiers failed to stop perpetrators of genocide (Serbs) and even cooperated with them, they experienced feelings of guilt particularly when they humanized the victims of the genocide. The collective guilt felt on behalf of members of their group was related to supporting reparation policies (Zebel, Zimmermann, Viki, \& Doosje, 2008). 
Emanating from social categorization, are the group norms that evolve and can influence actions towards victimized groups (Branscombe, 2004; Kroneberg,Yaish, \& Stocke, 2010; Reicher et al., 2006; Thomas \& Louis, 2013). For example, when the social and economic disadvantages of people in developing countries were made salient, and a group norm that suggested that people should be outraged by this was elicited, citizens of developed countries showed greater intentions to take actions to reduce this disadvantage in comparison to people who were not primed with the outrage norm (Thomas \& McGarty, 2009). However, the process through which social norms influence behavioral intention is unclear and remains to be investigated.

People might be exposed to multiple norms. While certain group norms can promote action, others can deter action. People might be apathetic toward genocide occurring in another region of the world when norms that prescribe action against genocide are overshadowed by norms that promote non-interference in the internal affairs of sovereign states (Badescu \& Bergholm, 2009; Warner, 2003). With that in mind and drawing from the emerging literature on the Responsibility to Protect (R2P) norm (Arbour, 2008; Badescu \& Bergholm, 2009; Chalk, Dallaire, Matthews, Barqueiro, \& Doyle, 2010; De Waal, 2007; Glanville, 2012; Montreal Institute for Genocide and Human Rights Studies [MIGS], 2009; Prantl \& Nakano, 2011; Warner, 2003; Williams \& Bellamy, 2005), it was of interest to examine what happens to prosocial actions against genocide when individuals' attention is drawn toward both the norm promoting a responsibility to protect and the competing norm of non-intervention, in comparison to when attention is only drawn to the responsibility to protect norm, or no norm is made salient. 
There is a wealth of evidence indicating that salient norms influence emotions (Tarrant, Dazeley, \& Cottom, 2009) and behaviors (Cialdini, Reno, \& Kallgren, 1990; Harvey \& Enzle, 1981; Jetten, Spears, \& Manstead, 1996; Krupka \& Weber, 2009; Steg $\&$ de Groot, 2010). When individuals violate a moral norm (e.g., norms that proscribe interpersonal violence or criminal behavior, or norms that prescribe social equality), they experience negative self-critical emotions, including guilt, and thereby try to make amends in order to alleviate the negative emotion (Lopez-Perez, 2010). However, when there is a competing norm that liberates individuals from their obligation, they will most likely conform to this latter norm (Schwartz, 1977). Therefore, in the present context, it is reasonable to think that individuals whose attention was drawn to a situation where a norm that prescribes a responsibility to protect citizens from a genocide is ousted by a norm that prescribes inaction would be less likely to endorse prosocial actions (e.g., collective action to encourage social mobilization and government intervention) in comparison to individuals for whom only a single norm that prescribes a clear course of action is salient.

Understanding the process by which social categorization and norms influence prosocial actions against an ongoing genocide may provide insights to encouraging third party nation to prevent or stop genocide. Additionally, identifying the psychological factors that mediate the impact of international norms on the will to intervene against genocide would provide insights into the challenges of implementing international agreements. The scarce social psychological literature on genocidal conflict has focused on psychological factors (cognitive and emotional) that could foster forgiveness of past transgressions (Wohl \& Branscombe, 2005), reconciliation (Kanyangara, Rime, 
Philippot, \& Yzerbyt, 2007; Staub, 2006) or reparation of harm done (Rensmann, 2004) after conflicts are resolved (Staub et al., 2005; Zebel et al., 2008). While these studies provide some insights into how and what psychological factors motivate prosocial actions towards past genocide, it is unclear whether the same psychological factors and mechanisms can explain prosocial actions against an ongoing genocide. It is suggested, as presented in Figure 0.1, that prosocial actions against genocide are influenced by how victims are categorized as well as by salient norms regarding appropriate behavioral reactions to genocide, and that these relations are mediated by individuals' appraisals and emotions.

The present research, which comprised three studies, investigated social psychological factors that motivate citizens of Canada, a third party nation, to support participation in actions to intervene in an ongoing genocidal conflict in a distant region of the world within the theoretical framework of social identity and self-categorization theories (Tajfel, 1978, 1982; Tajfel \& Turner, 1979, 1986; Turner, 1982). Study 1 examined the influence of levels of social categorization (decategorization, outgroup, and common ingroup) on endorsement of prosocial actions and the mediating role of psychological antecedents, including perception of complicity in the genocide due to inaction, perception that the ingroup could be held accountable for their inaction, and emotional guilt toward both the situation of the victims and Canada's inaction. Study 2 built on the results of Study 1 to explore whether the influence of levels of social categorization (outgroup and common ingroup) on endorsement of prosocial actions and its psychological antecedents (including perception of complicity in the genocide due to inaction, perception that the ingroup could be held accountable for their inaction and 


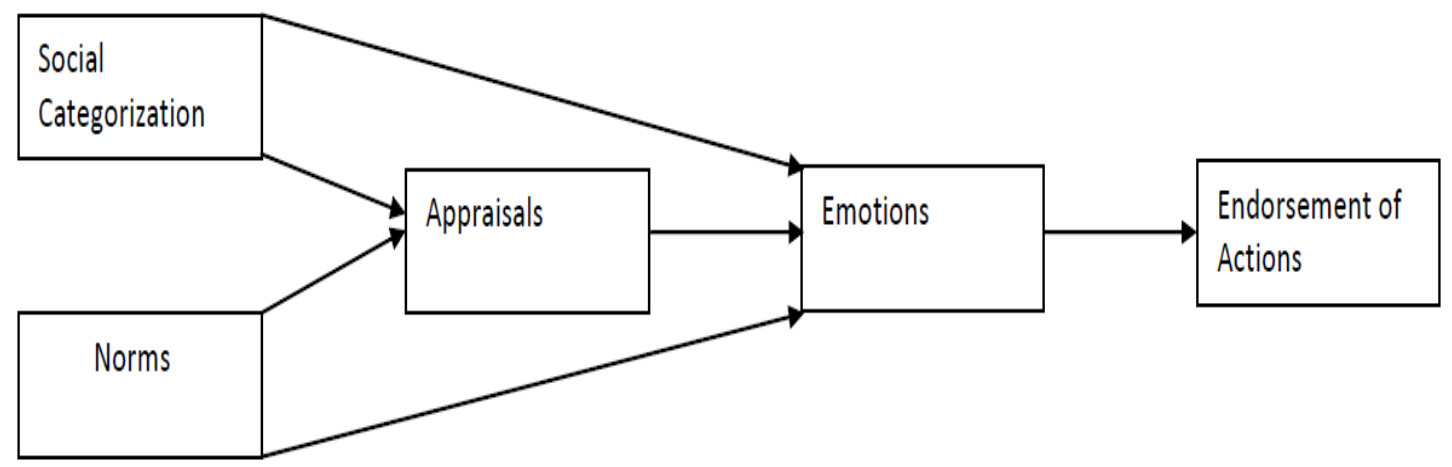

Figure 0.1. Explanatory model of the process by which social categorization and norms influence endorsement of actions through the mediation of appraisals and emotions. 
feelings of guilt) was moderated by an individual difference factor, namely humanityesteem. Study 3 assessed whether the relations among complicity, feelings of guilt and prosocial actions were altered when competing norms that prescribed action against genocide were made salient.

\section{Chapter 1: Theoretical Background}

\section{The Impact of Categorization, Re- and De-Categorization on Reactions to a Genocide}

In the past two decades, there has been increasing interest in factors that motivate prosocial actions in an intergroup context (Dovidio, Gaertner, Validizic, Matoka, Johnson, \& Frazier, 1997; Tarrant et al., 2009). The factors include perceived responsibility (complicity) and perceptions that one's group could be held accountable (accountability) for their action or inaction, as well as emotional reactions (e.g., guilt) regarding the event or the persons involved in the event (Lickel et al., 2004). Categorization is one overarching psychological process that influences not only prosocial action but also the related appraisals and emotions (Gordijn et al., 2001). Social identity and self-categorization theories (Tajfel, 1978, 1982; Tajfel \& Turner, 1979, 1986) provide a framework to understand and explain how categorization of victims into one group or another, or re-categorization of victims into a common ingroup that include both groups, as well as de-categorization of victims (which emphasizes the individual identity) influence prosocial action and its predictors. According to these theories, how people evaluate, feel and behave depends on the relative salience of their personal or their social identity (Tajfel \& Turner, 1986; Turner, Hogg, Oakes, Reicher, \& Wetherell, 1987). 
In general, when people are categorized as members of an ingroup versus members of the outgroup, this categorization facilitates intergroup bias and derogation of the outgroup (Tajfel \& Turner, 1986). Under these conditions, individuals embody the group and they think and behave in the ingroup's interest vis-à-vis the outgroup (Tajfel, 1978, 1982; Tajfel \& Turner, 1979, 1986). For instance, people were more likely to help ingroup members as opposed to outgroup members (Dovidio et al., 1997; Kogut \& Ritov, 2007), and were more likely to intervene in a situation where a victim of violence was an ingroup member in comparison to an outgroup member (Levine et al., 2002; Levine, Prosser, Evans, \& Reicher, 2005; Levine \& Thompson, 2004). Thus, it is possible that Canadians failed to encourage national action against the genocide of Darfurians because they categorized them as an outgroup; had the victims been categorized as ingroup members, actions might have been taken to stop the genocide.

Sometimes outgroup members can be re-categorized into a common ingroup that includes both the ingroup and the former outgroup (Turner, 1982). When both ingroup and outgroup members are recategorized into one inclusive group, such as citizens of the world, intergroup bias is no longer evident, being kept in abeyance at least for the moment. In such instances, group members become cognitively, emotionally and behaviorally responsive to the needs of other members of their common ingroup (Dovidio \& Gaertner, 2010; Levine et al., 2002; Levine et al., 2005; Ray, Mackie, Rydell, \& Smith, 2008). There is a wealth of evidence that recategorization promotes prosocial behaviors. For example, white students from Colgate University in the United States were willing to volunteer the most time in a black students organization on campus when they were exposed to a videotape where a black student viewed himself as a Colgate student 
(Common ingroup) in comparison to when he viewed himself as a unique individual (unique individual identity), a black Colgate student (dual identity) or a black person (different racial identity). There were no differences between the last two conditions, which were the conditions that evoked the least amount of volunteering time (Study 1). In study 2, in an attempt to help the black student confederate complete his research project, as he was supposedly behind due to a serious illness, study participants distributed more posters for the black student when he portrayed himself as a Colgate student in comparison to when he portrayed himself as a black Colgate student (dual identity) or a black person (different racial identity) (Dovidio et al., 2010). Another example is the more Canadians perceived that they formed a single group with people living in developing countries, the greater their engagement in collective action on behalf of people living in those countries (Beaton \& Deveau, 2005). With respect to genocide, qualitative research conducted by Monroe (1991) suggested that the best explanation of why individuals selflessly and at the expense of their own life rescued strangers, in particular Jews who were persecuted by Nazis during the Holocaust, was because they perceived themselves as "strongly linked to others through a shared humanity" (p. 417). Specific to the Darfur genocide, African American lobby groups who perceived the Darfur conflict in terms of Arabs persecuting Blacks pressured the government of the United States (US) to declare the Darfur conflict as genocide so that appropriate actions could be taken to stop the atrocities against fellow Blacks. Christian conservatives who perceived the conflict in terms of an Islamic government who was persecuting good Christians (as opposed to African Arabs persecuting African Blacks) lobbied the US government to act against the atrocities (Barltrop, 2011). Hence, there is evidence that 
when third parties perceived the Darfur victims as ingroup members, they were more likely to encourage national action on behalf of the victims. Drawing from these findings, it is reasonable to think that the salience of a common ingroup that is inclusive of the victimized citizens of Darfur, ought to influence Canadians to endorse greater prosocial actions on the form of government intervention and collective action on their behalf.

Inasmuch as social identity and self-categorization theories suggest that people are more likely to help common ingroup members and are less likely to help outgroup members, de-categorization or perceptions of people as individuals (individualization) rather than group members has also been found to reduce intergroup bias by eliminating group boundaries (Brewer \& Miller, 1984; Miller, 2002; Wilder, 1981, 1986). For instance, Whites provided similar positive evaluation for individualized Blacks, relative to individualized Whites, who were working on the same task with them, but separately, in the same room (Nier, Gaertner, Dovidio, Banker, Ward, \& Rust, 2001). Moreover, this individualization not only leads to favorable perceptions and actions toward the identified outgroup member but also extends to other members of the outgroup (Brewer \& Miller, 1984; Gaertner \& Dovidio, 2010).

There is some evidence that people also react to a single identifiable individual differently than to a group of unidentifiable individuals. This phenomenon is referred to as the identifiable victim effect (Small \& Loewenstein, 2003) or the singularity effect (Kogut \& Ritov, 2005a, 2005b). People are more willing to aid an identified victim than a group of unidentified or statistical victims (Kogut \& Ritov, 2005a, 2005b, 2007; Small \& Loewenstein, 2003, 2005; Jenni \& Loewenstein, 1997; Small, Loewenstein, \& Slovic, 2007). It has been suggested that the story of an identified individual victim may be more 
powerful in helping bystanders to discover the people behind the numbers (Slovic, 2007). The story of one identified victim, as opposed to the presentation of the plight of large number of victims, prevents psychophysical numbing, a phenomenon wherein sensitivity to a stimulus decreases as the magnitude of the stimulus increases (Baron, 1997;

Fetherstonhaugh, Slovic, Johnson, \& Friedrich, 1997; Slovic, 2007; Small et al., 2007; Ubel, Baron, \& Asch, 2001).

Psychophysical numbing helps explain why "the statistics of mass murder or genocide, no matter how large the numbers [...] fail to spark emotion or feeling and thus fail to motivate action" among people who usually are ready to lose their lives to save one life (Slovic, 2007, p. 80). Indeed, people were willing to contribute more money to the rescue of large number of victims than a single victim when victims were categorized as outgroup members (Kogut \& Kitov, 2007; experiment 1). Yet, there is also some evidence that people are more willing to contribute money to rescue one identifiable victim than to rescue a larger number of victims regardless of their group membership (Kogut \& Ritov, 2007). Because a small number is more likely to convey the importance of a life, it is possible that presenting the plight of the Darfur victims in the story of one identifiable individual (decategorization) in comparison to hundreds of thousands of unidentified Darfurians (categorization as outgroup) or hundreds of thousands innocent citizens in countries around the world (recategorization as a common ingroup) might be the most likely to motivate prosocial action against the genocide.

\section{National Complicity}

While social categorization can influence the behavioral reactions (action or inaction) of members of a third nation party toward an ongoing genocide, this influence 
might be mediated by their perceptions of their role with regard to the ongoing genocide. People around the world are expected to act against genocide, as it is a crime against humanity. Individuals, groups or states that create the conditions or encourage others to commit genocide may be perceived as complicit in genocide (LeBor, 2006; Nolte \& Aust, 2009; May, 2010). In a similar fashion, individuals, groups or states (LeBor, 2006; Wettstein, 2010) that are not directly involved in genocide, but that know that genocide is likely to be or is being committed, but do nothing to prevent or stop it, might be considered as passively, silently, or morally complicit in genocide (LeBor, 2006; May, 2010; Wettstein, 2010). Although this type of complicity is not legally punishable (Nolte $\&$ Aust, 2009), perceptions of complicity may threaten the image of implicated individuals, groups or states mainly because inaction in the face of genocide may be considered wrong.

Complicity allows the evolution of atrocities (May, 2010; Stanton, 2004; Staub, 2006) and could be "interpreted as implicit moral approval of the wrongdoing" (Wettstein, 2010, p. 37). From this perspective, members of a third nation party may perceive that they are complicit in the genocide when they fail to prevent or stop it. The extent to which people will blame themselves and their group for their inaction likely depends on how they categorize the victims in relations to themselves. In particular, if the victims (and perpetrators) are perceived as outgroup members, individuals might not see themselves as complicit, whereas when the victim is an ingroup member or is perceived as an individual, self-blame for complicity may be more evident. 


\section{National Accountability}

Given a responsibility to act against genocide, those who perceive themselves as complicit in the genocide because of inaction might also perceive that others could hold them accountable for failure to act against the genocide (Espeland \& Vannebo, 2007; Nolte \& Aust, 2009). Indeed, some authors argue that the Security Council of the UN, whose mandate is to maintain international peace and security, never officially declared the ongoing Darfur conflict as genocide because no one wanted to be held accountable for failure to prevent or stop a genocide (LeBor, 2006). Accountability for a transgression is associated with punishment of perpetrators (Newheiser, Sawaoka, \& Dovidio, 2012). When people are called to account for their actions, they are expected to answer for their obligations and are motivated to avoid reprimand (Lerner \& Tetlock, 1999).

Accountability is a complex construct that is used in the law and justice literature, but also in several other disciplines, including psychology. It "refers to the implicit or explicit expectation that one may be called on to justify one's beliefs, feelings, and actions to others $[\ldots]$ according to some normative ground rules and with some implied consequences" (Lerner \& Tetlock, 1999, p. 255). Although social categorization was suggested as an important predictor of the perception that one's ingroup could be held responsible for wrongdoing (Branscombe, 2004), few empirical studies, if any, have explored this idea in relation to actions (inactions) that allowed for harm-doing of another group.

\section{Guilt}

One mechanism by which social categorization diminishes or motivates prosocial actions is through its effect on emotions (Ray et al., 2008; Thomas et al., 2009). Social 
categorization is associated with emotions (Seger, Smith, \& Mackie, 2009). For instance, research has shown that people expressed greater intentions to help an ingroup member in comparison to an outgroup member through feelings of empathy for the group member (Tarrant et al., 2009). In the context of genocide, an emotion such as guilt is of particular relevance. Guilt is defined as "an individual's unpleasant emotional state associated with possible objections to his or her actions, inaction, circumstances, or intentions" (Baumeister et al., 1994, p. 245). Guilt is about feeling bad. It is an empathic distress, in that people feel bad in reactions to the suffering of others, particularly when the others are ingroup-members (Baumeister et al., 1994). Individuals also express guilt when they failed to help needy others ("failure of prosociality"). The omission to do what one should do is associated with guilt which in turn is associated with the performance of the omitted behavior in an attempt to restore one's morality (Sheikh \& Janoff-Bulman, 2010).

Whereas guilt is an unpleasant self-conscious emotion that arises when a person feels bad about the suffering of others or failed to act according to internalized norm (McGraw, 1987), a person can also feel bad when members of their group are responsible for a negative outcome that violates moral norms and principles of justice (Branscombe, Doosje, \& McGarty, 2002; Branscombe \& Miron, 2004; Wohl et al., 2006) such as the Holocaust (Rensmann, 2004). People express guilt when they, or their group, is perceived as complicit in illegitimate misdeeds or as responsible for harm doing (Iyer, Schmader, \& Lickel, 2007; Lickel, Steele, \& Schmader, 2011; Mallet \& Swim, 2007). This sense of responsibility is a key antecedent to feelings of guilt (Branscombe, Slugoski, \& Kappen, 2004; Wohl et al., 2006). Group members expressed greater guilt on behalf of their group 
when they perceived their group to be responsible for others' suffering (Zimmerman et al., 2011). The more people perceived that they or their group could have done something to stop perpetrators of harm doing, the more guilt they would experience (Branscombe et al., 2004; Power, 2003).

Guilt may also reflect an empathic concern for the harmed group (Miron, Branscombe, \& Schmitt, 2006), but there is evidence to suggest that actions emanating from guilt may reflect a greater concern for reducing one's own distress rather than empathic concern for the victims (Baumeister et al., 2007). The 'death wish' that the renowned general Romeo Dallaire experienced after the Rwanda genocide illustrates the power of guilt and the need to do something to alleviate the guilt. Dallaire mentioned: "I was trying to get myself destroyed in looking to get released from the guilt" (as cited in Power, 2003, p. 385). Thus, when people experience personal or collective guilt they may be more motivated to repair the wrong or to compensate the harmed group out of a desire to reduce their own distress (Baumeister et al., 1994; Doosje, Branscombe, Spears, \& Manstead, 1998; Karacanta \& Fitness, 2006; Schmitt, Branscombe, \& Brehm, 2004; Stewart, Latu, Branscombe, \& Denney, 2010). According to Baumeister and colleagues (1994), "the affective roots of guilt lie [...] in the human capacity to feel the suffering and distress of others" (p. 246). It is possible that recategorization of victims of genocide as humans (the most inclusive ingroup category) would elicit greater guilt than would categorization of victims as outgroup members. It is also possible that members of a third party nation might feel greater guilt when the genocide is presented through the story of an individual or as affecting citizens of the world in comparison to when the genocide is presented as 
affecting Darfur citizens. Research has found that humanization of outgroup victims of genocide predicted greater feelings of collective guilt, which then was associated with more support of reparation policies (Zebel et al., 2008). The relationship between social categorization and guilt was expected to be mediated by individuals' perceptions of their complicity in the genocide as well as their acknowledgement that others could hold their group accountable for their inaction. As mentioned earlier, when individuals feel emotionally guilty they are more likely to endorse actions to repair the wrongdoing (see Figure 0.1, p. 10).

\section{Prosocial Actions}

Actions that are performed in an attempt to elicit a collective response to cease or prevent group injustice suffered by one's ingroup or by outgroup members (in the case of the victims of the Darfur conflict) are considered as collective action (van Zomeren \& Iyer, 2009, p. 646). When individuals perform collective actions for the benefit of outgroup members, these actions are considered to be prosocial actions (Penner, Dovidio, JPiliavin, \& Schroeder, 2005). In a democratic society such as Canada, citizens have access to numerous means to influence national policies and actions that pertain to other regions of the world. Citizens can take collective political action (Stern, Dietz, Abel, Guagnano, \& Kalof, 1999; Louis, 2009; McGarty et al., 2009), which includes participation in demonstrations to protest against their government's decisions, writing letters to their political representatives in order to encourage them to act a certain way, donating money to organizations that lobby the government, and voting strategically for political candidates that support a particular position. 
Governments can also take actions against genocide, including through their articulation of foreign policy, participation in diplomatic talks, humanitarian intervention, as well as military intervention, if necessary (MIGS, 2009). The Darfur genocide provided a fertile ground to examine what might motivate Canadians citizens to endorse both government intervention and collective action against genocide. As presented earlier, categorization, perceived complicity in the genocide, perception that Canadians could be held accountable, and feelings of guilt about both the situation of the victims and Canadians' inaction may play an important role in influencing endorsement of prosocial actions.

\section{Overview of the Present Research}

Factors that might motivate citizens to encourage their own government to take actions against genocide in another region of the world include levels of social categorization (individual vs. outgroup vs. common ingroup). It is suggested that the relation between social categorization and prosocial actions is mediated by the increased salience of perceived complicity in the genocide due to inaction, perceptions that the ingroup could be held accountable, and feelings of guilt. In particular, it was expected that when the Darfur genocide was framed as an individualized story (individual), compared to when it is constructed as the plight of several hundreds of thousands of Darfurians (outgroup) or innocent citizens throughout the world (common ingroup), citizens of third party nations would perceive greater complicity in the genocide and have greater perception that their group could be held accountable for inaction, and experience more negative emotional reactions (guilt). This configuration of appraisals and emotions 
would, in turn, predict greater willingness to act prosocially (support for collective action and endorsement of government intervention to stop the genocide).

The goal of the present research was to investigate social psychological factors that motivate individuals from a bystander nation to take actions against genocide. Study 1 examined the role of levels of social categorization (individual vs. outgroup vs. common ingroup) on endorsement of prosocial actions and whether this relationship is sequentially mediated by appraisals of complicity in the genocide in Darfur due to inaction or perceptions that the ingroup could be held accountable for inaction, and feelings of guilt. Based on the results of Study 1, Study 2 examined whether the mediated relationship between levels of social categorization and prosocial actions was moderated by individual factors such as humanity-esteem. Study 3 assessed whether the relations among appraisals, emotions, and actions were altered when norms that prescribed action against genocide were made salient.

\section{Chapter 2: Study 1}

As noted earlier, self-categorization theory (Turner et al., 1987) posits that responses to others depend on the way others are categorized relative to the self (ingroup vs. outgroup). When groups are perceived as us versus them, it promotes intergroup bias and conflict. However, when the former us and them are recategorized into a greater common group that effectively creates a "we", cooperation and reconciliation are facilitated. Besides recategorization, group members might be decategorized to diminish salience of group boundaries and increase the relevance of personal identities and individualized stories. The goal of Study 1 was to examine whether social categorization at the levels of individual, outgroup, or common ingroup influenced participants' 
endorsement of prosocial actions (collective action or governmental intervention) against the genocide in Darfur. A second goal was to explore the mechanism through which levels of categorization influenced prosocial actions, and in particular the role of perceived complicity for failing to act, perceptions that the ingroup could be held accountable for inaction, and feelings of guilt.

It was hypothesized that:

1. There would be a main effect of social categorization. When the conflict was framed at the level of the individual, participants would be more likely to appraise the situation as one in which their own group had greater complicity and perceive greater ingroup accountability for inaction, experience more guilt (for the situation of the victims and for Canadians' inaction), and greater willingness to endorse prosocial actions (collective action on behalf of victims of genocide and support for government intervention to stop the genocide), in comparison to participants for whom the victims' were depicted as a common ingroup and an outgroup. The same would be true for individuals to whom victims of the conflict were presented as members of the common ingroup in comparison to those to whom victims were presented as members of the outgroup.

2. The relations between levels of social categorization and endorsement of prosocial actions (collective action on behalf of victims of genocide and government intervention to stop the genocide) would be sequentially mediated through perceived complicity, perceptions that the ingroup could be held accountable, and feelings of guilt (toward the situation of the victims and toward Canadians' inaction). 


\section{Method}

\section{Participants}

A community sample of men $(n=30,22.2 \%)$ and women $(n=105,77.8 \%)$ ranging in age from 18 to $66(M=35.39, S D=11.80)$ was recruited through email notices to community and cultural centers, services organizations, and by word-of-mouth. The study was described as a survey assessing Canadians' perspective on various international conflicts. Darfur was not mentioned in order to reduce self-selection biases based on knowledge of this particular conflict. The majority of participants self-identified as White/Euro-Caucasian ( $n=94,69.6 \%)$, whereas the remainder self-identified as Asian ( $n=12,8.9 \%), \operatorname{Arab} /$ West Asian $(n=6,4.4 \%)$, South Asian $(n=6,4.4 \%)$, Black $(n=6$, 4.4\%), South East Asian ( $n=4,3.0 \%)$, Aboriginal ( $n=2,1.5 \%$ ), Latin American/Hispanic $(n=1,0.7 \%)$, or mixed ethnic status $(n=4,3.0 \%)$. In terms of religious affiliation, most participants were either Protestant ( $n=41,30.4 \%)$, Catholic (n $=36,26.7)$ or had no religion $(n=36,26.6 \%)$. The rest were Muslim $(n=8,5.9 \%)$, Jewish $(n=2,1.5 \%)$, or were members of other religious groups $(n=12,8.9 \%)^{2}$. A high proportion of participants had completed at least one year of college/university $(n=95$, $70.4 \%)$, and only a minority were currently full-time or part-time students $(n=20$,

\footnotetext{
${ }^{2}$ As mentioned in the introduction section of this dissertation, the Darfur genocide was perceived by American Christian conservative groups as Muslims persecuting Christians. As such, religious affiliation may affect responses to this conflict, particularly in terms of bond to victims versus bond to perpetrators. While it would have been of interest to assess whether the responses of self-identified Christian and Muslim participants differ from one another or from responses of other religious groups, the number of participants from Islam and other religions (e.g. Judaism) was too small to represent a meaningful comparison.
} 
$14.8 \%)$. The median level of their annual family income was between $\$ 45,000$ and $\$ 54,999$. About $15.6 \%$ of the participants self-identified with the New Democratic Party, $20.7 \%$ with the Liberal, $25.9 \%$ with the Conservative, $3.0 \%$ with the Green Party, $1.5 \%$ with the Bloc Quebecois, and 33.3\% did not identify with any party or did not provide an answer.

\section{Procedure}

The study was conducted online in an attempt to reach individuals from across Canada. To qualify for the study, participants had to be Canadian citizens and aged 18 years or older. The advertisements directed potential volunteers to a website address if they wished to participate (Appendix A). Upon entering the study website, participants were presented with an explanation of what was involved in completing the study (Appendix B). After providing informed consent (Appendix C), participants completed questionnaires that assessed their socio-demographic characteristics as well as their engagement with current news (Appendix D). These latter questionnaires were embedded within a larger set of questionnaires ${ }^{3}$ (Appendix E). They were then randomly assigned to read one of the three scenarios describing the Darfur conflict (Appendix F), after which their interest in the situation in Darfur, emotional reactions, perceptions of the ingroup's role in the conflict, and action endorsements were assessed (see Appendix G). Because it is possible that some individuals would experience mild emotional discomfort when completing the study, a positive mood induction was given at the end of the measures,

\footnotetext{
${ }^{3}$ The set of questionnaires included a variety of measures, only some of which were relevant to the current research questions. The list of all the questionnaires that were used in the present research is provided in Appendix E. Questionnaires that were unique to a study are identified with the study number after the name of the questionnaire.
} 
asking individuals to think of a positive interaction they recently had with others (see Appendix H) (Gill \& Matheson, 2006; Matheson \& Anisman, 2008; Matheson, Gill, Kelly, \& Anisman, 2008). Participants were able to pause during the completion of the questionnaire, as long as they returned to complete it within the same day of starting it. The study took about 45 minutes to complete. At the end, participants received a written debriefing (Appendix I) and a \$10 gift certificate for national chain establishments as compensation for their time. The quality of the data provided was evaluated in terms of random responding (contradictory ratings to reversed items) and reasonable time to completion. Only respondents whose data met the quality check criteria were included in the final analyses.

Manipulation of levels of social categorization. Participants were randomly assigned to read a vignette (See Appendix F) that provided a short summary paragraph of the Darfur conflict that was developed on the basis of information provided in the Canadian media (see http://www.cbc.ca/news/background/sudan/darfur.html).

The region of Darfur in Sudan of Africa is home to communities or tribes of settled farmers who identify as African, alongside tribes of nomadic herders who identify as Arabic. In 2003, the African residents of Darfur accused the government of ethnic discrimination and of ignoring the economical development of their region. They start to rebel against the government. In response, the Sudanese government has sponsored the Janjaweed, an Arab militia on horseback, who use rape, displacement, organized starvation, and mass murder to terrorize innocent African civilians in Darfur. Despite talk on taken action to stop the violence in Darfur, the international community has not yet taken action to end the mass killings of Africans. As a result, 
more than 300,000 African Darfurians have died and more than 2.5 million have fled their homes. This conflict is still ongoing today.

This paragraph was followed by a statement of the impact of the Darfur conflict, which varied as a function of the different experimental conditions. In the decategorized individual condition, participants then read that "Hasan Al-Fashir is one more innocent African citizen who has been murdered in Darfur, leaving behind family who continue to live in fear". In the outgroup condition, participants read that "Hundreds of thousands of innocent citizens have been murdered in Darfur because of their ethnicity among other things"). In the common ingroup condition, participants read that "Hundreds of thousands of innocent citizens have been murdered in countries around the world because of their ethnicity among other things".

To communicate the need for intervention, these statements, respectively, were followed by a final statement (the words in parentheses are for the common ingroup condition): "There is evidence that the perpetrators of these murders are supported by the Sudanese government (by the government of the state). Several organizations are asking the international Criminal Court to do justice and make the government of Sudan (governments of states) accountable for heinous crimes committed against specific groups in Darfur (against citizens of their countries)".

\section{Measures}

General knowledge and interest in the situation in Darfur. In order to provide an overview of participants' engagement with the situation in Darfur, several questionnaires were administered. Indifference to international news due to perceived geographical distance was assessed using six items (e.g., "Most issues discussed in the 
news don't affect me personally" or "Whatever disaster happens in Africa is too far from Canada for me to be concerned"). Respondents rated each item using a 7-point rating scale ranging from 1 (strongly disagree) to 7 (strongly agree). An index of indifference to international news due to perceived geographical distance was created by averaging the scores of the six items. Higher score indicated higher indifference $(\alpha=.91)$. General knowledge of the situation in Darfur was measured with one item ("how familiar are you with this issue"). Importance of the situation in Darfur for oneself was measured with one item ("How important is this issue to you?"), as was importance of the situation in Darfur for Canadians ("How important do you think this issue is to most Canadians"). Respondents rated each item using a 7-point scale ranging from 1(not at all) to 7 (extremely). The two items that measure importance were moderately correlated $(r=.40$, $p<.001)$. Knowledge correlated with importance for oneself $(r=.24, p<.01)$, but not with perceived importance for Canadians $(r=-.03, n s)$.

\section{Perceptions of ingroup role. Perceived complicity in the genocide because of}

inaction. Complicity was measured using 2 items (e.g., "If I don't take action on behalf of the people of Darfur, I become complicit in the genocide of the people of Darfur"; "If Canada does not intercede on behalf of the people of Sudan, we become complicit in the genocide of the people of Sudan"). Participants rated their agreement with each statement on a 7 -point scale $(1=$ strongly disagree, $7=$ strongly agree $)(r=.48, p<.001)$. Scores were averaged for an index of perceived complicity in the genocide because of inaction.

Perception that the ingroup could be held accountable. Accountability was assessed using Branscombe et al. (2004) measure of whole group accountability. This measure comprised five items that were modified to assess the extent to which 
participants thought that Canadians should be held accountable for their inaction in the Darfur conflict, e.g., "All Canadians ought to be held responsible for the inaction of their government" $(\alpha=.88)$. Participants were asked to indicate how much they agreed with each of statement, on a scale ranging from 1 (strongly disagree) to 7 (strongly agree). Scores were averaged to form a scale reflecting ingroup (Canadians') accountability such that higher scores represented greater ingroup accountability.

Guilt. Feelings of guilt for the plight of the people of Darfur. Emotional guilt for the situation of the victims was measured using a single mood adjective (immersed among other mood adjectives) that assessed the extent to which respondents felt guilty 'when they think about the conflict in Darfur'. Respondents rated their emotions on a 7point scale ranging from 1 (not at all) to 7 (extremely).

Collective guilt for Canada's inaction. Collective guilt was assessed using four items taken from Branscombe et al. (2004), and modified to refer to Canada's inaction towards the conflict in Darfur, e.g., "I feel guilty about the inaction of Canada toward the Darfurians". Respondents indicated their agreement with each statement on a scale ranging from 1 (strongly disagree) to 7 (strongly agree). Scores were averaged and higher scores indicated greater collective guilt $(\alpha=.89)$.

Endorsement of prosocial actions. Participants' endorsement of prosocial action in Darfur was assessed in two different ways.

Government intervention. Endorsement of government intervention was assessed with 10 items modified from the recommendations of the will to intervene project (MIGS, 2009). Following a principal components analysis with varimax rotation conducted on the 10 items, Kaiser's criterion indicated one component with an 
eigenvalue greater than 1.00 , which accounted for $58.54 \%$ of the variance. Examples of items included "Prevention of mass atrocities needs to be integrated into Canadian foreign policy" and "if international military action is taken in Darfur, then Canada should participate". Respondents rated the extent to which they agreed or disagreed with each item using a 7-point scale ranging from 1(strongly disagree) to 7 (strongly agree) ( $\alpha$ $=.92)$. Scores were averaged, with high score reflecting greater endorsement of government intervention.

Collective action. To measure endorsement of collective action, participants indicated the extent to which they agreed or disagreed, using a 7-point scale ranging from 1(strongly disagree) to 7 (strongly agree), with seven statements assessing actions that they would be willing to take on behalf of the Darfurians (e.g., "I'd be willing to join a protest march to bring peace and reconciliation in Darfur"). These statements were adapted from other studies on collective action (e.g., Foster \& Matheson, 1995; Gill \& Matheson, 2006; van Zomeren, Spears, Fischer, \& Leach, 2004). A principal components analysis with varimax rotation was conducted on the seven items. Kaiser's criterion suggested that these items assessed one component with eigenvalues greater than 1.00 , which accounted for $59.55 \%$ of the variance. Scores were averaged, with high score indicating greater endorsement of collective action $(\alpha=.88)$.

\section{Statistical Analyses}

Prior to the main analyses, a series of one sample $t$-tests was performed to assess whether participants' responses significantly differed from the mid-point of each of the scales that assessed the engagement of participants (indifference to international news due to perceived geographical distance, general knowledge of the situation in Darfur, 
importance of this issue for oneself and for Canadians). A series of independent $t$-tests was performed to assess gender differences on the variables of interest. Pearson correlations were performed to assess whether the variables varied as a function of age and to examine the bivariate associations among the major variables in the study.

With respect to the main analyses, a series of one-way multivariate analysis of variance (MANOVA) with planned contrasts was conducted on the two ingroup perceptions, the two dimensions of guilt, and the two forms of prosocial action, respectively. The first contrast compared the decategorized individual condition with the two group-based conditions (i.e. common ingroup and outgroup). The second contrast compared the common ingroup with the outgroup condition. When the MANOVA was significant, follow-up ANOVAs were performed to test whether perceptions of ingroup's role in the genocide (complicity, accountability), guilt (toward the situation of the victims and Canadians inaction), and prosocial actions (endorsement of government intervention and collective action) differed as a function of 1) individual versus the common ingroup and outgroup conditions, 2) common ingroup versus outgroup condition.

Following examination of Pearson correlations to assess bivariate relations among the variables of interest, a path analysis was conducted to test the second hypothesis concerning the mechanism by which social categorization influences prosocial action. One advantage to this approach was that it allowed for the testing of sequential mediation with multiple mediating variables in one overall model, thus accounting for multicollinearity between the hypothesized mediating variables. Another advantage to this approach was that it allowed us to determine whether the indirect effects of social 
categorization on prosocial actions operated through different perceptual and emotional processes.

To assess whether the model fit the data, chi-square $\left(\chi^{2}\right)$ measure of fit was considered. The objective is to obtain a nonsignificant $\chi^{2}$. Because $\chi^{2}$ is sensitive to sample size, other indexes of fit were additionally considered, including comparative fit index (CFI) and goodness of fit index (GFI), for which values greater than .90 are deemed acceptable (Pedhazur \& Schmelkin, 1991) as well as Root Mean Square Error of Approximation (RMSEA), for which values less than .08 are deemed acceptable (Brown, 2006).

\section{Results}

\section{Data screening}

The data were examined for missing values, outliers, univariate and multivariate normality, homoscedasticity and multicollinearity. Results of evaluation of linearity and multicollinearity were satisfactory and assumptions of normality and homogeneity of variance matrices were met. There were no missing values or influential outliers and all assumptions of the planned analyses were met.

\section{Preliminary analyses}

Characteristics of respondents. Engagement with the issue. As revealed by one-sample t-tests comparing response means against the midpoint of the relevant scales (i.e., 4), it appears that participants mildly disagreed that what was happening in Sudan was too far from Canada for them to be concerned $(M=2.96, S D=1.30), t(134)=-9.26$, $p<.001$. However, participants were not especially familiar with the situation in Darfur $(M=3.00, S D=1.78), t(134)=-6.55, p<.001$. Despite this, they perceived this issue to 
be more important to them personally $(M=4.37, S D=1.52)$ than to Canadians in general $(M=3.22, S D=1.46, t(134)=8.15, p<.001$.

Influence of gender and age $e^{4}$. Most of the variables that reflected knowledge or the importance of the issue varied as a function of gender. Men $(M=4.00, S D=1.80)$ reported being more familiar with the Darfur conflict than did women $(M=2.71 S D=$ $1.67), t(133)=-3.66, p<.001, \mathrm{~d}=.63$. As well, women $(M=3.35, S D=1.43)$ perceived this issue to be more important to Canadians than did men $(M=2.77, S D=1.48), t(133)$ $=1.96, p=.05, \mathrm{~d}=.34$. None of our main variables of interest, including complicity, ingroup accountability, emotions (guilt and collective guilt), and participants' endorsement of prosocial actions (government intervention and collective action) varied as a function of gender or age.

Intercorrelations among the main variables in the study. Intercorrelations among complicity, ingroup accountability, guilt (for the situation of the victims and for the inaction of Canada), and prosocial actions (government intervention and collective action) are presented in Table 2.1. All the variables were significantly intercorrelated, with the exception of guilt for the situation of the victims, which was only marginally correlated with endorsement of government action, $r=.16, p=.06$. A noteworthy observation is that guilt for the plight of the people of Darfur only moderately correlated

\footnotetext{
${ }^{4}$ Because the Darfur conflict directly involves Blacks $(n=6)$ and Arabs $(n=6)$, it would have been of interest to assess whether the responses of self-identified Black and Arab participants differed from one another or from the responses of Whites $(n=94)$ (a group that is not directly involved in the conflict). However, the number of Black and Arab participants was too small to present a meaningful comparison.
} 
Table 2.1

Correlations Among the Main Variables of the Study

\begin{tabular}{|c|c|c|c|c|c|c|}
\hline & 1 & 2 & 3 & 4 & 5 & 6 \\
\hline 1. Complicity & & $.55 * * *$ & $.42 * * *$ & $.56 * * *$ & $.44 * * *$ & $.50 * * *$ \\
\hline 2. Ingp Account & & & $.27 * *$ & $.60 * * *$ & $.36^{* * *}$ & $.48 * * *$ \\
\hline 3. Guilt for Victims & & & & $.41 * * *$ & $.16^{\mathrm{t}}$ & $.37 * * *$ \\
\hline 4. Guilt for Canada & & & & & $.66^{* * *}$ & $.66 * * *$ \\
\hline 5. Gov. interv. & & & & & & $.59 * * *$ \\
\hline 6. Coll. action & & & & & & \\
\hline
\end{tabular}

Note. $N=135$. Ingp Account = Ingroup accountability; Guilt for Victims $=$ Guilt for the situation of the victims; Guilt for Canada = Guilt for Canada's inaction; Gov. interv. = Government intervention; Coll. action $=$ Collective action.

${ }^{\mathrm{I}} p<.10 .{ }^{*} p<.05 . * * p<.01 . * * * p<.001$. 
with guilt for the inaction of Canada against the conflict, $r=.41, p<.001$. This suggests that these two dimensions of guilt indeed measure different things, that is, reaction to the situation of the victims versus reaction to Canada's inaction.

\section{Main Analyses}

Perceptions of ingroup role. The one-way omnibus MANOVA, conducted to assess the influence of levels of categorization on ingroup perceptions of their role in the genocide (perceived complicity and ingroup accountability) was not significant, Pillai's $=.045 ; F(4,264)=1.51, p=.20$. However, because a priori hypotheses were made about the relations between levels of categorization and perceptions, planned constrast were nonetheless conducted. The MANOVA contrast for the first hypothesis, which tested the influence of individual versus outgroup and common ingroup on perceptions, approached significance, Pillai’s $=.021 ; F(2,131)=2.67, p=.07$. The follow-up planned contrast assessing the influence of individual vs. outgroup and common ingroup categorizations on perceived complicity was significant, $F(1,132)=$ $5.15, p<.05, \eta^{2}=.038$, suggesting that participants reported greater perceived complicity in the Darfur genocide due to inaction when the situation was presented at the individual level $(M=4.47, S D=1.53)$ in comparison to when it was presented at the level of an outgroup $(M=3.78, S D=1.63)$ and common ingroup $(M=3.91, S D=1.29)$. Ingroup accountability did not vary as a function of levels of categorization, $F<1$. Overall, participants did not perceive that Canadians could be held accountable for their inaction $(M=3.30, S D=1.44)$ relative to the scale midpoint (i.e., 4$), t(134)=-5.64, p<.001$, irrespective of how the conflict was categorized (individual $(M=3.45, S D=1.55)$, outgroup $(M=3.29, S D=1.37)$ and common ingroup $(M=3.17, S D=1.41)$. There were 
no differences in perceptions of the role of participants' ingroup when victims were categorized at the level of outgroup or common ingroup, Pillai's $=.005 ; F<1$.

Guilt. The omnibus one-way MANOVA conducted to assess the influence of levels of categorization on guilt (toward the situation of the victims and Canada's inaction) was significant, Pillai's $=.071 ; F(4,264)=2.44, p<.05$. The MANOVA contrast between individual versus the combination of outgroup and common ingroup categorizations was significant, Pillai's $=.052 ; F(2,131)=3.59, p<.05$. Follow-up univariate ANOVAs revealed an effect of levels of categorization on feelings of guilt regarding the situation of the victims, $F(1,132)=7.15, p<.01, \eta^{2}=.051$, but not for Canada's inaction, $F(1,132)=1.71, n s$., which was uniformly high $(M=4.32, S D=$ 1.38 ) relative to the scale midpoint (i.e., 4$), t(134)=2.72, p<.01$. Specifically, participants felt greater guilt for the ongoing genocide when it was presented as affecting an individual $(M=3.66, S D=1.93)$ in comparison to when it was presented as affecting an outgroup $(M=2.49, S D=1.72)$ and common ingroup $(M=3.00, S D=1.94)$. The MANOVA for the contrast between the common ingroup and the outgroup was not significant, Pillai's $=.020 ; F(2,131)=1.34, n s$, indicating that the common ingroup and outgroup conditions did not differ on feelings of guilt.

Prosocial actions. As expected, a one-way MANOVA revealed that support for prosocial actions (endorsement of government intervention and collective action) varied as a function of levels of categorization, Pillai's $=.089 ; F(4,264)=3.09, p<.05$. Specifically, the MANOVA for the contrast between the individual and the combined outgroup and common ingroup was significant, Pillai's $=.075 ; F(2,131)=5.35, p<.01$. Follow-up ANOVAs revealed an effect of levels of categorization on endorsement of 
both government intervention, $F(1,132)=3.71, p=.06, \eta^{2}=.027$, and collective action, $F(1,132)=10.77, p<.01, \eta^{2}=.075$. More specifically, as expected, participants expressed greater endorsement of government intervention when genocide was presented at the individual level of categorization $(M=6.68, S D=0.90)$ in comparison to when genocide was presented at the outgroup $(M=5.14, S D=1.30)$ and the common ingroup $(M=5.45, S D=0.96)$ levels of categorization. Similarly, participants expressed greater endorsement of collective action when the genocide was presented at the individual level of categorization $(M=4.40, S D=1.43)$ in comparison to when genocide was presented at the outgroup level $(M=3.49, S D=1.46)$ and the common ingroup level of categorization $(M=3.68, S D=1.17)$. The contrast between common ingroup and outgroup level of categorization was not significant.

Summary. As hypothesized, participants perceived greater complicity, expressed greater feelings of guilt for the conflict in Darfur, and indicated greater endorsements of government intervention and collective action when the genocide was presented at the individual level in comparison to when it was presented at the outgroup and common ingroup levels of categorization. There were no differences between these latter conditions. Neither perceptions that Canadians could be held accountable for their inaction (which were low), nor feelings of guilt for Canada's inaction (which was high) varied as a function of levels of categorization.

Path model. Path analysis was used to test the hypothesized relations among the manipulation of social categorization, complicity, ingroup accountability, guilt and prosocial actions. Because categorization at the level of the outgroup versus the common ingroup did not differ on any of the variables of interest, they were collapsed for this 
analysis. Thus, the sequential pathway assessed in the present model reflects the contrast between the individual (coded 2) versus the group-based categorization conditions (coded -1). A first model specification, as illustrated in Figure 0.1 (See p.10), was constructed such that levels of social categorization was specified to predict action endorsements through the sequential mediation of perceived complicity for inaction, accountability ${ }^{5}$, and the guilt emotions. In order to control for collinearity, the appraisals (complicity and ingroup accountability) and the two guilt variables were free to covary, as were the outcome variables (endorsements of government intervention and collective action). Results of the path analysis revealed that the hypothesized model did not fit the data well. The chi-square value was significant, $\chi^{2}(d f=7, N=135)=22.69, p<.01$ and the RMSEA was above $.08($ RMSEA $=.12)$, although the other fit indexes were as required, above $.90(\mathrm{CFI}=.97 ; \mathrm{GFI}=.96)$.

The model was re-specified by setting the non-significant paths linking categorization to accountability and guilt for Canada's inaction, respectively, to zero. Because it is plausible that participants might perceived that their group might be held accountable for inaction if they are perceived to be complicit in the genocide, a path was added from complicity to accountability. The modified model had a good fit to the data. The chi-square value was nonsignificant, $\chi^{2}(d f=9, N=135)=12.24, p=.20$, RMSEA was as required, below.08 (RMSEA $=.05)$, and other fit indexes were as required, above $.90(\mathrm{CFI}=.99 ; \mathrm{GFI}=.98)$.

As shown in Figure 2.1, tests of the indirect effect of levels of categorization on prosocial actions indicated that the association between categorization and endorsement

\footnotetext{
${ }^{5}$ Ingroup accountability was specified to predict feelings of collective guilt, i.e., guilt for the inaction of the group (Canada).
} 


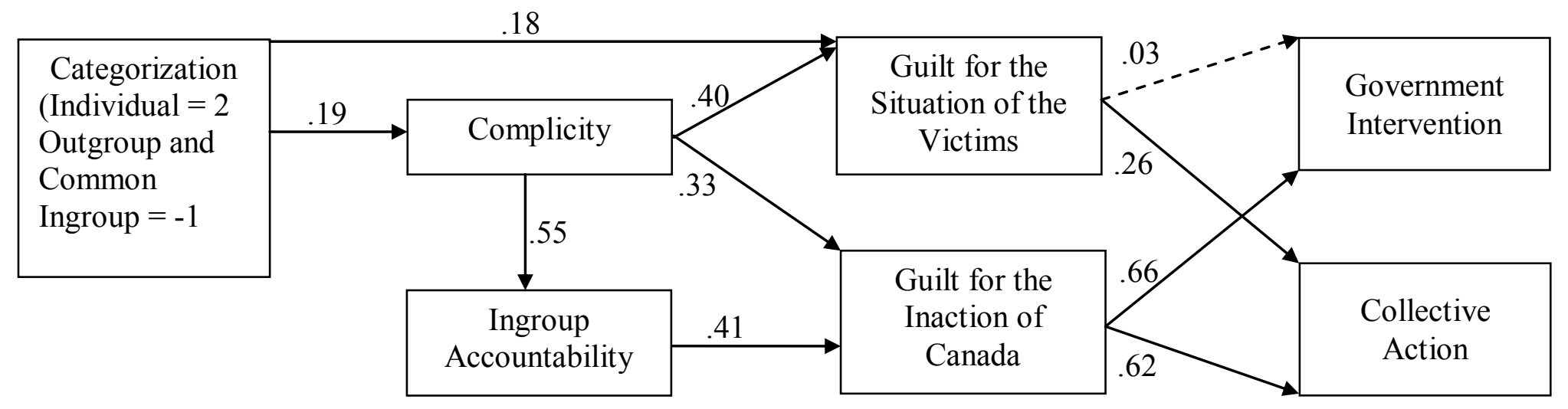

Figure 2.1. Standardized beta ( $\beta$ ) estimates of the model of prosocial actions against genocide relating levels of categorization, complicity in the genocide, ingroup accountability, guilt for the situation of the victims, guilt for the inaction of Canada, and endorsement of government intervention and collective action. All paths were significant, $p s<.05$, with the exception of the path linking guilt for the situation of the victims with endorsement of government intervention. 
of prosocial actions was mediated through several paths. As noted earlier, individualization of victims was associated with greater perceived complicity in the genocide, which in turn predicted greater perceived ingroup accountability, which in turn was associated with greater guilt for Canada's inaction, which in turn was associated with endorsements of government intervention $(z=1.97, p<.05)$ and support for collective action $(z=1.96, p<.05)$. A shorter pathway, which did not involve accountability, was also viable, wherein individualization of victims was associated with greater perceived complicity in the genocide, which in turn predicted greater guilt for Canada's inaction, which in turn was associated with endorsement of government intervention $(z=1.96, p<$ $.05)$ and support for collective action $(z=1.95, p<.05)$. Another sequential pathway was also identified, wherein perceived complicity in the genocide was associated with feelings of guilt for the situation of the victims, which in turn predicted endorsement of collective action $(z=1.81, p<.05)$. This dimension of guilt also directly mediated the relation between levels of the categorization of victims of the genocide and support for collective action $(z=2.01, p<.05)$.

Summary. It appears that individualization of the conflict was associated with greater endorsements of government intervention as a result of greater perceptions of complicity in the genocide due to inaction, which in turn were associated with greater feelings of guilt regarding Canada's inaction. In addition, individualization of the conflict was indirectly associated with greater endorsement of collective action through the experience of greater feelings of guilt for the plight of the people of Darfur. 


\section{Discussion}

The present research draws on social identity theory and the identifiable victim effect (Jenni \& Loewensten, 1997) in order to first examine whether framing the Darfur genocide at different levels of categorization (individual, outgroup, or common ingroup) would influence participants' endorsement of prosocial actions (government intervention and collective action) against the genocide. Consistent with the identifiable victim effect, which refers to the fact that people are more inclined to help one identifiable victim in comparison to a large group of unidentifiable victims, the findings suggest that Canadians endorsed greater government intervention and collective action on behalf of the Darfur victims when victims were individualized through the story of one identified individual (decategorization), in comparison to when victims were presented as several hundreds of thousands innocent Sudanese citizens (categorization as outgroup) or as several hundreds of thousands innocent citizens in countries around the world (recategorization into a common ingroup).

While it was expected that respondents would also endorse more prosocial actions when the Darfur conflict was framed as affecting members of a common ingroup in comparison to members of an outgroup, this did not appear to occur. Participants indicated similar levels of endorsement of government intervention and collective action when victims were presented as outgroup members in comparison to when victims were presented as members of a common ingroup. Similarily, participants perceived greater complicity in the genocide because of their inaction and expressed greater feelings of guilt toward the conflict in Darfur when victims were individualized in comparison to when they were presented as hundreds of thousands outgroup members and common 
ingroup members. Perceptions of complicity and feelings of guilt did not vary in these latter two conditions. These findings are inconsistent with the common ingroup identity model (Gaertner \& Dovidio, 2000), which suggests that the recategorization of members of different groups (in this case Sudanese and Canadian citizens) into a common group (citizens in countries around the world) would influence individuals to having more positive attitude and behavior toward members of their common group relative to members of an outgroup. Presumably, recategorization into a common ingroup prevents ingroup bias (Aberson, Healy, \& Romero, 2000, p. 157). In this regard, when Whites and Blacks were part of the same group, Whites were more likely to evaluate Blacks favorably and to behave prosocially toward Blacks (Nier et al., 2001). However, recent research suggests that the positive effect of recategorization into a common ingroup on intergroup relations is inconsistent (Dovidio, Gaertner, Saguy, 2009). For instance, introductory psychology students who were categorized as university students (common ingroup) expressed more ingroup bias towards those who were categorized as members of both humanities and math-science faculties (outgroups) in comparison to introductory psychology students who were categorized as individuals, members of a specific faculty or university students of a specific faculty (Hornsey \& Hogg, 2000). Likewise, as British individuals perceived British and African nations as a single group of humans, they perceived less responsibility and expressed lesser feelings of guilt for the involvement of Britain in the slave trade (Morton \& Postmes, 2011a).

In the context of the present study, one possible explanation for the lack of differential outcomes between the common ingroup and the outgroup conditions might be that the positive influence of an inclusive common group on intergroup relations depends 
on other factors that might be relevant to intergroup conflicts. For example, it has been suggested that the benefit of human categorization over outgroup categorization might depend on the extent to which people perceive human nature as benevolent or malevolent. People are more likely to respond morally towards harms perpetrated against the outgroup by their ingroup when they perceive human nature to be benevolent (Morton \& Postmes, 2011b). Given this possibility, Study 2 investigated whether the influence of social categorization, at the highest level of common ingroup (human) relative to the outgroup categorization, on prosocial actions and its antecedents (complicity, ingroup accountability, and guilt) was moderated by the extent to which one positively evaluates human beings in general, that is, humanity-esteem.

Participants' expressions of feelings of guilt for Canada's inaction or perceptions that their ingroup could be held accountable because of their inaction to stop the genocide, did not vary as a function of how the victims were presented (individual, outgroup members or common ingroup members). One possible explanation could be that individual level of categorization is not directly associated with group-based guilt and perceptions of one's ingroup accountability. However, this explanation does not hold, as the group-level categorizations were not associated with these latter variables either. Instead, the present findings showed that individualization of the victims of the genocide indirectly influenced participants' feelings of guilt for their group's inaction and their acknowledgement that their group could be held accountable through their increasing perceptions of complicity in the genocide. Thus, perception of theirs and their group's silent complicity in the genocide appears to be a precondition for individuals to feeling guilty for the inaction of their group and for acknowledging that their group could be held 
accountable for their inaction. Logically, in order for individuals to perceive themselves and their group complicit in the genocide because of their inaction, they most know that they have a responsibility to act against genocide when they are aware that a genocide is ongoing. Although some studies have shown that social categorization can directly influence feelings of guilt (Wohl \& Branscombe, 2005) other studies also support that acknowledgement of one's group responsibility for harm done to others is a precondition to feeling guilty on behalf of one's group (Cehajic-Clancy et al., 2011). Accomplices might be held accountable for failure to their obligations only if they have a responsibility to act against genocide (Espeland \& Vannebo, 2007; Nolte \& Aust, 2009).

A second goal of Study 1 was to understand the psychological mechanism by which social categorization influenced endorsements of prosocial actions. In this regard, consistent with predictions, participants felt guilty when their attention was drawn to the conflict in Darfur, and these feelings of guilt was associated with increased likelihood of endorsing collective action to pressure the government to intervene against the genocide. This finding therefore provided empirical support for the theoretical model proposed by Slovic (2007) to explain reactions to genocide. In addition, this finding is in keeping with previous findings that showed that levels of social categorization directly influenced emotions, which in turn are linked to action propensities (Ray et al., 2008; Tarrant et al., 2009). Notwithstanding, the present results also suggest that when the victims of the Darfur conflict were individualized through the story of one identifiable individual, participants were more likely to perceive that their group and themselves could become complicit in the genocide if they did not take action against it, felt guilty because of the inaction of their group, and endorsed both government intervention and collective action. 


\section{Chapter 3: Study 2}

Contrary to expectations, in Study 1, recategorization of the victims into a common ingroup did not lead to different outcomes in comparison to their categorization as outgroup members. Several individual factors may affect the strength and/or the direction (i.e. moderators) of the relationship between recategorization and positive intergroup relations. For instance, how people evaluate themselves and other human beings may affect how they react to other human beings who are in distress. Indeed, the evaluation that people make of their group category may help predict their responses towards members of their group and of outgroups (Long, Spears, \& Manstead, 1994). It was suggested that while self-categorization provides the cognitive basis for behaving benevolently toward other ingroup members, group self-esteem supplies the motivational force for doing so (Bergami \& Bagozzi, 2000).

Of note, social identity theorists recognize that people can derive feelings of value and worth not only from their personal qualities (self-esteem) but also from their association with a social group (collective self-esteem) (Swann \& Bosson, 2010). Of particular relevance, people react in ways that differentiate their own group (ingroup) from other groups (outgroups) in order to maintain or enhance self-esteem (Tajfel, 1982; Tajfel \& Turner, 1979). Humanity-esteem is regarded as a trait that refers to a person's evaluation of other human beings in general. It is the global evaluation that the individual makes of humanity. In effect, some people have a positive view of human beings whereas others have a negative view of humanity. There is some agreement that the type of selfesteem that is measured must be consistent with the identity level that is made salient (De Cremer \& Oosterwegel, 1999; Long et al., 1994; Verkuyten \& Hagendoorn, 2002). At the 
individual level of categorization, self-esteem should be measured; at the social level, collective self-esteem (Crocker \& Lutanen, 1990; Verkuyten \& Hagendoorn, 2002); and at the human level of categorization, humanity-esteem (Luke \& Maio, 2009).

Few studies, if any, have investigated the role of humanity-esteem on intergroup relations, most research focused on individual (Findler, Taubman-Ben-Ari, Ben-Shlomo, 2005) and collective self-esteem (Crocker \& Lutanen, 1990; De Cremer \& Oosterwegel, 1999; Rubin \& Hewstone, 1998; Verkuyten \& Hagendoorn, 2002). While findings are inconsistent, there is evidence that individuals with greater self-esteem are more likely to help needy people in comparison to individuals with lower self-esteem. For example, young ultra-orthodox female Jews with high self-esteem were more willing than their low self-esteem counterparts to help a person with a disability despite being in a context where association with a person with disability may hinder their marriage prospects (Findler, Taubman-Ben-Ari, \& Ben-Shlomo, 2005). Further, individuals with higher selfesteem were more likely to express greater feelings of guilt (Sheikh \& Janoff-Bulman, 2010).

At the level of group interactions, social identity theory predicts that individuals with low self-esteem are more likely to discriminate against outgroup members in comparison to individual with high self-esteem. There is evidence that individuals with high collective self-esteem evaluated outgroup members less negatively than those with low collective self-esteem (De Cremer \& Oosterwegel, 1999). In a similar vein, as individuals held humanity in greater esteem, they expressed lower group-based discrimination and greater positive emotions toward other people (Luke \& Maio; 2009). These findings suggest that individuals who have a positive image of their group 
responded benevolently toward both ingroup and outgroup members. Therefore, it could be expected that regardless of how victims were categorized, as individuals greatly evaluate human beings they would indicate greater endorsements of government intervention and collective action, greater perceptions that themselves and their group could become complicity in the genocide and that their group could be held accountable for their inaction. In addition, they could express greater feelings of guilt for the situation of victims of genocide and for the inaction of their country.

Although findings on the role of personal and collective self-esteem on intergroup relations are inconsistent (Abrams \& Hogg, 1988), there is some evidence that individuals with low self-esteem are more likely to express ingroup favoritism and to derogate outgroup members (Brown, Collins, Schmidt, 1988). For example, in an evaluation task, Dutch psychology students with greater collective-esteem provided similar evaluations for environmental advertisements (that encouraged the use of phosphate-free detergents in Britain) that were submitted by a) other Dutch psychology students (their own group), b) another group of Dutch psychology students (ingroup), or c) Swiss psychology students (outgroup). In comparison, Dutch psychology students with lower collective-esteem rated similar the advertisement submissions of their own group and another group of Dutch psychology students (ingroup). Yet, they rated the advertisement submissions of Swiss psychology students (outgroup) more negatively than that of another group of Dutch psychology students (ingroup) (Long et al., 1994).

Drawing upon the above mentioned findings, which suggest that individuals with low collective self-esteem favor members of their ingroup and derogate outgroup members, some propositions were made as to when the common ingroup category could 
lead to different outcomes than the outgroup category. Specifically, in the context of the ongoing genocide in Darfur, it is plausible that individuals who hold human beings in lower esteem (low humanity-esteem) would be most influenced by levels of categorization. Specifically, in contrast to when victims were categorized at the outgroup level, when the common ingroup was made salient Canadians with lower humanityesteem would be expected to show ingroup favoritism. In particular, they would express greater appraisals of complicity in the genocide because of theirs and their group's inaction in the conflict. They would perceive to a greater extent that Canada could be held accountable for its inaction, express greater feelings of guilt (for the situation of the victims and the inaction of Canada) and endorse greater prosocial actions (government intervention and collective action). Canadians who evaluate humans positively (i.e., who hold humans in high esteem) would be expected to express similar appraisals (perceived complicity and ingroup accountability), feelings of guilt (for the situation of the victims and the inaction of Canada) and prosocial actions toward the victims, irrespective of levels of categorization. It was the goal of the present study to investigate whether individuals' evaluation of their human identity (humanity-esteem) moderated the influence of recategorization (relative to outgroup categorization) of the victims of the Darfur genocide on their endorsements of prosocial actions (government intervention and collective action) and its antecedents (appraisals and feelings of guilt).

\section{Present Investigation}

The present study investigated whether humanity-esteem moderated the impact of recategorization into a common ingroup (relative to outgroup categorization of victims of genocide) on support for prosocial actions (government intervention and collective 
action) and its antecedents (complicity, ingroup accountability, feelings of guilt). The following hypotheses were made:

1. There would be a main effect of humanity-esteem. Higher humanity-esteem (i.e., positive image of humanity) would be associated with greater perceived complicity and accountability, more feelings of guilt, and greater willingness to endorse prosocial actions.

2. Humanity-esteem would moderate the effects of group categorization.

Specifically, at low levels of humanity-esteem, recategorization of the victims as humans (in comparison to Sudanese citizens) would have a strong positive effect on appraisals, feelings of guilt, and endorsement of prosocial actions. This difference was not expected to be evident among individuals with high humanity-esteem.

\section{Method}

\section{Participants}

In an effort to recruit a community sample of Canadians, the study was conducted online and participants were recruited through several means. A link to the study was distributed to participants through word-of-mouth, through advertisements posted on free classified web sites (e.g., Kijiji and Craigslist) in several major Canadian cities, on the website of the laboratory, and through Amazon Mechanical Turk (MTurk; https://www.mturk.com) (Appendix J). MTurk gives access to more than 500,000 persons located across 190 countries (see https://requester.mturk.com/tour) and about 3\% of them are located in Canada (Ross, Zaldivar, Irani, \& Tomlinson, 2010). To be eligible to participate in the present study, participants were required to be Canadian citizens aged 18 years or older and fluent in English. As in Study 1, this study was described as a 
survey assessing Canadians' perspective on various international conflicts. Darfur was not mentioned in order to reduce self-selection biases based on knowledge of this particular conflict. All volunteers were directed to the website address of the study, which was hosted on PsycData. MTurk participants were thanked for their time with $\$ 1$ (based on average compensation for MTurk participants in other studies). All other participants were thanked with a $\$ 5$ gift certificate for a national chain establishment.

The final sample comprised 100 participants ( 33 men and 67 women) ranging in age from 18 to 72 years with a mean of $36.68(S D=14.24)$. The majority of participants self-identified as White/Euro-Caucasian (81\%), whereas the remainder self-identified as Asian (8\%), Arab/West Asian (1\%), South Asian (3\%), South East Asian (3\%), Aboriginal (2\%), or mixed ethnic status (2\%) (one participant did not specify ethnicity). In terms of religious affiliation, most participants were either Protestant (28\%), Catholic $(22 \%)$ or had no religion (43\%). The rest were Jewish $(2 \%)$ or were from other religions (5\%). There were no Muslim participants. The majority of participants had completed at least one year of college/university ( $80 \%)$, and only a minority were currently full-time or part-time students (28\%). The median level of their annual family income was between $\$ 45,000$ and $\$ 54,999$. About $78 \%$ of participants participated in the last federal election, $29 \%$ of the participants self-identified with the New Democratic party, $19 \%$ with the Liberal, $18 \%$ with the Conservative, $6 \%$ with the Green party, $1 \%$ with the Libertarian party of Canada, $27 \%$ did not identify with any party or did not provide an answer.

\section{Procedure}

Data collection was conducted from June 19 to December 1, 2012. Upon entering the study website, participants were presented with an explanation of what was involved 
in completing the study (Appendix K). An informed consent form (Appendix L) provided the options to accept or to decline to participate in the study. Those who accepted to participate were then asked to completed questionnaires that assessed their sociodemographic characteristics, their humanity-esteem (Appendix M), and their engagement with current news. They were then randomly assigned to one of the experimental conditions (Appendix N), after which general knowledge about the situation in Darfur, emotional reactions to the conflict, appraisals, and action endorsements were assessed. As in Study 1, a positive mood induction was given at the end of the measures, asking individuals to think of a positive interaction they recently had with others. Then, participants were provided with a debriefing form (Appendix O) that contained contact information for professional help, should they experience any distress. Additionally the debriefing provided information about the role of Canada in the process of peace building and in contributing humanitarian aid and development aid in Sudan since 2006. Participants who chose to withdraw from the study, by answering yes to a 'withdraw' question located at the end of each page of the online questionnaire were also directed to the debriefing and contact page.

Manipulation of levels of social categorization. Participants were randomly assigned to read a vignette similar to the one used in Study 1. The paragraph describing the conflict was followed by a statement that formed the basis of the different experimental conditions. In study 1 , it could be argued that the decategorized individual condition differed from the outgroup and the common ingroup conditions in more ways than that evoked by the categories, because information about the harm and suffering caused by the genocide was provided in this vignette. Therefore, in the present study, to 
reduce possible confounds in the manipulation of the levels of categorization, information about harm and "families who continue to live in fear" was added in both the outgroup and the common ingroup conditions. Similarly, mention that people were murdered "because of their ethnicity among other things" was made in all the experimental vignettes $^{6}$.

In the outgroup condition, participants read that "Hundreds of thousands of Sudanese citizens have been murdered in Darfur, because of their ethnicity among other things, leaving behind families who continue to live in fear. There is evidence that the perpetrators of these murders are supported by the Sudanese government. Several organizations are asking the International Criminal Court to do justice and make the government of Sudan accountable for heinous crimes committed against specific groups in Darfur."

In the common ingroup condition, participants read that "Hundreds of thousands of humans have been murdered in countries around the world, because of their ethnicity among other things, leaving behind families who continue to live in fear. There is evidence that the perpetrators of these murders are supported by governments of states. Several organizations are asking the International Criminal Court to do justice and make governments of states accountable for heinous crimes committed against humans in our planet."

\footnotetext{
${ }^{6}$ Some participants were assigned to read a decategorized individual condition; however it was realized afterward that some of the wording may have made "ethnicity" salient, hence eliciting an outgroup identity. Indeed, preliminary analysis revealed that this condition did not differ from the outgroup condition on any of the main variables. Therefore, participants who were in this condition were not considered further.
} 


\section{Measures}

Similar to study 1 , the questionnaire included numerous measures, but only those that were relevant to the current research questions are presented in this thesis. The same measures used in Study 1 were used in the present study with the exception of guilt toward the plight of the people of Darfur that were measured with two additional adjectives for a total of three adjectives: guilty, regretful, remorse. Measures specific to Study 2 are presented below.

Humanity-esteem. The humanity-esteem scale (Luke \& Maio, 2009) was based on the Rosenberg self-esteem scale and consists of 10 items that measure favorability and unfavorability toward humanity in general (e.g., "I feel that human beings have a number of very good qualities"). Respondents indicated how much they agreed with each statement on a scale ranging from 1 (strongly disagree) to 7 (strongly agree). Responses to negatively worded items were reverse-scored, and a total score was computed by averaging the responses across all the items. Higher scores represented higher humanityesteem $(\alpha=.92)$.

\section{Statistical Analyses}

Prior to the main analyses, a series of one sample $t$-tests was performed to assess whether responses significantly differed from the mid-point of each of the scales ${ }^{7}$ that assessed engagement with current news and general knowledge of the situation in Darfur. A series of independent $t$-tests were performed to assess gender differences on the

\footnotetext{
${ }^{7}$ All measures were on a scale ranging from 1 to 7 , where 4 was the mid-point of the scale.
} 
variables of interest ${ }^{8}$. Pearson's correlations were performed to assess whether the variables varied as a function of age and to examine the bivariate associations among the major variables in the study.

With respect to the main analyses, a series of hierarchical multiple regression analyses were conducted to test the effects of categorization and humanity-esteem on appraisals, feelings of guilt, and prosocial actions. Regression was used as it does not require the artificial dichotomization of scores on the humanity-esteem scale (MacCallum, Zhang, Preacher, \& Rucker, 2002). Categorization was coded 1 for the common ingroup condition and -1 for the outgroup condition. The interaction term was computed by calculating the cross-product of humanity-esteem and categorization. Categorization was entered on the first step, followed by humanity-esteem on the second step, and the interaction term was entered on the last step of the regression. The increment in $\mathrm{R}^{2}$ due to each of the variables and the interaction term was assessed in order to test the significance of the unique proportion of variance attributable to each variable and their interaction.

\section{Results}

\section{Data Screening}

The quality of the data provided was evaluated in terms of random responding (e.g., contradictory rating to reverse scored items) and data from participants who responded at random were excluded from analyses. Prior to all analyses, data were

\footnotetext{
${ }^{8}$ Ethnic differences on the variables of interest were not assessed, as this sample had no self-identified Arab or Black participants. The influence of religious affiliation was not assessed as this sample had no participants who indicated that they were Muslim, a group that is involved in the Darfur conflict.
} 
examined for missing values and outliers, as well as for assumptions related to regression analysis including normality, linearity, independence, homoscedasticity, and multicollinearity. One participant's data were discarded from further analysis because of missing data. Box plots on the variables of interest indicated no univariate outliers. The criterion of Mahalanobis distance at $p<.001$ was used to screen for multivariate outliers. One participant was identified as a multivariate outlier and was excluded from the analyses. Some of the variables (e.g., government intervention and collective action) showed significant skewness; however, given the large sample size, the deviation of these variables from normality was not enough to make a substantive difference in the analyses (Tabachnick \& Fidell, 2007).

\section{Preliminary Analyses}

Characteristics of respondents. Engagement with the issue. As in Study 1, participants indicate that what was happening in Sudan was not too far from Canada for them to be concerned $(M=3.02, S D=1.47), t(99)=-6.70, p<.001$. However, as expected, participants were not especially familiar with the situation in Darfur $(M=2.69$, $S D=1.56), t(98)=-8.40, p<.001$, and they were neutral about the importance of the issue to them personally $(M=3.94, S D=1.55)$. However, similar to Study 1 , they perceived this issue to be more important to them personally than to Canadians in general $(M=3.05, S D=1.66), t(98)=5.93, p<.001$.

Influence of gender and age. Similar to findings in Study 1, men $(M=3.15, S D$ $=1.60)$ reported being more familiar with the Darfur conflict than did women $(M=2.45$, $S D=1.49), t(97)=-2.14, p<.05$. Men and women did not differ on the other engagement variables. None of the engagement variables correlated with age. None of the 
main variables of interest (human-esteem, complicity, accountability, feelings of guilt and prosocial actions) varied as a function of gender or age, with the exception of humanesteem, which was positively correlated with age $(r=.20, p<.05)$.

Descriptive statistics and correlations analyses. Means and standard deviations for the common ingroup and outgroup categorizations, as well as for the total sample on the primary measures are reported in Table 3.1, and correlations among the variables are presented in Table 3.2. Of note, participants felt greater guilt toward the situation of the victims when the conflict was presented as affecting humans around the world than when the conflict was presented as affecting Sudanese citizens (Table 3.1). As can be seen in Table 3.2, all the variables were intercorrelated in the expected directions, with the exception of humanity-esteem which only correlated with endorsement of government intervention.

\section{Main Analyses}

Contrary to predictions, humanity-esteem had no moderation effect on the relations between social categorization and appraisals (complicity and ingroup accountability), feelings of guilt (toward the situation of the victims and for the inaction of Canada) or prosocial actions (government intervention and collective action). There were also no main effects of humanity-esteem on the above mentioned variables, with the exception that greater humanity-esteem was associated with greater endorsement of government action, $\Delta \mathrm{R}^{2}=.089, F(2,97)=5.00, p<.01($ see Table 3.3). Unexpectedly, the manipulation of the level of group categorization resulted in a trend toward greater perceptions of accountability for the inaction of the government in the common ingroup condition compared to the outgroup categorization condition, $\Delta \mathrm{R}^{2}=.035$, 
Table 3.1

Descriptive Statistics (Means and Standard Deviations) for the Common Ingroup and the Outgroup Categorizations and the Total Sample

\begin{tabular}{|c|c|c|c|c|c|c|}
\hline & \multirow{2}{*}{\multicolumn{2}{|c|}{$\begin{array}{l}\text { Common ingroup } \\
\mathrm{n}=51\end{array}$}} & \multirow{2}{*}{\multicolumn{2}{|c|}{$\begin{array}{l}\text { Outgroup } \\
n=49\end{array}$}} & \multirow{2}{*}{\multicolumn{2}{|c|}{$\begin{array}{l}\text { Total } \\
\mathrm{N}=100\end{array}$}} \\
\hline & & & & & & \\
\hline & $\mathrm{M}$ & SD & $\mathrm{M}$ & SD & $\mathrm{M}$ & SD \\
\hline Humanity-esteem & - & - & - & - & 5.10 & 1.31 \\
\hline Complicity & 4.08 & 1.74 & 3.72 & 1.65 & 3.91 & 1.70 \\
\hline Ingroup Accountability $^{+}$ & 3.64 & 1.57 & 3.05 & 1.56 & 3.35 & 1.58 \\
\hline Guilt for the situation of the victims* & 3.69 & 1.58 & 3.05 & 1.54 & 3.38 & 1.59 \\
\hline Guilt for Canada's inaction & 4.46 & 1.68 & 4.06 & 1.68 & 4.26 & 1.68 \\
\hline Government intervention & 5.58 & 0.97 & 5.43 & 1.28 & 5.51 & 1.32 \\
\hline Collective action & 3.91 & 1.48 & 3.68 & 1.40 & 3.80 & 1.44 \\
\hline
\end{tabular}

Note. ${ }^{+} p<.10 . * p<.05$. 
Table 3.2

Item-total Reliabilities ${ }^{\mathrm{a}}$ and Bivariate Correlations Among the MainVariables

\begin{tabular}{|c|c|c|c|c|c|c|c|}
\hline & 1 & 2 & 3 & 4 & 5 & 6 & 7 \\
\hline 1. H-esteem & .92 & -.12 & -.03 & .14 & .14 & $.30 * *$ & .07 \\
\hline 2. Complicity & & $.68^{\mathrm{b}}$ & $.56 * * *$ & $.47 * * *$ & $.62 * * *$ & $.40 * * *$ & $.57 * * *$ \\
\hline 3. Ingrp Account & & & .91 & $.45 * * *$ & $.63 * * *$ & $.33 * *$ & $.50 * * *$ \\
\hline 4. Guilt for victims & & & & .93 & $.49 * * *$ & $.31 * *$ & $.32 * *$ \\
\hline 5. Guilt for Canada & & & & & .89 & $.63 * * *$ & $.64 * * *$ \\
\hline 6. Gov. interv. & & & & & & .92 & $.54 * * *$ \\
\hline 7. Coll. action & & & & & & & .91 \\
\hline
\end{tabular}

Note. $N=100$. H-esteem $=$ Humanity-esteem; Ingroup Account $=$ Ingroup accountability;

Guilt for Victims $=$ Guilt for the situation of the victims; Guilt for Canada $=$ Guilt for Canada's inaction; Gov. interv. $=$ Government intervention; Coll. action $=$ Collective action.

${ }^{\text {a}}$ Cronbach's alpha for each measure are in the diagonal.

${ }^{\mathrm{b}}$ Correlation between the two items that assessed complicity.

${ }^{\mathrm{f}} p<.10 .{ }^{*} p<.05 . * * p<.01 . * * * p<.001$. 
Table 3. 3.

Regression Coefficients for Moderation Model

\begin{tabular}{|c|c|c|c|c|c|c|c|c|c|}
\hline & \multicolumn{3}{|c|}{ Complicity } & \multicolumn{3}{|c|}{ Ingroup accountability } & \multicolumn{3}{|c|}{ Guilt for the victims } \\
\hline & $\mathrm{B}$ & SE & $\mathrm{B}$ & $\mathrm{B}$ & SE & $\beta$ & $\mathrm{B}$ & $\mathrm{SE}$ & $\mathrm{B}$ \\
\hline \multicolumn{10}{|l|}{ Step 1} \\
\hline Categorization & 0.177 & 0.170 & .11 & 0.295 & 0.156 & $.19^{\mathrm{a}}$ & 0.321 & 0.156 & $.20^{*}$ \\
\hline \multicolumn{10}{|l|}{ Step 2} \\
\hline Humanity-esteem & -0.231 & 0.171 & -.14 & -0.075 & 0.158 & -.05 & 0.196 & 0.157 & .12 \\
\hline \multicolumn{10}{|l|}{ Step 3} \\
\hline Categorization $\mathrm{x}$ & -0.039 & 0.186 & -.02 & 0.117 & 0.172 & .07 & 0.118 & 0.171 & .07 \\
\hline Humanity-esteem & & & & & & & & & \\
\hline
\end{tabular}


Table 3.3

Regression Coefficients for Moderation Model (suite)

\begin{tabular}{|c|c|c|}
\hline $\begin{array}{l}\text { Guilt for Canada's } \\
\text { inaction }\end{array}$ & Government intervention & Collective action \\
\hline $\mathrm{SE}$ & $\mathrm{SE}$ & $\mathrm{B}$ \\
\hline
\end{tabular}

Step 1

Categorization

$\begin{array}{lll}0.201 & 0.168 \quad .12\end{array}$

0.076

$0.114 \quad .07$

0.115

0.144

.08

Step 2

Humanity-esteem

$\begin{array}{lll}0.215 & 0.169 & .13\end{array}$

0.339

$0.110 .30^{* *}$

$0.096 \quad 0.146$

.07

Step 3

Categorization $\mathrm{x}$

$-0.168$

$0.184-.10$

$-0.084$

$0.120 \quad-.07$

0.048

0.159

.03

Humanity-esteem

Note. ${ }^{\mathrm{a}} p<.10 .{ }^{*} p<.05 .{ }^{* *} p<.01$. 
$F(1,98)=3.55, p=.06$, as presented in Table 3.3. Levels of categorization were a significant predictor of feelings of guilt toward the situation of the victims in Darfur, $\Delta \mathrm{R}^{2}$ $=.041, F(1,98)=4.43, p<.05$. Specifically, categorization of the victims at the more inclusive level (common ingroup) was associated with greater guilt than when they were categorized as outgroup members (Table 3.3).

Summary. Contrary to predictions, humanity-esteem did not moderate any of the effects of group categorization. All effect sizes were small, .011 or less, suggesting that the lack of significant effects was a meaningful finding rather than being due to a lack of power emanating from the small sample size. In line with predictions, higher humanityesteem was associated with greater endorsement of government intervention, but not with any of the remaining variables. In contrast to results in Study 1, presentation of the conflict at the common ingroup level, relative to the outgroup level, was associated with stronger feelings of guilt to the situation of the victims and with a trend for greater perception that Canada could be held accountable for its inaction. Levels of categorization did not influence appraisals of complicity or feelings of guilt for Canada's inaction, or prosocial action endorsements.

\section{Discussion}

The common ingroup identity model (Gaertner \& Dovidio, 2000) posits that recategorization of a former outgroup into a superordinate category that includes both ingroup and outgroup members has positive effects for intergroup relations. However, findings regarding the impact of social recategorization on positive intergroup relations are inconsistent and might depend on the context and on individuals' evaluation of the common ingroup. The goal of Study 2 was to investigate whether individuals' evaluation 
of human beings in general (humanity-esteem) predicted the endorsement of prosocial actions and its antecedents (appraisals and emotional guilt) in response to the Darfur conflict, and whether these beliefs altered the effect of framing such conflicts as affecting humans in countries over the world (common ingroup) in comparison to when the conflict was presented as affecting Sudanese citizens (outgroup categorization).

On the whole, as in Study 1, categorization of the victims at the common ingroup vs. outgroup levels did not have a strong effect on appraisals, feelings of guilt, or prosocial action endorsements. This said, the present study found that Canadians expressed greater feelings of guilt about the situation of the victims when the conflict was presented at the common ingroup level, and they were more inclined to perceive that their group could be held accountable for their inaction in the Darfur genocide. However, this latter finding failed to reach the conventional level of statistical significance. The finding that recategorization of the victims was associated with feelings of guilt about the situation of the victims provided partial support for the common ingroup identity model (Dovidio, Gaertner, Validzic, Matoka, Johnson, \& Frazier, 1997; Dovidio \& Gaertner, 2010; Gaertner \& Dovidio, 2000). However, this finding is inconsistent with that in Study 1 demonstrating that Canadians expressed similar levels of emotional guilt when the victims were seen as part of a common ingroup in comparison to when they were seen as outgroup members. These different findings could be due to differences in how guilt was measured in Study 1, with one item, and Study 2, with three items. Indeed, post-hoc analysis (not shown here) using only one item showed a similar pattern to that found in Study 1. Replication of either finding in future research that uses a reliable measure of 
guilt is needed to clarify the influence of common ingroup categorization of victims of genocide on citizens of third party nations' expressed feelings of guilt.

It had been anticipated that the effect of social recategorization on endorsement of prosocial actions and its antecedents (appraisals and feelings of guilt) would depend on variations in humanity-esteem. However, individuals' evaluations of human beings did not moderate the effects of recategorization on endorsement of prosocial actions and its antecedents in the context of genocide. While it could be that a negative image of humanity does not influence the relationship between social recategorization and reactions to harm done by an outgroup to another outgroup, one alternative explanation could be that portraying the genocide as affecting humans or citizens in countries around the world had the unintended consequence of suggesting that genocide is pervasive. This pervasiveness of genocide could have been interpreted by individuals who hold a negative image of humanity as being intrinsic to the malevolent nature of human beings. People react more leniently to perpetrators of genocide when they perceive genocide to be pervasive and to be part of human nature (Wohl \& Branscombe, 2005).

It could be additionally argued that the common ingroup included not only Canadians and the victims of genocide but also the perpetrators, because they are all humans or citizens of a country. Hence, it is unclear whether the study participants perceived themselves as similar to the victims or similar to the perpetrators. There is evidence that individuals who hold a negative image of human beings and whose ingroup members had harmed an outgroup tended to not perceive violence against the outgroup as immoral when a common ingroup category was made salient (Morton \& Postmes, 2011b). Hence, it is possible that Canadians who hold a negative image of humanity did 
not react in favor of the victims of the genocide when these latter were part of a common ingroup in comparison to when they were portrayed as outgroup members because they banalized the atrocities. To address the shortcomings of the manipulation of levels of social categorization, one possible solution could be for future research to first present the context of the genocide, as it was done in the first paragraph of all the experimental vignettes, followed by the presentation of the need for intervention. Then, manipulate group membership of study participants by priming them to think of themselves as individuals, members of a particular groups, or member of a common ingroup that include the victims but not the perpetrators of genocide.

Although the hypothesis of a moderation effect was not supported, it was found that regardless of how the victims were categorized, as Canadian citizens held human beings in greater esteem they were more likely to endorse greater government intervention. This finding is similar to findings on the role of self-esteem on prosocial actions (Bergami \& Bagozzi, 2000; Findler et al., 2005) and contributes to the literature on prosocial behaviour by demonstrating that the image people have of human beings can influence their support for policies and actions of their government in the context of genocide. Humanity-esteem was not associated with appraisals (complicity and ingroup accountability), feelings of guilt towards the situation of the victims or for Canada's inaction or endorsement of collective action. These findings are inconsistent with research that found an association between humanity-esteem and positive emotions toward others (Luke \& Maio, 2009). Yet, they are consistent with research that did not find a direct link between perceptions of humans and feelings of guilt (Morton \& 
Postmes, 2011b). It is possible that humanity-esteem is associated with positive but not negative emotions (e.g., guilt).

\section{Chapter 4: Study 3}

"[H]elping is neither a fixed function of personality nor automatically invoked by context. Rather it is something that can be actively created through argument. Helping is not something individuals come to alone through internal processes. It is something that can be publicly mobilized" (Reicher et al., 2006, p. 53).

A number of studies have shown that drawing attention to a social norm motivates behavior congruent with this norm (Berkowitz \& Daniels, 1964; Cialdini et al., 1990; Harvey \& Enzle, 1981; Kallgren, Reno \& Cialdini, 2000; Krupka \& Weber, 2009). Norms refer to "shared beliefs with a culture as to what constitutes socially appropriate conduct” (Cialdini, Reno, \& Kallgren, 1990, p. 1023). However, less is known about what happens when a norm that prescribes action is simultaneously activated with a competing norm that prescribes inaction. The present research draws on a theoretical framework delineating the implications of norm activation (Schwartz, 1970, 1977) in an attempt to examine how people's perceptions of their own role and responsibility, their emotions and actions towards genocide might be influenced when a norm promoting a responsibility to protect $(\mathrm{R} 2 \mathrm{P})$ innocent others is activated in comparison to when the R2P norm and the competing norm of non-intervention in the internal affairs of a sovereign country are activated simultaneously, or when no norm is explicitly activated.

\section{Responsibility to Protect}

Before the endorsement of R2P by world leaders at the 2005 World Summit, inaction in the face of genocide could be justified by referring to an international norm of 
non-intervention in Article 2.7 of Chapter I of the UN Charter. Basically, this article stipulates that other states have the obligation to not intervene in the internal affairs of a sovereign country. If this norm is violated, the victim state has the right to defend its territory as well as its political independence. Hence, interventions to protect civilians from government-sponsored slaughter were rare, as such actions could be considered an assault on another nation's sovereignty (International Commission on International and State Sovereignty; ICISS, 2001; Mullenbach, 2005).

Following the failure to prevent or stop the Rwanda genocide in 1994 or the Srebrenica genocide in 1995, the notion of sovereignty as a nation's unequivocal right was revisited (ICISS, 2001). Specifically, in 1999, the then UN Secretary-General Kofi Annan asked the UN General Assembly to 'prevent another Rwanda'. In response to this request, in 2000, Canada established the International Commission on Intervention and State Sovereignty, which released its report, 'The Responsibility to Protect', in 2001. Basically, R2P recognizes the need to respect state sovereignty and the responsibility of each state to protect its citizens from mass killings and other gross violations of their rights. However, in the instance when a state is unable or unwilling to carry out that function, the state is considered to have given up its sovereignty, and the responsibility to protect is passed on to the international community. Thus, sovereignty is no longer considered to be a right, but rather, as a sovereign responsibility to protect the lives of innocent citizens (Arbour, 2008; ICISS, 2001). Despite the R2P norm, the international community failed to prevent or to put a timely stop to the Darfur genocide (Badescu \& Bergholm, 2009; Bellamy \& Williams, 2005). So, how does one explain that R2P did not motivate the global will to protect the civilians in Darfur? 
One plausible explanation why R2P did not elicit intervention against the Darfur genocide might be that the norm of non-intervention in a sovereign country countered actions that were consistent with the emerging R2P norm. Indeed, there is reason to think that when norms that prescribe opposite behaviors (action versus inaction) are simultaneously activated, individuals will be more likely to conform to the norm that liberates them from the more costly (or effortful) behavior with respect to their own selfinterests (Schwartz, 1977). Hence, when the apparent consensus about the R2P norm is challenged by the long-standing non-intervention norm, citizens of other nations may remain passive, as their inaction is normatively justified.

\section{Normative Behaviors}

Research on normative influence suggests that two main types of social norms govern human behavior, namely descriptive and injunctive (prescriptive) norms. The descriptive norm refers to what most people do, what is normal or typical; it motivates action through observations of others' actions. This type of norm leads to the reasoning that if others are doing it, it must be a sensible thing to do. Therefore, observers imitate the behavior (Cialdini et al., 1990). The injunctive norm specifies "what ought to be done" and it "refers to rules or beliefs as to what constitutes morally approved and disapproved conduct" by one's own group (Cialdini et al., 1990, p. 1015). This latter type of norm is the focus of this study, as the R2P norm can be qualified as an injunctive norm.

There has been considerable support for the influence of injunctive norms, when they are made salient, across a wide range of behaviors, including anti-social behaviors (e.g., littering; Cialdini et al., 1990; Kallgren et al., 2000), intentions of Anglophone 
Quebecers to use English in consumer contexts (Louis, Taylor, \& Douglas, 2005), intentions of homeless people to use an outreach program and their actual attendance to the programme (Christian \& Abrams, 2003), intentions and actual donations to charitable organizations (Smith \& McSweeney, 2007), and willingness to engage in collective action (Smith \& Louis, 2008). Together, this body of research suggests that injunctive norms elicit norm-consistent behavior when individuals' attention is draw to the norm (Cialdini et al., 1990; Harvey \& Enzle, 1981; Krupka \& Weber, 2009). Notwithstanding, individuals are often confronted with multiple norms about the same situation in real life, and sometimes injunctive norms concerning a same situation may prescribe conflicting behaviors.

There is a paucity of literature on what happens when people are exposed to conflicting behavioral norms. One of the few studies that investigated the influence of conflicting descriptive (but not injunctive) norms on individuals' behavioral intentions suggested that even if individuals do not consciously engage in a deliberative process about the dilemma presented by these norms, such norms still influence their behaviours. Specifically, it was found that conflicting norms about pro-environmental behaviours motivated some individuals to take environmental action but de-motivated others to engage in such behaviors (McDonald, Fielding, \& Louis, 2013). Based on this latter finding and those mentioned earlier, it was hypothesized that when the R2P norm is salient, individuals would endorse greater government intervention and collective action. In contrast, there will be less support for such actions when the R2P norm is juxtaposed with the injunctive norm of respecting sovereign independence or when no norm is made salient. 
Findings from research on prescriptive norm might also be relevant to make predictions about the relationship between injunctive norm and the antecedents of prosocial actions (complicity and feelings of guilt). For instance, there is some suggestion that prescriptive regulation that promotes overcoming inertia may evoke feelings of guilt among individuals who failed to act (Sheikh \& Janoff-Bulman, 2010). It was therefore expected that when the R2P norm is salient, individuals would perceive greater complicity in the genocide and express greater feelings of guilt for the situation of the victims of the Darfur conflict and for the inaction of Canada, respectively. Alternatively, they will perceive less complicity, and express less feelings of guilt when the R2P norm is juxtaposed with the injunctive norm of respecting sovereign independence or when no norm is made salient.

\section{Present Investigation}

In the present study, participants were randomly assigned to one of three conditions: a scenario describing the norm to protect (R2P norm); a scenario juxtaposing the R2P norm with the nonintervention norm (conflicting norms); or a scenario simply describing a victim of the Darfur conflict (no norm). The individual level of categorization was used because it was important not to make victims' group membership salient in order to avoid appraisals (perceived complicity), emotions (guilt about the situation and for the inaction of Canada) and endorsement of prosocial actions (government intervention and collective action) being differentially influenced by ingroup biases.

It was hypothesized that: 
1. There would be a main effect for norm activation. When the R2P norm alone was activated, greater appraisals of complicity, more guilt, and greater endorsement of prosocial actions would be expressed compared to conditions in which either the conflicting norms were activated or no norm was activated. There would be no difference between these latter two conditions.

2. The norm activation conditions (R2P norm, conflicting norms, no norm) would influence endorsement of prosocial actions (collective action and government intervention) through the sequential mediation of appraisals and guilt, respectively.

\section{Method}

\section{Participants}

Participants $(N=321)$ were 104 men $(32.4 \%)$ and 217 women $(67.6 \%)$ ranging in age from 18 to 82 years $(M=43.55, S D=15.54)$. Participants were recruited through several means. An email invitation (see Appendix P) was sent to previous participants in the lab who had agreed to be contacted for future studies. However, people who had participated in previous studies concerning their perspective on the Darfur conflict were excluded from the mailing. Participants were also recruited via a Zoomerang panel. Similar to the previous studies presented, this study was described as a survey assessing Canadians' perspective on various international conflicts. Darfur was not mentioned in order to reduce self-selection biases based on knowledge of this particular conflict.

The majority of participants self-identified as White/Euro-Caucasian (84.8\%), whereas the remainder self-identified as Asian (4.2\%), South Asian (3.6\%), Aboriginal (1.8\%), Black (1.5\%), Latin American (0.9\%), South East Asian (0.6\%), or mixed ethnic status (2.4\%). In terms of religious affiliation, most participants were either Protestant 
(30.5\%), Catholic (19.6\%) or had no religion (35.2\%). The rest were Muslim (2.2\%), Jewish (1.6\%), or were from other religions (10.9\%). The majority of participants had completed at least one year of college/university (77.6\%), and only a minority were currently full-time or part-time students (14.2\%). The median level of annual family income was between $\$ 45,000$ and $\$ 54,999$. About $80.9 \%$ of them participated in the last federal election, $25.8 \%$ of the participants self-identified with the New Democratic party, $19.4 \%$ with the Liberal, $26.7 \%$ with the Conservative, $4.2 \%$ with the Green party, $1.2 \%$ with the Bloc Québécois, $1.8 \%$ with other parties, $2.9 \%$ did not identify with any party or did not answer.

\section{Procedure}

The procedure was similar to that of Study 2. Presentation of the study, consent form and debriefing are presented in Appendices Q, R, and S, respectively.

Manipulation of norms. Participants were randomly assigned to read a vignette in which a norm associated with the responsibility to protect vulnerable citizens was presented alone or in conjunction with a norm of non-intervention, or no norm was presented (Appendix T). Specifically, the $R 2 P$ norm scenario was introduced as:

“The United Nations' norm Responsibility to Protect (R2P) states that each state has a responsibility to protect its citizens from mass killings and other gross violations of their rights. In the instance that a state is unable or unwilling to carry out that function, the state is considered to have given up its sovereignty, and the responsibility to protect is passed on to the international community." 
The conflicting norms scenario, that is the R2P norm in conjunction with the nonintervention norm vignette, additionally included the following lines after the last sentence of the R2P norm scenario:

"However, the fundamental principle of international law regarding state sovereignty stipulates that any intervention of the international community into a state is a violation of this state's sovereignty and freedom."

The no norm group received only the content of the individualization scenario in Study 1 with no information about norms (see Appendix T). The groups in the R2P norm only and the conflicting norms conditions read this scenario describing the Darfur situation after the presentation of the norms.

\section{Measures}

Measures of socio-demographic characteristics, engagement with current news, appraisals of complicity, guilt (toward the situation of the victims and for the inaction of Canada), and endorsement of prosocial actions (collective action and government intervention) were the same as those in Study 2.

\section{Statistical Analyses}

A series of independent $t$-tests was performed to assess gender differences on the variables of interest. Pearson correlations were performed to assess whether the variables varied as a function of age. A one-way ANOVA was performed to assess whether norm activation affected perceived complicity. A series of one-way MANOVAs was performed to assess whether norm activation affected emotions and action endorsements, respectively. All omnibus (M)ANOVAs were followed by planned contrast analyses. Orthogonal contrasts were used to test the hypothesis that R2P norm condition (coded as 
2) would elicit greater perceptions of complicity, emotions and endorsement of prosocial actions than the combined conflicting norm (coded as -1) and the no norm conditions (coded as -1). Orthogonal contrasts were additionally used to test the hypothesis that participants in the conflicting norm condition would not differ from participants in the no norm condition on perceptions of complicity, emotions and endorsement of prosocial actions (the conflicting norm condition was coded as -1 , the no norm condition as 1 , and the R2P norm condition as 0 ).

A path analysis was conducted to test the relations model wherein norms (with R2P norm (coded 2), conflicting norm (coded -1$)$, and no norm (coded -1)) were specified to directly predict feelings of guilt and complicity, respectively. Further, perceived complicity in the genocide was specified to predict guilt for the situation of the victims and for the inaction of Canada, respectively. Each feeling of guilt was specified to predict endorsement of government intervention and collective action.

To assess whether the model fit the data, chi-square $\left(\chi^{2}\right)$ measure of fit was considered. The objective is to obtain a nonsignificant $\chi^{2}$. Because $\chi^{2}$ is sensitive to sample size, several other indexes of fit that provide different information for evaluating model were additionally considered: comparative fit index (CFI) and goodness of fit index (GFI), for which values greater than .90 are deemed acceptable (Pedhazur \& Schmelkin, 1991), as well as Root Mean Square Error of Approximation (RMSEA), for which values less than .08 are deemed acceptable (Brown, 2006). 


\section{Results}

\section{Data Screening}

The data were examined for missing values, outliers, univariate and multivariate normality, homoscedascity and multicollinearity. There were no missing values on the main variables of the study. Five cases with low scores on government intervention were identified as univariate outliers and four others were identified as multivariate outliers. These cases were dropped from further analyses; hence, the final sample size was reduced to 321 participants. Results of evaluation of linearity and multicollinearity were satisfactory and assumptions of normality were met. Assumptions of homogeneity of variance-covariance matrices were not met for government intervention and collective action, as Box's $M$ test was significant, $p=.003$. It is important to note that when sample sizes are unequal ${ }^{9}$, the robustness of the MANOVA is not guaranteed only if Box's $M$ test is significant at $p<.001$ (Tabachnick \& Fidell, 2007). Nonetheless, Pillai's criterion was used to evaluate multivariate significance, because of its robustness against violations of the assumption of variance-covariance matrices (Tabachnick \& Fidell, 2007).

\section{Preliminary Analyses}

Characteristics of respondents. Engagement with the issue. Participants mildly disagreed that what was happening in Sudan was too far from Canada for them to be concerned $(M=2.93, S D=1.23), t(320)=-15.42 p<.001$. They were not especially familiar with the situation in Darfur $(M=2.74, S D=1.53), t(320)=-14.78, p<.001$. Yet, as in the previous studies, they perceived this issue to be more important to them

\footnotetext{
${ }^{9}$ There were 100 participants in the R2P, 110 in the conflicting norms and 111 in the no norm groups.
} 
personally $(M=4.16, S D=1.58)$, than to Canadians in general $(M=3.15, S D=1.44)$, $t(320)=11.77, p<.001$.

Influence of gender and age $\boldsymbol{1}^{10}$. None of the variables that reflected engagement with the issue (indifference due to geographical distance, familiarity with the situation in Darfur, importance of the issue to them personally and to Canadians in general) varied as a function of gender or age, with the exception of familiarity with the situation in Darfur. Specifically, as in Study 1, men $(M=3.13, S D=1.59)$ reported being more familiar with the Darfur conflict than did women $(M=2.55 S D=1.47), t(319)=3.20, p<.01$. None of the main variables of the study (complicity, feelings of guilt, and endorsement of prosocial actions) were influenced by gender and age, with the exception of a small positive correlation between age and guilt about the situation of the victims $(r=.12, p<$ $.05)$.

Intercorrelations among the main variables in the study. All the variables were significantly intercorrelated, $r$ s varied between .41 and $.73, p s<.001$ (see table 4.1 ).

\section{Main Analyses}

Perceptions of complicity. A one-way ANOVA conducted to test the impact of norms on perceived complicity was significant, $F(2,318)=2.25, p=.11, \eta^{2}=.014$. The ANOVA contrast for the first hypothesis, which tested the influence of the R2P norm condition versus the combination of the conflicting norms and the no norm conditions on perceptions of complicity in the genocide was significant, $F(1,318)=4.25, p<.05, \eta^{2}=$ .013 , suggesting, as expected, that participants reported greater perceived complicity in

\footnotetext{
${ }^{10}$ The influence of religious affiliations was not assessed as the number of participants from some religious groups, including Muslim ( $\mathrm{n}=7)$, were too small to present a meaningful comparison.
} 
Table 4.1

Item-total Reliabilities ${ }^{\mathrm{a}}$ and Bivariate Correlations Among the MainVariables

\begin{tabular}{lccccc}
\hline & 1 & 2 & 3 & 4 & 5 \\
& & & & & \\
\hline 1. Complicity & $.72^{\mathrm{b}}$ & .53 & .73 & .56 & .62 \\
2. Guilt for victims & & .75 & .58 & .41 & .56 \\
3. Guilt for Canada & & .93 & .67 & .73 \\
4. Gov. interv. & & & & .93 & .65 \\
5. Coll. action & & & & & \\
\end{tabular}

Note. $N=321$. Guilt for victims $=$ Guilt toward the situation of the victims; Guilt for Canada $=$ Guilt for Canada's inaction; Gov. interv. = Government intervention; Coll. action $=$ Collective action. All correlation coefficients were significant, $p \mathrm{~s}<.001$. ${ }^{a}$ Cronbach's alphas for each measure are in the diagonal.

${ }^{\mathrm{b}}$ Correlation between the two items that assessed complicity, $p<.001$. 
the Darfur genocide due to inaction when their attention was drawn to the R2P norm ( $M$ $=3.72, S D=1.74)$ in comparison to when their attention was drawn to conflicting norms $(M=3.24, S D=1.63)$ and no norm $(M=3.35, S D=1.72)$. The ANOVA contrast testing the difference in perceptions of complicity in the genocide when participants' attention was drawn to conflicting norms versus no norm was not significant, $F<1$.

Guilt. A one-way MANOVA conducted to assess the influence of norms on guilt (toward the situation of the victims and for Canada's inaction in the Darfur conflict) was not significant, Pillai's $=.025, F(4,636)=2.04, p=.09$. Planned contrasts were nonetheless examined. The MANOVA for the contrast of R2P norm versus the combination of the conflicting norms and the no norm condition was significant, Pillai's $=.023, F(2,317)=3.70, p<.05$. The follow-up ANOVA contrasts revealed that participants in the R2P norm condition $(M=3.75 S D=1.56)$ expressed greater feelings of guilt in reaction to the plight of the people of Darfur than participants in the conflicting norms $(M=3.22 S D=1.51)$ and no norm $(M=3.29 S D=1.42)$ conditions, $F(1,318)=$ $7.43, p<.01, \eta^{2}=.023$. Although the results were on the expected direction, norms did not significantly influence feelings of guilt toward Canada's inaction in the Darfur conflict, $F(1,318)=2.52, p=.11, \eta^{2}=.008$. The MANOVA for the contrast between the conflicting norms and the no norm condition was not significant, Pillai's $=.003, F<1$.

Prosocial actions. The one-way MANOVA that assessed the influence of norm activation on endorsement of prosocial actions (government intervention, collective action) was also not significant, Pillai's $=.023, F(4,636)=1.86, p=.12$. Planned contrasts were pursued because of a priori hypotheses. The MANOVA for the contrast between R2P norm and the combined conflicting norms and no norm conditions was 
significant, Pillai's $=.020, F(2,317)=3.25, p<.05$. Follow-up ANOVAs revealed an effect of norms on endorsement of both government intervention, $F(1,318)=4.56, p<$ $.05, \eta^{2}=.014$, and collective action, $F(1,318)=5.96, p<.05, \eta^{2}=.015$. Specifically, as predicted, participants in the $\mathrm{R} 2 \mathrm{P}$ norm condition expressed greater endorsement of government intervention $(M=5.72 S D=0.91)$ than participants in the conflicting norms $(M=5.51 S D=1.22)$ and the no norm $(M=5.35 S D=1.27)$ conditions. Similarly, participants in the R2P norm condition expressed greater endorsement of collective action on behalf of the Darfur victims $(M=3.90 S D=1.43)$ than participants in the conflicting norms $(M=3.51 S D=1.66)$ and the no norm $(M=3.38 S D=1.53)$ conditions. The MANOVA for the contrast between the conflicting norms and the no norm condition was not significant, Pillai's $=.003, F(2,317)<1$.

Summary. Participants perceived greater complicity in the genocide, expressed greater feelings of guilt toward the situation of the victims and indicated greater endorsements of government intervention and collective action when their attention was drawn to the R2P norm in comparison to when their attention was drawn to the conflicting norms or when no norm was made salient. There were no differences between these latter conditions.

Path model. Path analysis was used to test the hypothesized mechanism by which the manipulation of norms affects prosocial actions against genocide. It was hypothesized that the R2P norms would be associated with endorsements of government intervention and collective action respectively through feelings of guilt, as well as through the sequential mediation of perceived complicity in the genocide and feelings of guilt. Because the conflicting norm versus the no norm condition did not differ on any of the 
variables of interest, they were collapsed for this analysis. Thus, the sequential pathway assessed in the present model reflected the contrast between the R2P norm versus the combined conflicting norms and no norm conditions. A first model specification, as illustrated in Figure 0.1, was constructed such that norms (coded 2 for the R2P condition and -1 for both the conflicting norms and the no norm conditions) were specified to predict action endorsements, with sequential mediation through perceived complicity for inaction and guilt. In order to control for collinearity the two guilt variables were free to covary, as were the outcomes variables (endorsements of government intervention and collective action). Results of the path analysis revealed that the hypothesized model fit the data well. The chi-square value was not significant, $\chi^{2}(d f=4, N=321)=2.13, p=$ .71 , the RMSEA was below .08 (RMSEA $=.00)$, and the other fit indexes were as required above $.90(\mathrm{CFI}=1.00 ; \mathrm{GFI}=1.00)$.

As shown in Figure 4.1, tests of the indirect effect of norms on prosocial actions indicated that the association between the $\mathrm{R} 2 \mathrm{P}$ norm and endorsement of prosocial actions was mediated through several paths. The R2P norm was associated with greater perceived complicity in the genocide, which in turn predicted greater guilt for Canada's inaction, which in turn was associated with endorsements of government intervention $(z=$ $2.02, p<.05)$ and support for collective action $(z=2.02, p<.05)$. A second sequential pathway was also identified, wherein perceived complicity in the genocide was associated with feelings of guilt for the situation of the victims, which in turn predicted endorsements of government intervention $(z=1.83, p<.05)$ and collective action $(z=$ $1.95, p<.05)$. This dimension of guilt also directly mediated the relation between the 


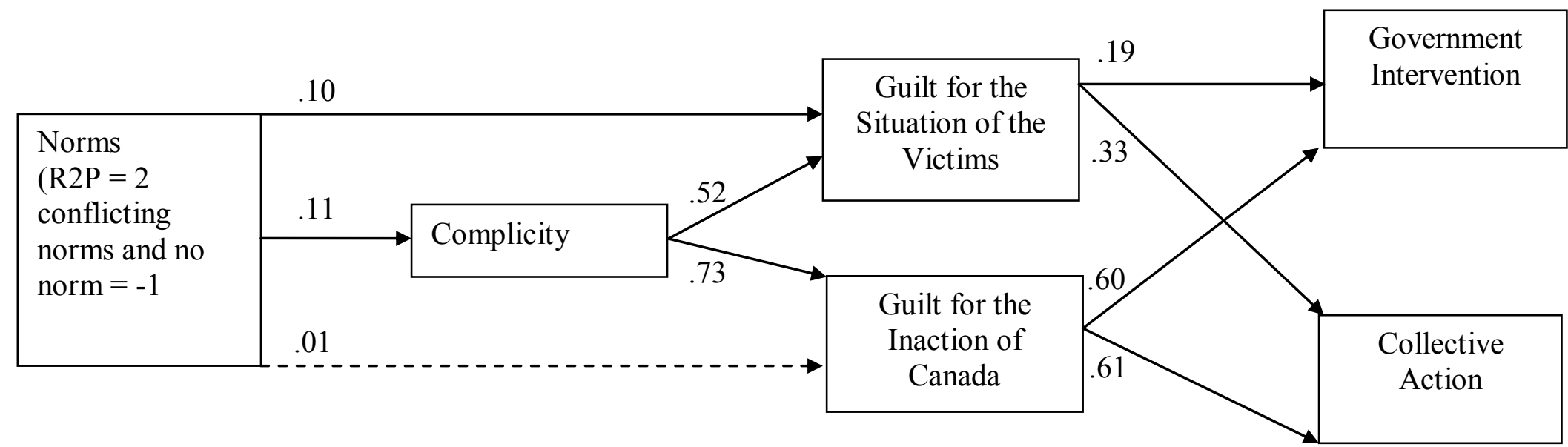

Figure 4.1. Predictive path model linking norms, perceived complicity in the genocide, guilt (for the situation of the victims and for the inaction of Canada) and endorsements of government intervention and collective action. All path coefficients (standardized betas) were significant, $p \mathrm{~s}<.05$, with the exception of the path linking norms to guilt for the inaction of Canada. 
R2P norm and endorsement of government intervention $(z=1.99, p<.05)$ and collective action $(z=2.16, p<.05)$.

Summary. It appears that the R2P norm (relative to both the conflicting norms

and no norm) was associated with greater endorsements of both government intervention and collective action as a result of greater perceptions of complicity in the genocide due to inaction, which in turn were associated with greater feelings of guilt toward the situation of the victims and regarding Canada's inaction, respectively. In addition, salience of the R2P norm was indirectly associated with greater endorsement of government intervention and collective action through the experience of greater feelings of guilt toward the situation of the victims.

\section{Discussion}

Several activist scholars have raised the concern that the R2P norm does not motivate the will to intervene (MIGS, 2009). One important contribution of this study was to show that normative contexts influence how citizens of third party nation feel and act in response to an ongoing genocide in another region of the world. Specifically, the results showed that citizens of a third party nation felt greater guilt toward the plight of the people of Darfur, perceived greater complicity in the genocide due to their inaction, and endorsed greater government intervention and collective action on behalf of the victims when their attention was drawn to the R2P norm in comparison to when their attention was drawn to conflicting norms about responsibility to protect and nonintervention in the affairs of a sovereign country or when no specific norm on how to act was brought to their attention. The finding that the R2P norm influenced endorsement of prosocial actions against the genocide is consistent with previous finding that Bulgarians' 
norm of opposition to oppressors influenced them to take collective action against the deportation of Jews during WWII (Reicher et al., 2006; Reicher \& Haslam, 2010). The present study, moreover, investigated the impact of norm on the responsibility to protect while the genocide was ongoing and thereby strengthened the results of earlier studies that used archival documents to investigate the role of norm on rescuers of Jews during the Holocaust (Reicher et al., 2006).

It appears that people are more likely to comply with norms that prescribe demanding actions when there are no alternative norms that provide an escape from the prescribed obligations. In contrast, when the norm of responsibility to protect innocent citizens from systemic and gross violations of their human rights and the conflicting norm on the respect of state sovereignty were considered simultaneously, the respect of state sovereignty overshadowed the prescription to protect innocent citizen. In this particular context, people responded as if no particular norm prescribing action against genocide was made salient. This could mean that multiple norms diminish the salience of a given norm that might otherwise guide participants, such that they do not endorse action. It is also possible that people are conflicted about the issues requiring intervention when multiple norms compete for their attention.

One of the strengths of Study 3 was that it included a control condition wherein no specific norm was presented. This condition served to provide a benchmark against which to compare how norms reinforce the prescribed behavior and how conflicting norms hinder movement. While the conflicting norms did not demotivate individuals to endorse action against genocide, it also did not motivate them to take action, given that they reacted in a manner similar to when no norm was available to guide their actions. It 
could be argued that the order in which the $\mathrm{R} 2 \mathrm{P}$ norm and the non-intervention norm were presented in the conflicting norms condition may have led participants to pay more attention to the prohibition of action than the invitation to take action. In order words, one could wonder whether the conflicting norms manipulation could have evoked different reactions (i.e., greater endorsement of prosocial actions) if the statement about the R2P norm was presented after the statement about the non-intervention norm. In future research, it might be best to present the conflicting statements in a counterbalanced order. Specifically, a vignette that presents the R2P statement and then the non-intervention statement could be read by half of the participants and a vignette that presents the nonintervention statement and then the R2P statement could be read by the other half of participants who are assigned to the conflicting norms condition. Then, the effect of order of presentation should be assessed and controlled for if need be. This said, there is reason to think that people are more likely to endorse the less demanding norm (Schwartz, 1977). Moreover, there is evidence that the implementation of the new international norm of a responsibility is constrained by several factors associated with the principles of state sovereignty and non-intervention in countries that traditionally adhered to a nonintervention (Prantl \& Nakano, 2011). This suggests that the presentation of the R2P norm after the non-intervention norm may not readily prompt endorsement of action.

This study also aimed at understanding the mechanism by which norms influenced endorsements of prosocial actions in favor of the victims of an ongoing genocide. Consistent with predictions, when participants' attention was drawn to the R2P norm, as oppose to when the conflicting norms or no norm was made salient, they expressed greater guilt about the plight of the people of Darfur. These feelings of guilt 
were associated with increasing likelihood of supporting governmental measures against genocidal process and endorsing collective action, which pressure the government to intervene against the genocide. The present results suggest that when the R2P norm was salient, participants were more likely to perceive that their group and themselves could become complicit in the genocide if they did not take action against it. They felt guilty about the plight of the people of Darfur and for the inaction of Canada, respectively. These feelings of guilt, in turn, were associated with increasing likelihood of endorsing both government intervention and individual's collective action against the genocide. This pattern of results is congruent with findings that feelings of guilt invoked by a transgression influence actions to repair the harm done (Brown \& Cehajic, 2008; Brown, Gonzalez, Zagefka, Manzi, \& Cehajic, 2008; Cehajic-Clancy et al., 2011).

\section{Chapter 5: General Discussion}

Conflicts between groups can be expected to become increasingly common due to globalization, overpopulation, discrimination and aspirations for self-determination (Staub et al., 2005). When groups are involved in ongoing genocidal conflicts, they may appeal to third parties for support and assistance (Nolte \& Aust, 2009; Simon \& Klandermans, 2001). However, there is a lack of empirical research regarding the social psychological factors that might influence third party nations to act against genocide. While self-interest, be it socio-political or economic, may prevent a third party nation from intervening to stop a conflict in another region of the word, the present thesis argued that social psychological processes that are rooted in social identities and norms may influence actions against an ongoing genocide. Using the ongoing Darfur genocide as a reference, the present research contributes to the literature by demonstrating that when 
victims of a genocide are portrayed to citizens of a third party country through social decategorization - which increases the individuality of the victim - and when norms regarding a responsibility to act are made salient, individuals' appraisals of their role and their emotional reactions are influenced in such a way as to increase their likelihood of endorsing prosocial actions on behalf of the victims.

This thesis started with a quote of Samantha Power (2003) who asked why we have all been bystanders to genocide. The literature on bystander actions and that on reactions to genocide suggests that intergroup processes (Reicher et al., 2006) and in particular, psychophysical numbing (Slovic, 2007), may be involved. However, while for the most part this line of research helped to explain bystandership, or inaction in situations in which outgroup and ingroup members shared the same geographical space, it does not specify what would influence a third party nation to take action against a genocide that is ongoing in another region of the world. Moreover, explanatory models of third party's reactions to genocide are theoretical (Branscombe, 2004; Slovic, 2007). The aim of the present research was to fill this gap by using a combination of social identity theory (Tajfel, 1978, 1982; Tajfel \& Turner, 1979, 1986; Turner, 1982) and the identifiable victim effect (Jenni \& Loewenstein, 1997; Small \& Loewenstein, 2003, 2005; Small et al., 2007; Slovic 2007) as a main framework to empirically examine this phenomenon.

Findings from Study 1 suggested that one way to counter bystandership or apathy in the context of a genocide is to decategorize the victims through the presentation of the personal story of a single victim. This is one of the few published studies, if not the only one, to provide quantitative support for the benefit of decategorization (Brewer \& Miller, 1984; Miller, 2002; Wilder, 1981, 1986) and the identifiable victim effect (Jenni \& 
Loewenstein, 1997; Small \& Loewenstein, 2003, 2005; Small et al., 2007; Slovic 2007), which is also called the singularity effect (Kogut \& Ritov, 2005a, 2005b, 2007) in the context of an ongoing genocide. Study 1 showed that focusing on the story of one individual victim of genocide, in comparison to framing the genocide as affecting hundreds of thousands of citizens in countries around the world or hundreds of thousands of citizens in Darfur, influenced Canadian citizens (a third nation) to endorse greater government intervention and collective action on behalf of the victims of the genocide. As mentioned earlier, the singularity effect is such that the story of one identified victim, as opposed to the presentation of the plight of a large number of victims, prevents psychophysical numbing (Baron, 1997; Fetherstonhaugh et al., 1997; Slovic, 2007; Small et al., 2007). Indeed, charitable organizations often individualize victims of natural disasters or economic disadvantage when they are making appeal to the public for donations, as they are more likely to attract such donations when they do so (Slovic, 2007). The particularity of Study 1 is that it showed that this strategy works in the context of mobilizing support for intervention in a genocide occurring in a distant region.

Contrary to expectations, the presentation of the victims as part of a common group (citizens in countries around the world) elicited similar responses compared to when the victims were described in outgroup terms, namely as citizens of Darfur. This is inconsistent with previous findings that recategorization of victims could reduce bystandership in the context of physical violence perpetrated toward a stranger (Levine et al., 2002). One possible explanation could be that Canadians did not perceive a mega contrast between citizens in Darfur and citizens in countries around the world. Specifically, given the social context of genocide or ethnic cleansing, and the 
unlikelihood of genocide happening in Canada, it is possible that Canadians failed to perceive Canada as the prototype of countries in which ethnic cleansing is happening. Therefore, they might not have acknowledged the inclusion of themselves in this common category. In this regard, they likely perceived the genocide as happening in the region of Darfur in Sudan together with other countries in the world, which in either case represent outgroups for Canadians. Indeed, the problems associated with trying to eliminate ingroup-outgroup differentiation have been acknowledged in numerous studies (see Machunsky, Meiser, \& Mummendey, 2009; Wenzel, Mummendey, \& Waldsus, 2007).

One way to address this problem and that warranted further investigation was to identify for whom recategorization of the victims as a common ingroup would make a difference, in comparison to categorization of the victims as outgroup members. Building upon the idea that the esteem in which people hold their group is an important predictor of their responses towards members of their own and other groups (Abrams \& Hogg, 1988), it was hypothesized that the extent to which Canadians would respond to recategorization of the victims into a common group relative to categorization of the victims as outgroup members (Sudanese citizens) would depend on their perception of the worth of human beings. It was expected that when the common ingroup was made salient, Canadians with lower humanity-esteem would express greater appraisals (complicity and ingroup accountability), greater feelings of guilt (for the situation of the victims and the inaction of Canada) and more strongly endorse prosocial actions (government intervention and collective action). Canadians with higher humanity-esteem would express similar appraisals, feelings of guilt, and prosocial actions toward the 
victims, irrespective of levels of categorization. However, this moderation hypothesis was not supported in Study 2. Rather, independently of how victims were categorized, as individuals held human beings in higher esteem they were more likely to endorse government intervention in the Darfur conflict. Future research may explore whether interventions that increase humanity-esteem would influence citizens of third party nations to endorse greater government intervention to stop genocide.

Another goal of this research was to explore the processes by which the salience of a particular social categorization influenced citizens of a third party country to endorse actions against genocide, which represents a vicarious emotion-eliciting event (Lickel et al., 2004). Several pathways were revealed. Of particular relevance, alteration of the way the victims were portrayed to citizens of a third party country, by individualizing the victims, influenced Canadian citizens to make greater appraisals that they and their group were complicit in the genocide if they did not take action. Perceptions of complicity in the genocide if they do not act against it, in turn, influenced Canadians expressions of guilt, and ultimately their endorsements of greater prosocial actions. This finding is in keeping with previous findings. For example, during WWII, Bulgarians acted to prevent the deportation of Jews because they did not want to be complicit in mass slaughter (Hopkins, Reicher, Harrison, Cassidy, Bull, \& Levine, 2007). That said, while these authors argued that the Bulgarian rescue of Jews was out of self-interest (i.e., concern about their reputation), the present research, which was conducted while the Darfur genocide was ongoing, suggested that individualization of the victims (Study 1) and group norms (Study 2) influenced perception of complicity in genocide because of inaction and further influenced endorsement of collective actions that pressure 
governmental authorities to intervene in the genocide through feelings of guilt. Because complicity allows the evolution of atrocities (May, 2010; Stanton, 2004; Staub, 2006), inaction could be interpreted as an approval of the genocide (Wettstein, 2010), and this is morally wrong.

The consistent findings in the present studies regarding the mediating role of guilt for the situation of the victims in eliciting support for collective action on behalf of the victims provided empirical support for a previously articulated theoretical model delineating the role of guilt in linking levels of categorization to reactions to genocide (Slovic, 2007). In addition, the findings of Study 3 indicate that drawing attention to a norm that prescribes intervention can also elicit guilt and the subsequent endorsement of prosocial actions against the genocide. Moreover, whereas individualization of the victims was associated with individual guilt and support for government intervention, drawing attention to the $\mathrm{R} 2 \mathrm{P}$ norms enhances feelings of individual and collective guilt which together influenced Canadians to endorse both government interventions and collective action that pressure the government to implement measure against the genocide. These findings suggest that in order for citizens of a third party nation to simultaneously endorse collective action that pressures their government to act against genocide and support intervention to stop an ongoing genocide, they must be presented with the R2P norm in conjunction with the individualized story of a single victim.

As mentioned earlier, norms that are espoused by particular groups contribute to collective responses to genocide. Study 3 tested the influence of the international norm of a responsibility to protect, commonly referred to as $\mathrm{R} 2 \mathrm{P}$, as this norm aims to provide a code of conduct in case of a genocide or ethnic cleansing (Prantl \& Nakano, 2011). When 
a norm is internalized, individuals are not necessarily aware of its influence on their responses to a given situation. For example, the norm of helping needy people is ingrained in Western society. Therefore, if a Westerner, who is in a position to help, sees a person distress, the Westerner would probably instantly help this person without much thinking about what the rules are in such a situation. That said, sometimes, even when there is a norm to intervene, people do not necessarily follow the norm. Along this line, there are concerns expressed regarding why the norm that calls for responsibility to protect (R2P) failed to mobilize intervention, particularly in the genocide of Darfur, as the International R2P Agreement was, in fact, endorsed during the Darfur conflict (Prantl \& Nakano, 2011).

Why were citizens of third party nations still bystanders to genocide despite the adoption of the international R2P norm? To answer this question, Study 3 took into consideration the fact that people might have been exposed to conflicting norms that are viewed as equally legitimate. In this regard, a second international norm was considered, namely the norm of non-intervention in a sovereign country. Indeed, Canadians who were exposed to the R2P norm endorsed greater government intervention and collective action in comparison to those who were either exposed to the conflicting norms of R2P and nonintervention in a sovereign country, or to no norm. However, when the norm of a responsibility to protect was juxtaposed with the conflicting norm of non-intervention, people reacted as if no norm about a course of action to be taken was available. These findings suggest that the salience of a norm of non-intervention releases people from the demanding duty to protect innocent citizens. Further, these findings are consistent with propositions from the international relations literature that suggest, for example, that 
China and Japan do not promote the R2P norm locally because they emphasize the competing norms of non-interference in the internal affairs of sovereign countries and respect of state sovereignty (China) and anti-militarism (Japan) (Prantl \& Nakano, 2011).

Taken together, the present studies extend the literature on transforming collective inaction toward genocide into collective action against genocide in at least three ways. First, this research provided empirical support for the model of antecedents and consequences of collective guilt (Branscombe, 2004) as well as for the theoretical model of reactions to genocide (Slovic, 2007). It thereby provided some insights for the literature on mobilization of the will to intervene (Chalk et al., 2010) by demonstrating the mechanism by which collective inaction can be transformed into collective action. Second, most research efforts assessing reactions to genocide have focused on past harm doings (Monroe, 2008). The present investigation is among the few, if not the only one, to empirically investigate reactions and intentions during the time of an ongoing genocide. Although this was not a comparative study, the present research showed that post-genocide reactions and reactions to an ongoing genocide share some similarities. For instance, the results are in keeping with the view that social categorization influenced actions against genocide. However, contrary to previous findings that inclusion of the victimized group into a common group with the rescuers elicits prosocial responses (Reicher et al., 2006), the present results suggest it is the individualization of the victims that is integral to action. As noted earlier, an important contextual difference between the above mentioned study and the present research was the geographical distance between the Canadians and Dafurians. Although respondents did not seem to perceive that what is happening in Darfur is too far for them to be concerned, groups who live in the same 
space may be perceived to share more similarities in terms of societal values and other aspects of life derived from living in the same country. The greater individuals perception that others are similar to them the more likely they were to provide assistance (Reicher et al. 2006).

Third, most social psychological research has focused on victims or perpetrators of genocide. Few studies have explored the influence of feelings of complicity and guilt on action taken on behalf of an outgroup that has harmed another outgroup. The present results provide empirical evidence that, similar to research findings on reactions to ingroup-perpetrated harm (Wohl et al., 2006), determinants of the willingness of citizens of third party nation to endorse prosocial actions against genocide depend on the situational context; that is, how the victims are categorized, and salient norms.

These results have implications for the media coverage of ongoing genocide. The role of the media in evoking public mobilization is very important. Indeed, the way victims of genocide are presented may facilitate or hinder third's party willingness to take action on behalf of the victims. The individualization of the victims seems to be beneficial in the context of public mobilization against an ongoing genocide. Further, the norm of R2P can be highlighted. For example, educational programs and media campaigns might promote the R2P norm by showing how this norm fits into global norms that are internalized and valued by Canadians.

Canada is recognized as a peacekeeping country. While peacekeeping deployment usually happens after the conflict ceases and serves to reinforce the maintenance of peace agreements between the groups who were in conflict, Canada could integrate the mandate to promote diplomatic talks with countries perceived to be on the verge of genocide in its 
international policies, as most of the time influential countries like Canada are aware of an oncoming genocide before it is executed. However, things are not so simple.Genocide is considered a crime against humanity (Convention on the Prevention and Punishment of the Crime of Genocide, 1948). Should a country or an entity, such as the UN, acknowledge that there is genocide, it has the responsibility to halt the genocide. As a result, it takes time for third party nations to qualify an ongoing conflict as genocide. Thus, it would be unrealistic to think they would qualify a conflict that has not yet started as oncoming genocide. Hence, initiating preemptive diplomatic talks may not be possible.

It is important to note that although this research focuses on third party interventions in genocide, it is not arguing that third parties should always intervene in all intrastate conflicts. In an attempt to prevent hegemony, there is a limitation to the extent the international community can intervene in the internal affairs of a sovereign country (Badescu \& Bergholm, 2009). Moreover, there are times when intervention should not be encouraged (see Carment \& Rowlands, 1998). This said, genocide is a crime against humanity that necessitates intervention in favor of the victims.

\section{Limitations}

One of the strengths of this series of studies was the use of a community sample as opposed to a student sample, which increases the generalizability of the results to the Canadian population. That said, the sample was constituted mainly of women. This could raise the question of whether these findings equally reflect reactions of men. However, there were no gender differences on any of the main variables of the study. Therefore, it could be assumed that these results are not influenced by gender. 
Although the present research hypothesizes a sequential series of responses to elicit support for prosocial actions, the measures were collected at the same time. Therefore, no strong causal inferences can be made. However, in an effort to disentangle the directional relations, alternative directional models that assessed reverse pathways were explored. The results revealed that the original models were more viable. Hence, the direction of the relations proposed in the present models provides a better explanation of the mechanism by which social categorization as well as norms, respectively, influenced prosocial actions against an ongoing genocide.

The studies were conducted online which could raise questions about the reliability of the responses and the self-selecting nature of the sample. However, consistency checks were performed and only internally-consistent data were included in the data analysis. Further, online studies provide anonymity and thus, participants who completed a questionnaire at distance may feel less social pressure and less coercion to respond in a socially desirable manner in comparison to those who performed this task in a face-to-face environment (Wilt, Condon, \& Revelle, 2012). That said, our results parallel that reported from previous studies that were conducted face-to-face. For example, levels of reported guilt were similar to those reported by studies conducted face-to-face (Cehajic-Clancy et al., 2011) or online (Pagano \& Huo, 2007).

The issue of self-selection bias is not unique to online studies. It is equally problematic for face-to-face studies in which participants choose to take part on their own volition. Measures were taken to reduce self-selection bias. Specifically, Darfur was not mentioned in order to reduce participation based on the knowledge of this particular conflict. While having a representative sampling is the ideal goal, one advantage of 
online research over traditional methods of data collection is that it allows the recruitment of a highly diverse sample in terms of locations, socioeconomic status, and age, to name only a few (Wilt et al., 2012). For instance, participants were from different provinces and territories of Canada.

One could question the generalizability of the presented models of mobilization of action to other genocides or intrastate conflicts. Specifically, it could be asked whether the presented models of mobilization of action are applicable to other ongoing conflicts, for example the current civil war in Syria, as the models were only tested in the context of the Darfur conflict. Each conflict is unique and presents its own stakes and challenges (Slovic, 2007), these particular models of mobilization of action might not be applicable to explain reactions to all conflicts. There might be a need to consider other variables that may influence reactions of third party nations, for example the religious affiliation of the perpetrators and the victims or the ethnic similarities between the victims and the citizens of an influential third party country. Along the same line, given that third-party intervention in intrastate conflict are influenced by their group's norms, it might be of interest to test the presented models among citizens of countries that adhere to a norm of non-intervention or a norm of anti-militarism such as China and Japan, respectively (Prantl \& Nakano, 2011) in comparison to citizens of countries, such as Canada, that are more likely to adopt a norm of a responsibility to protect.

A final limitation of this research was that behavioral intentions and not actual behaviors were measured. While some studies have found that behavioral intentions are not a reliable predictor of actual behavior, others provided evidence that behavioral intentions did predict actual behaviors (Louis, Duck, Terry, Schuller, \& Lalonde, 2007). 
Despite these limitations mentioned earlier, this research undoubtedly contributes to the social psychological literature about genocide by demonstrating how collective inaction can be transformed into collective action in the context of an ongoing genocide.

\section{Future directions}

In responding to the question of why Canadians did not take action sooner against the Darfur Genocide, one could argue that Canadians were unaware of the mass atrocities. With the exception of the New York Times, where the columnist Nicholas Kristof reported relentlessly on the conflict, there was little media coverage of this event (Slovic, 2007). Nonetheless, at the time that data were collected for Study 1 (May 25, 2010 to July 2, 2010), major Canadian media outlets continued coverage of the situation in Sudan. For example, in June 7, 2010, the Globe and Mail published an article entitled "Darfur sees bloodiest month in two years, UN says" (see http://www.theglobeandmail.com/news/world/darfur-sees-bloodiest-month-in-two-yearsun-says/article4321582/). However, in the present research, assessment of the knowledge of Canadians of the Darfur situation showed that participants believed that they were not especially familiar with the issues. It could be worth exploring the role of media coverage of genocide on prosocial actions on behalf of the victims.

Study 1 showed that the way victims are portrayed may influence emotions associated with prosocial behavior. Notwithstanding, in addition to feelings of guilt, other prosocial emotions, including shame and anger, could play a role in influencing citizens of third party nation to endorse prosocial actions against genocide. Shame and anger might have different implications for the subsequent types of actions in which individuals are willing to engage. For example, whereas guilt has been found to be more likely to 
motivate reparation of damaged relations (Mallett, Huntsinger, Sinclair, \& Swim, 2008), anger fostered a willingness to confront the perpetrator and to support compensation for harm done (Iyer et al., 2007), and shame motivated advocacy for withdrawal of troops in occupied Iraq (Iyer et al., 2007). Future research may extend the present model by exploring the implications of eliciting various emotional reactions.

Shame may motivate action in the short-term when there is a concern about reestablishing the group's reputation (Brown \& Cehajic, 2008; Brown et al., 2008). There is evidence that individuals who were concerned with their self-image, or their countries' image (Iyer et al., 2007; Lickel et al., 2011), felt ashamed when they or their group committed transgressions that harmed others (Johns, Schmader, \& Lickel; 2005). Personal shame led to greater willingness to overcome previous personal failure (De Hooge, Zeelenberg, \& Breugelmans, 2010) and feelings of collective shame led to support for reparatory action toward harmed groups (Brown \& Cehajic, 2008; Brown et al., 2008) in an attempt to restore the positive image of self or the group. Along these lines, in the context of genocide, it was found that Bulgarians advocated against the deportation of Jews when failure to do so was perceived to reflect badly on their reputation (Reicher et al., 2006). It remains to be determined whether individualization of victims of ongoing genocide may lead to endorsement of intervention against the genocide through feelings of shame, including shame due to concern about one's own or ingroup reputation. It is plausible that silent complicity in genocide may be perceived to reflect some form of moral cowardice (LeBor, 2006).

In some contexts, particularly when a group has committed an injustice, feelings like guilt or anger might be elicited (Iyer et al., 2007). When the self or the group is 
responsible for a moral transgression against others, anger may be directed at oneself (Wiener, 2006) or one's group (Iyer et al. 2007). Such anger is considered to reflect moral outrage (Batson et al. 2007) and has been found to prompt efforts to restore justice (Carlsmith, Darley, \& Robinson, 2002; Darley \& Pittman, 2003; de Riviera, Gerstmann, \& Maisels, 2002; Haidt, 2003; Iyer et al., 2007). For instance, as supporters of the Water for Life movement felt outrage regarding a water shortage in developing countries, they expressed greater intentions to participate in Water for Life activities aiming at reducing water-related disadvantage among citizens of developed countries (Thomas, Mavor, \& McGarthy, 2012). In the context of genocide, qualitative research suggested that perceptions of shared humanity influenced individuals' feelings of anger and motivated citizens of several countries to rescue targeted victims of genocide (e.g. Jews during the Holocaust; Monroe, 1991, 2008; Reicher et al., 2006). It remains to be seen whether the situation of the victims of genocide or the inaction of their group would elicit moral outrage and thereby influence endorsements of actions to punish perpetrators of genocide.

In Study 2, humanity-esteem did not moderate the relations between social recategorization and prosocial actions against the then-ongoing genocide. One other avenue that was not explored that might account for this result involved perceptions of the efficacy of action to mobilize intervention to stop genocide. A growing line of research has provided evidence that personal and collective efficacy, that is, the belief in one's personal and collective ability to achieve change (Stewart et al, 2010), predicted behavior in several social contexts, including politics (Valentino, Gregorowicz, \& Groenendyk, 2009), structural sexism (Foster \& Matheson, 1995), institutionalized racism (Stewart et al., 2010), social movements (van Zomeren, Postmes, \& Spears, 
2008), and in opinion-based groups (McGarty et al., 2009; Thomas et al., 2012). While these studies have explored the role of efficacy of taking action for self or on behalf of one's group, few studies have explored the influence of perceived efficacy on action taken on behalf of an outgroup for an issue as large in scope as ethnic genocide (Beaton \& Deveau, 2005; Stewart et al., 2010). It possible that group-based presentations of victims of genocide as members of a common ingroup or an outgroup might influence emotions and actions on their behalf through perceptions that one's action will be more efficacious. This hypothesis remains to be investigated.

Study 3 suggested that when people consider both the R2P norm and the norm about nonintervention, they would prefer the liberating norm of nonintervention over the norm of the responsibility to act. However this might not be the case for people who already have a positive attitude toward intervention in states that perpetrate atrocities on their own citizens. People who are convinced that third party nations should intervene to stop any genocide might support collective action against genocide despite the presence of a norm prescribing otherwise. This hypothesized moderating role of attitudes toward external intervention remains to be explored.

\section{Conclusion}

Intergroup conflicts are anticipated to increase in the future as there are more and more interactions between different cultures and nations. When groups are in conflict they may appeal to a third party for help. Although overcoming apathy and inaction toward genocide is an important priority of governments and nongovernmental activist organizations (Thomas \& Louis, 2013), there is little empirical research on the social psychological factors that could influence a third party nation to take actions on behalf of 
victims of genocidal conflict. This study is unique in that it investigated how reactions to inaction in itself could mobilize action in the context an ongoing genocide.

Individualization of victims and clear norms eliciting a responsibility to protect were found to be predictive of action endorsements against genocide. In particular, these factors gained active support through their influence on appraisals of the role of the third party nation (complicity) and feelings of guilt toward the situation of the victims and the group's inaction. The present findings have implications for how the media covers ongoing genocide and national responsibilities. 


\section{References}

Abrams, D., \& Hogg, M. A.(1988). Comments on the motivational status of self-esteem in social identity and intergroup discrimination. European Journal of Social Psychology, 18, 317-334.

Aberson, C. L., Healy, M., \& Romero, V. (2000). Ingroup bias and self-esteem: A metaAnalysis. Personality and Social Psychology Review, 4, 157-173.

Arbour, L. (2008). The responsibility to protect as a duty of care in international law and practice. Review of International Studies, 34, 445-458.

Badescu, C. G., \& Bergholm, L. (2009). The responsibility to protect and the conflict in Darfur: The big let-down. Security Dialogue, 40, 287-309.

Barltrop, R. (2011). Darfur and the international community: The challenges of conflict resolution in Sudan. New york: I. B. Tauris.

Baron, J. (1997). Confusion of relative and absolute risk in valuation. Journal of Risk and Uncertainty, 14, 301-309.

Baumeister, R. F., Stillwell, A. M., \& Heatherton, T. F. (1994). Guilt: An interpersonal approach. Psychological Bulletin, 115, 243-267.

Baumeister, R. F., Vohs, K. D., DeWall, C. N., \& Zhang, L. (2007). How emotion shapes behavior: Feedback, anticipation, and reflection, rather than direct causation. Personality and Social Psychology Review, 11, 167-203.

Batson, C. D., Kennedy, C. L., Nord, L., Stocks, E. L., Fleming, D. A., Marzette, C. M., ... Zerger, T. (2007). Anger at unfairness: Is it moral outrage? European Journal of Social Psychology, 37, 1272-1285.

Beaton, A. M., \& Deveau, M. (2005). Helping the less fortunate: a predictive model of 
collective action. Journal of Applied Social Psychology, 35, 1609-1629.

Bellamy, A. J., \& Williams, P. D. (2005). The responsibility to protect and the crisis in Darfur. Security Dialogue, 36, 27-47.

Bergami, M., \& Bagozzi, R. P. (2000). Self-Categorization, affective commitment and group-self-esteem as distinct aspects of social identity in the organization. British Journal of Social Psychology, 39, 555-577.

Berkowitz, L., \& Daniels, L. R. (1964). Affecting the salience of the social responsibility norm: Effects of past help on the response to dependency relationships. Journal of Abnormal and Social Psychology, 68, 275-281.

Booker, T. (2008). Genocide in Sudan: A look at three events. The International Journal of Regional and Local Studies, 4, 71-88.

Branscombe, N. R. (2004). A social psychological process perspective on collective guilt. In N. R., Branscombe \& B. Doosje (Eds.), Collective guilt: International perspectives (pp.320-334). New York, NY: Cambridge University Press.

Branscombe, N. R., Doosje, B., \& McGarty, C. (2002). Antecedents and consequences of collective guilt. In D. M. Mackie \& E. R. Smith (Eds.), From Prejudice to intergroup emotions: Differential reactions to social groups (pp. 44-66). Philadelphia, PA: Psychology Press.

Branscombe, N. R., \& Miron, A. M. (2004). Interpreting the ingroup's negative actions toward another group: Emotional reactions to appraised harm. In L. Z. Tiedens \& C. W. Leach (Eds.), The social life of emotions (pp. 314-335). New York: Cambridge University Press.

Branscombe, N. R., Slugoski, B., \& Kappen, D. M. (2004). The measurement of 
collective guilt: What it is and what it is not. In N. R., Branscombe \& B. Doosje (Eds.), Collective guilt: International perspectives (pp.16-34). New York, NY: Cambridge University Press.

Brewer, M. B., \& Miller, N. (1984). Beyond the contact hypothesis: Theoretical perspectives on desegregation. In Norman Miller \& Marilynn B. Brewer (Eds), Groups in Contact: The psychology of desegregation., Orlando, FL: Academic Press.

Brown, T. A. (2006). Confirmatory factor analysis for applied research. New York: Guilford Press.

Brown, R., \& Cehajic, S. (2008). Dealing with the past and facing the future: Mediators of the effects of collective guilt and shame in Bosnia and Herzegovina. European Journal of Social Psychology, 38, 669-684.

Brown, J. D., Collins, R. L., \& Schmidt, G. W. (1988). Self-esteem and direct versus indirect forms of self-enhancement. Journal of Personality and Social Psychology, 55, 445-453.

Brown, R., Gonzalez, R., Zagefka, H., Manzi, J., \& Cehajic, S. (2008). Nuestra culpa: Collective guilt as a predictor for reparation for historical wrong-doing. Journal of Personality and Social Psychology, 94, 75-90.

Campbell, D. T. (1958). Common fate, similarity, and other indices of the status of aggregate of persons as social entities. Behavioral Science, 3, 14-25.

Carlsmith, K. M., Darley, J. M., \& Robinson, P. H. (2002). Why do we punish? Deterrence and just deserts as motives for punishment. Journal of Personality and Social Psychology, 83, 284-299. 
Carment, D., \& Rowlands, D. (1998). Three's company. Evaluating third-party intervention in intrastate conflict. Journal of Conflict Resolution, 42, 572-599.

Cehajic-Clancy, S., Effron, D. A., Halperin, E., Liberman, V., \& Ross, L. D. (2011). Affirmation, acknowledgment of in-group responsibility, group-based guilt, and support for reparative measures. Journal of Personality and Social Psychology, $101,256-256-270$.

Chalk, F., Dallaire, R., Matthews, K., Barqueiro, C., Doyle, S. (2010). Mobilizing the will to intervene. Leadeship to prevent mass atrocities. Montreal: McGill-Queen's University Press.

Christian, J., \& Abrams, D. (2003). The effects of social identification, norms and attitudes on use of outreach services by homeless people. Journal of Community and Applied Social Psychology, 13, 138-157.

Cialdini, R., Reno, R., \& Kallgren, C. (1990). A focus theory of normative conduct: Recycling the concept of norms to reduce littering in public places. Journal of Personality and Social Psychology, 58, 1015-1026.

Convention on the Prevention and Punishment of the Crime of Genocide (1948). Retrieved from http://www. hrweb.org/legal/genocide.htm.

Crisp, R. J., Stone, C. H., \& Hall, N. R. (2006). Recategorization and subgroup identification: Predicting and preventing threats from common ingroups. Personality and Social Psychology Bulletin, 32, 230-243.

Crocker, J., \& Luhtanen, R. (1990). Collective self-esteem and ingroup bias. Journal of Personality and Social Psychology, 58, 60-67.

Darley, J. M., \& Pittman, T. S. (2003). The psychology of compensatory and retributive 
justice. Personality and Social Psychology Review, 7, 324-336.

De Cremer, D. \& Oosterwegel (1999). Collective self-esteem, personal self-esteem, and collective efficacy in in-group and outgroup evaluations. Current Psychology: Developmental, Learning, Personality, Social, 18, 326-339.

De Hooge, I. E., Zeelenberg, M., \& Breugelmans, S. M. (2010). Restore and protect motivations following shame. Cognition and Emotion, 24, 111-127.

De Rivera, J., Gerstmann, E., \& Maisels, L. (2002). Acting righteously: The influence of attitude, moral responsibility, and emotional involvement. In M. Ross, \& D. T. Miller (Eds.), The justice motive in everyday life (pp. 271-288). New York: Cambridge University Press.

De Waal, A. (2007). Darfur and the failure of the responsibility to protect. International Affairs, 83, 1039-1054.

De Waal, A. (2010). The humanitarians' tragedy: escapable and inescapable cruelties. Disasters, 34, S130-S137.

Doosje, B., Branscombe, N. R., Spears, R., \& Manstead, A. (1998). Guilty by association: When one's group has a negative history. Journal of Personality and Social Psychology, 75, 872-886.

Dovidio, J. F. \& Gaertner, S. L. (2010) Intergroup bias. In S. T. Fiske, D. T. Gilbert, \& G. Lindzey (Eds), Handbook of social psychology (pp. 1084-1121). Hoboken, NJ: John Wiley \& Sons.

Dovidio, J. F., Gaertner, S. L., \& Saguy, T.(2009). Commonality and the complexity of "we": Social attitudes and social change. Personality and Social Psychology Review, 13, 3-20. 
Dovidio, J. F., Gaertner, S. L., Shnabel, N., Saguy, T., \& Johnson, J. (2010).

Recategorization and prosocial behavior. Common ingroup identity and a dual identity. In S. Sturmer, \& M. Snyder (Eds), The psychology of prosocial behavior (pp. 191-207). Malden, MA: Wiley-Blackwell.

Dovidio, J. F., Gaertner, S. L., Validzic, A., Matoka, A, Johnson, B., \& Frazier, S. (1997). Extending the benefits of recategorization: evaluations, self-disclosure, and helping. Journal of Experimental Social Psychology, 33, 401-420.

Doosje, B., Branscombe, N. R., Spears, R., \& Manstead, A.S.R (1998). Guilty by association: When one's group has a negative history. Journal of Personality and Social Psychology, 75, 872-886.

Dumont, M., Yzerbyt, V., Wigboldus, D., \& Gordijn, E. H. (2003). Social categorization and fear reactions to the September $11^{\text {th }}$ terrorist attacks. Personality and Social Psychology Bulletin, 29, 1509-1520.

Espeland, W., \& Vannebo, B. I. (2007). Accountability, quantification, and Law. Annual Review of Law and Social Science, 3, 21-43.

Fetherstonhaugh, D., Slovic, P., Johnson, S. M., \& Friedrich, J. (1997). Insensitivity to the value of human life: A study of psychophysical numbing. Journal of Risk and Uncertainty, 14, 283-300.

Findler, L., Taubman-Ben-Ari, O. \& Ben-Shlomo, S. (2005). Journal of Religion, Disability \& Health, 9, 67-82.

Foster, M. D., \& Matheson, K. (1995). Double relative deprivation: Combining the personal and political. Personality and Social Psychology Bulletin, 21, 11671177. 
Gaertner, S. L., \& Dovidio, J. F. (2000). Reducing intergroup bias: The common ingroup identity model. Philadelphia, PA: Psychology Press.

Gill \& Matheson, K. (2006). Responses to discrimination: the role of emotion and expectations for emotional regulation. Personality and Social Psychology Bulletin, 32, 149-161.

Gizzi, M.C., Gladstone-Sovell,, T., \& Wilkerson. W. R. (2007). The web of democracy: An introduction to American Politics. United States: Wadsworth.

Glanville, L. (2012). The responsibility to protect beyond boders. Human Rights Law Review, 12(1), 1-32. Doi:10.1093/hrlr/ngr047

Gordijn, E. H., Wigboldus, D., \& Yzerbyt, V. Y. (2001). Emotional consequences of categorizing victims of negative outgroup behavior as ingroup or outgroup. Group Processes and Intergroup Relations, 4, 317-326.

Gordijn, E. H., Yzerbyt, V., Wigboldus, D., \& Dumont, M. (2006). Emotional reactions to harmful intergroup behavior. European Journal of Social Psychology, 36, 1530.

Haidt, J. (2003). The moral emotions. In R. J. Davidson, \& K. R. Scherer, \& H. H. Goldsmith (Eds.), Handbook of affective sciences (pp. 852-870). New York: Oxford University Press.

Harvey, M., \& Enzle, M. (1981). A cognitive model of social norms for understanding the transgression-helping effect. Journal of Personality and Social Psychology, $41,866-875$.

Harvey, R. D., \& Oswald, D. L. (2000). Collective guilt and shame as motivation for 
White support of Black programs. Journal of Applied Social Psychology, 30, $1790-1811$.

Haslam, N. (2006). Dehumanization: an integrative review. Personality and Social Psychology Review, 10, 252-264.

Hopkins, N., Reicher, S. Harrison, K., Cassidy, C., Bull, R., \& Levine, M. (2007). Helping to improve the group stereotype: On the strategic dimension of prosocial behavior. Personality and Social Psychology Bulletin, 33, 776-788.

Hornsey, M. J. , \& Hogg, M. A. (2000). Subgroup relations: A comparison of mutual intergroup differentiation and common ingroup models of prejudice reduction. Personality and Social Psychology Bulletin, 26, 242-256.

Hoyle, R. H. (1995). Structural Equation Modeling. Thousand Oaks: CA, SAGE Publications, Inc.

International Commission on International and State Sovereignty [ICISS] (2001). Responsibility to protect. Retrieved from http://www.iciss.ca/pdf/CommissionReport.pdf

Iyer, A., Leach, C. W., \& Pedersen, A. (2004). Racial wrongs and restitutions: The role of guilt and other group-based emotions. In N. R., Branscombe \& B. Doosje (Eds.), (2004). Collective guilt: International perspectives (pp.262-283). New York, NY: Cambridge University Press.

Iyer, A., Schmader, T., \& Lickel, B. (2007). Why individuals protest the perceived transgressions of their country: The role of anger, shame and guilt. Personality and Social Psychology Bulletin, 33, 572-587.

Jenni, K., \& Loewenstein, G. (1997). Explaining the "identifiable victim effect". Journal 
of Risk and Uncertainty, 14, 235-257.

Jetten, J., Spears, R., \& Manstead, A. S. R. (1996). Intergroup norms and intergroup discrimination: distinctive self-categorization and social identity effects. Journal of Personality and Social Psychology, 71, 1222-1233.

Johns, M., Schmader, T., \& Lickel, B. (2005). Ashamed to be an American? The role of in predicting vicarious shame for anti-Arab prejudice after 9-11. Self and Identity, 4, 331-348.

Kallgren, C. A., Reno, R. R., \& Cialdini, R. B. (2000). A focus theory of normative conduct: When norms do and do not affect behavior. Personality and Social Psychology Bulletin, 26, 1002-1012.

Karacanta, A., \& Fitness, J. (2006). Majority support for minority out-groups: The roles of compassion and guilt. Journal of Applied Social Psychology, 36, 2730-2749.

Kayangara, P., Rime, B., Philippot, P., \& Yzerbyt, V. (2007). Collective rituals, emotional climate and intergroup perception: participation in "Gacaca" Tribunals and assimilation of the Rwandan genocide. Journal of Social Issues, 63, 387-403.

Keltner, D., \& Haidt, J. (1999). Social functions of emotions at four levels of analysis. Cognition and Emotion, 13, 505-521.

Klandermans, B. (1997). The social psychology of protest. Oxford: Blackwell.

Kogut, T. \& Ritov, I. (2005a). The "Identified Victim" effect: An identified group, or just a single individual? Journal of Behavioral Decision Making, 18, 157-167.

Kogut, T., \& Ritov, I. (2005b). The singularity of identified victims in separate and joint evaluations. Organizational Behavior and Human Decision Processes, 97, $106-116$. 
Kogut, T, \& Ritov, I. (2007). “One of us”: Outstanding willingness to help save a single identified compatriot. Organizational Behavior and Human Decision Processes, 104, 150-157.

Kuppens, T., \& Yzerbyt, V. Y. (2012). Group-based emotions: The impact of social identity on appraisals, Emotions and Behaviors. Basic and Applied Social Psychology, 34, 20-33.

Kroneberg, C., Yaish,M., \& Stocke,V. (2010). Norms and rationality in electoral participation and in the rescue of Jews in WWII. Rationality and Society, 22, 336.

Krupka, E. \& Weber, R. A. (2009). The focusing and informational effects of norms on pro-social behavior. Journal of Economic Psychology, 30, 307-320.

LeBor, A. (2006). "Complicity with evil": The United Nations in the age of modern genocide. New Haven: Yale University Press.

Lerner, J. S., \& Tetlock, P. E. (1999). Accounting for the effects of accountability. Psychological Bulletin, 125, 255-275.

Levine, M., Cassidy, C., Brazier, G., \& Reicher, S. (2002). Self-categorization and bystander non-intervention: Two experimental studies. Journal of Applied Social Psychology, 32, 1452-1463.

Levine, M., Prosser, A., Evans, D., \& Reicher, S. (2005). Identity and emergency intervention: How social group membership and inclusiveness of group boundaries shapes helping behavior. Personality and Social Psychology Bulletin, $31,443-453$.

Levine, M., \& Thompson, K. (2004). Identity, place, and bystander intervention: Social 
categorization and helping after natural disasters. Journal of Social Psychology, 144, 229-245.

Lickel, B., Schmader, T., \& Barquissau, M. (2004). The evocation of moral emotions in intergroup contexts. In N. R., Branscombe \& B. Doosje (Eds.), Collective guilt: International perspectives (pp.35-55). New York, NY: Cambridge University Press.

Lickel, B., Schmader, T., Curtis, M., Scarnier, M., \& Ames, D. R. (2005). Vicarious shame and guilt. Group Processes and Intergroup Relations, 8, 145-157.

Lickel, B., Steele,R. R., \& Schmader, T. (2011). Group-based shame and guilt: Emerging directions in research. Social and Personality Psychology Compass, 5, 153-163.

Long, K. M., Spears, R., Manstead, A. S. R. (1994). The influence of personal and collective self-esteem on strategies of social differentiation. British Journal of Social Psychology, 33, 313-329.

Lopez-Perez, R. (2010). Guilt and shame: an axiomatic analysis. Theory, 69, 569-586.

Louis, W. R. (2009). Collective action - and then what? Journal of Social Issues, 65, 727-748.

Louis, W.R., Duck, J. M., Terry, D. J., Schuller, R. A., \& Lalonde, R. N. (2007). Why do citizens want to keep refugees out? Threats, fairness, and hostile norms in the treatment of asylum seekers. European Journal of Social Psychology, 37, 53-73.

Louis, W. R., Taylor, D. M., \& Douglas, R. L. (2005). Normative influence and rational conflict decisions: Group norms and cost-benefit analyses for intergroup behavior. Group Processes and Intergroup Relations, 8, 355-374.

Luke, M. A., \& Maio, G. R. (2009). Oh the humanity! Humanity-esteem and its social 
importance. Journal of Research in Personality, 43, 586-601.

MacCallum, R. C., Zhang, S., Preacher, K. J., \& Rucker, D. D. (2002). On the practice of dichotomization of quantitative variables. Psychological Methods, 7, 19-40.

Machunsky, M., Meiser, T., Mummendey, A. (2009). On the crucial role of the mental ingroup representation for ingroup bias and the ingroup prototypicality-ingroup bias link. Experimental Psychology, 56, 156-164.

Mallett, R. K., Huntsinger, J. R., Sinclair, S. \& Swim J. K. (2008). Seeing through their eyes: when majority group members take collective action on behalf of an outgroup. Group Processes and Intergroup Relations, 11, 451-470.

Mallett, R. K., \& Swim, J. K. (2007). The influence of inequality, responsibility and justifiability on report of group-based guilt for ingroup privilege. Group Processes and Intergroup Relations, 10, 57-69.

Matheson, K., Gill, R., Kelly, O., \& Anisman, H. (2008). Cortisol and cardiac reactivity in the context of sex discrimination: the moderating effects of mood and perceived control. The Open Psychology Journal, 1, 1-10.

Matheson, K., \& Anisman, H. (2008). Anger and shame elicited by discrimination: Moderating role of coping on action endorsements and salivary cortisol. European Journal of Social Psychology, 38, 1-23.

May, L. (2010). Complicity and the Rwandan genocide. Res Publica, 16, 135-152.

McDonald, R. I., Fielding, K. S., \& Louis, W. R. (2013). Energizing and de-motivating effects of norm-conflict. Personality and Social Psychology Bulletin, 39, 57-72. McGarty, C., Bliuc, A.-M., Thomas, E., \& Bongiorno, R. (2009). Collective action as the 
material expression of opinion-based group membership. Journal of Social Issues, 65, 839-857.

McGraw, K. M. (1987). Guilt following transgression: An attribution of responsibility approach. Journal of Personality and Social Psychology, 53, 247-256.

Miller, N. (2002). Personalization and the promise of contact theory. Journal of Social Issues, 58, 387-410.

Miron, A. M., Branscombe, N. R., Schmitt, M. T. (2006). Collective guilt as distress over illegitimate intergroup inequality. Group Processes and Intergroup Relations, 9, 163-180.

Monroe, K. R. (1991). John Donne’s people: Explaining difference between rational actors and altruists through cognitive frameworks. The Journal of Politics, 53, 394-433.

Monroe, K. R. (2008). Cracking the code of genocide: The moral psychology of rescuers, bystanders, and Nazis during the holocaust. Political Psychology, 29, 699-736.

Montreal Institute for Genocide and Human Rights Studies (MIGS, 2009). The will to intervene (W2I) project report, mobilizing the will to intervene: Leadership and action to prevent mass atrocities. Retrieved from http://www4.carleton.ca/cifp lapp /serve.php/1244.pdf

Morton, T.A., \& Postmes, T. (2011a). Moral duty moral defence? The effects of perceiving shared humanity with the victims of ingroup perpetrated harm. European Journal of Social Psychology, 41, 127-134.

Morton, T.A., \& Postmes, T. (2011b). What does it mean to be human? How salience of 
the human category affects responses to intergroup harm. European Journal of Social Psychology, 41, 866-873.

Mullenbach, M. T. (2005). Deciding to keep peace: An analysis of international influence on the establishment of third-party peacekeeping missions. International Studies Quaterly, 49, 529-555.

Newheiser, A-K., Sawaoka, T., \& Dovidio, J. F. (2012). Why do we punish groups? High entitative promotes moral suspicion. Journal of Experimental Social Psychology, 48, 931-936.

Nier, J. A., Gaertner, S. L., Dovidio, J. F., Banker, B. S., Ward, C. M., Rust, M. C. (2001). Changing interracial evaluations and behavior: The effects of a common group identity. Group Processes and Intergroup Relations, 4, 299-316.

Nolte, G., \& Aust, H. P. (2009). Equivocal helpers - complicit states, mixed messages and international law. International and Comparative Law Quarterly, 58, 1-30.

Pagano, S. J., \& Huo, Y. J. (2007). The role of moral emotions in predicting support for political actions in post-war Iraq. Political Psychology, 28, 227-255.

Pedhazur, E. J., \& Schmelkin, L. P. (1991). Measurement, Design, and Analysis: An integrated approach. Hiilsdale, NJ: Erlbaum.

Penner, L. A., Dovidio, J. F., Piliavin, J. A., \& Schroeder, D. A. (2005). Prosocial behavior: Multilevel perspectives. Annual Review of Psychology, 56, 365-392.

Power, S. (2003). A problem from hell: America and the age of genocide. New York: Perennial.

Prantl, J. \& Nakano, R. (2011). Global norm diffusion in East Asia: How China and 
Japan implemented the responsibility to protect. International Relations, 25, 204223.

Ray, Mackie, Rydell, \& Smith (2008). Changing categorization of self can change emotions about outgroups. Journal of Experimental Social Psychology, 44, 12101213.

Reicher, S., \& Haslam, S. A. (2010). Beyond Help. A social psychology of collective solidarity and social cohesion. In S. Sturmer, \& M. Snyder (Eds), The psychology of prosocial behavior (pp. 289-309). Malden, MA: Wiley-Blackwell.

Reicher, S., Cassidy, C., Wolpert, I., Hopkins, N., \& Levine, M. (2006). Saving Bulgaria's jews: An analysis of social identity and the mobilization of social solidarity. European Journal of Social Psychology, 36, 49-72.

Rensman, L. (2004). Collective guilt, national identity, and political processes in contemporary Germany. In N. R., Branscombe \& B. Doosje (Eds.), Collective guilt: International perspectives (pp.169-190). New York, NY: Cambridge University Press.

Ross, J., Zaldivar, A., Irani, L., \& Tomlinson, B. (2010). Who are the Turkers? Worker demographics in Amazon Mechanical Turk. Paper presented at the ACM CHI Conference.

Schmitt, M. T., Branscombe, N. R., \& Brehm, J. W. (2004). Gender inequality and the intensity of men's collective guilt. In N. R., Branscombe \& B. Doosje (Eds.), Collective guilt: International perspectives (pp.75-92). New York, NY: Cambridge University Press.

Schwartz, S. H. (1970). Elicitation of moral obligation and self-sacrificing behaviour: An 
experimental study of volunteering to be a bone marrow donor. Journal of Personality and Social Psychology, 15, 283-293.

Schwartz, S. H. (1977). Normative influences on altruism. Advances in Experimental Psychology, 10, 221-279.

Seger, C. R., Smith, E. R., Mackie, D. M. (2009). Subtle activation of a social categorization triggers group-level emotions. Journal of Experimental Social Psychology, 45, 460-467.

Sheikh, S., \& Janoff-Bulman, R. (2010). The "should" and "should nots" of moral emotions: A self-regulatory perspective on shame and guilt. Personality and Social Psychology Bulletin, 36, 213-224.

Simon, B., \& Klandermans, B. (2001). Politicized collective identity: A social psychology analysis. American Psychologist, 56, 319-331.

Slim, H. (2004). Dithering over Darfur? A preliminary review of the international response. International Affairs, 80, 811-833.

Slovic, P. (2007). "If I look at the mass I will never act": psychic numbing and genocide. Judgment and decision making, 2, 79-95.

Small, D. A., \& Loewenstein, G. (2003). Helping a victim or helping the victim: altruism and identifiability. Journal of Risk and Uncertainty, 26, 5-16.

Small, D. A. \& Loewenstein, G. (2005). The devil you know: The effects of identifiability on punitiveness. Journal of Behavioral Decision Making, 18, 311318.

Small, D. A., Loewenstein, G., \& Slovic, P. (2007). Sympathy and callousness: The 
impact of deliberative thought on donations to identifiable and statistical victims. Organizational Behavior and Human Decision Processes, 102, 143-153.

Smith, J. R., \& Louis, W. R. (2008). Do as we say and as we do: The interplay of descriptive and injunctive group norms in the attitude-behaviour relationship. British Journal of Social Psychology, 47, 647-666.

Smith, J. R., \& McSweeney, A. (2007). Charitable giving: the effectiveness of a revised theory of planned behavior model in predicting donating intentions and behaviour. Journal of Community and Applied Social Psychology, 17, 363-386.

Stanton, G. H. (2004). 'Could the Rwandan genocide have been prevented?' Journal of Genocide Research, 6, 115-133.

Staub, E. (2006). Reconciliation after genocide, mass killing, or intractable conflict: understanding the roots of violence, psychological recovery, and steps toward a general theory. Political Psychology, 27, 867-894.

Staub, E., Pearlman, L. A., Gubin, A., \& Hagengimana, A. (2005). Healing, reconciliation, forgiving and the prevention of violence after genocide or mass killing: an intervention and its experimental evaluation in Rwanda. Journal of Social and Clinical Psychology, 24, 297-334.

Steg, L. \& de Groot, J. (2010). Explaining prosocial intentions: testing causal relationships in the norm activation model. British Journal of Social Psychology, 49, $725-743$.

Stern, P. C., Dietz, T., Abel, T., Guagnano, G. A., \& Kalof, L. (1999). A value-beliefnorm theory of support for social movements: The case of environmentalism. Human Ecology Review, 6, 81-97. 
Stewart, T. L., Latu, I. M., Branscombe, N. R., \& Denney, H. T. (2010). Yes we can! Prejudice reduction through seeing (inequality) and believing (in social change). Psychological Science, 21, 1557-1562.

Swann, W. B., \& Bosson, J. K. (2010). Self and identity. In S. T. Fiske, D. T. Gilbert, \& G. Lindzey (Eds), Handbook of social psychology (pp. 589-628). Hoboken, NJ: John Wiley \& Sons.

Tabachnick, B. G., \& Fidell, L. S. (2007). Using multivariate statistics. Boston: Pearson/Allyn \& Bacon.

Tajfel, H. (1978). Differentiation between social groups: Studies in the social psychology of intergroup relations. London: Academic Press.

Tajfel, H. (1982). Social psychology of intergroup relations. Annual Review of Psychology, 33, 1-9.

Tajfel, H., \& Turner, J. C. (1979). An integrative theory of intergroup conflict. In S. Worchel \& W. G. Austin (Eds.), The social psychology of intergroup relations (pp. 33-47). Chicago, IL: Nelson-Hall.

Tajfel, H., \& Turner, J. C. (1986). The social identity theory of intergroup conflict. In S. Worchel \& W. G. Austin (Eds.), The social psychology of intergroup relations (pp. 7-24). Chicago, IL: Nelson-Hall.

Tarrant, M., Dazeley, S., Cottom, T. (2009). Social categorization and empathy for outgroup members. British Journal of Social Psychology, 48, 427-446.

Thomas, E. F., \& Louis W. R. (2013). Doing democracy: The social psychological mobilization and consequences of collective action. Social Issues and Policy review, 7, 173-200. 
Thomas, E. F., \& McGarty, C. (2009). The role of efficacy and moral outrage norms in creating the potential for international development activism through group-based interaction. British journal of Social Psychology, 48, 115-134.

Thomas, E. F., McGarty, C., \& Mavor, K. I. (2009). Transforming "apathy into movement": The role of prosocial emotions in motivating action for social change. Personality and Social Psychology Review, 13, 310-333.

Thomas, E. F., Mavor, K. I., McGarty, C. (2012). Social identities facilitate and encapsulate action-relevant constructs: A test of the social identity model of action. Group Processes and Intergroup Relations, 15, 75-88.

Tracy, J. L., \& Robins, R. W. Appraisal antecedents of shame and guilt: support for a theoretical model. Personality and Social Psychological Bulletin, 32, 1339-1351.

Turner, J. C. (1982). Towards a cognitive redefinition of the social group. In H. Tajfel (Ed.), Social identity and intergroup relations (pp.15-40). Cambridge: Cambridge University Press.

Turner, J. C., Hogg, M. A., Oakes, P. J., Reicher, S. D., \& Wetherell, M. (1987). Rediscovering the social group: A self-categorization theory. Oxford: Blackwell. Ubel, P. A., Baron, J., \& Asch, D. A. (2001). Preference for equity as a framing effect. Medical Decision Making, 21, 180-189.

Valentino, N. A., Gregorowicz, K., \& Groenendyk, E. W. (2009). Efficacy, emotions and the habit of participation. Political Behavior, 31, 307-330.

van Zomeren, M., \& Iyer, A. (2009). Introduction to the social and psychological dynamics of collective action. Journal of Social Issues, 65, 645-660.

van Zomeren, M., Postmes, T., \& Spears, R. (2008). Toward an integrative social 
identity model of collective action: A quantitative research synthesis of the three socio-psychological perspective. Psychological Bulletin, 134, 504-535.

van Zomeren, M., Spears, R., Fischer, A. H., \& Leach, C. W. (2004). Put your money where your mouth is! Explaining collective action tendencies through groupbased anger and group efficacy. Journal of Personality and Social Psychology, $87,649-664$.

Verkuyten, M., \& Hagendoorn, L. (2002). In-group favoritism and self-esteem: The role of identity level and trait valence. Group Processes and Intergroup Relations, 5, 285-297.

Warner, D. (2003). The responsibility to protect and irresponsible, cynical engagement. Millenium: Journal of International Studies, 32, 109-121.

Wenzel, M., Mummendey, A., \& Waldzus, S. (2007). Superordinate identities and intergroup conflict: The ingroup projection model. European Review of Social Psychology, 18, 331-372.

Wettstein, F. (2010). The duty to protect: Corporate complicity, political responsibility, and human rights advocacy. Journal of Business Ethics, 96, 33-47.

Wilder, D. A. (1978). Reduction of intergroup discrimination through individuation of the out-group. Journal of Personality and Social Psychology, 36, 1361-1374.

Wilder, D. A. (1986). Social categorization: Implications for cration and reduction of intergroup bias. In L. Berkowitz (Ed.), Advances in Experimental Social Psychology (vol. 19, pp. 291-355). New York: Academic Press.

Williams, P., \& Bellamy, A. J. (2005). The responsibility to protect and the crisis in Darfur. Security Dialogue, 36, 27-47. 
Wilt, J., Condon, D. M., \& Revelle, W. (2012). Telemetrics and online data collection: Collecting data at a distance. In B. Laursen, T. D. Little, and N. A. Card (Eds.) Handbook of developmental research methods (pp. 163-180). New York: Guilford Press.

Wohl, M. J. A. \& Branscombe, N. R. (2005). Forgiveness and collective guilt assignment to historical perpetrator groups depend on level of social category inclusiveness. Journal of Personality and Social Psychology, 88, 288-303.

Wohl, M. J. A., Branscombe, N. R. \& Klar, Y. (2006). Collective guilt: Emotional reactions when one's group has done wrong or been wronged. European Review of Social Psychology, 17, 1-37.

Zebel, S., Zimmermann, A., Viki, G. T., \& Doosje, B. (2008). Dehumanization and guilt as distinct but related predictors of support for reparation policies. Political Psychology, 29, 193-219.

Zimmerman, A., Abrams, D., Doosje, B. J, \& Manstead, S. R. A. (2011). Causal and moral responsibility: Antecedents and consequences of group-based guilt. European Journal of Social Psychology, 41, 825-839. 


\section{Your Take on International Conflicts}

Researchers at Carleton University are currently conducting a community survey, assessing Canadians' perspective on various international conflicts. We are hopeful that your answers will help provide us with a good idea of some of the factors that influence Canadians' views.

\section{Let us in on your perceptions and receive a \$10 gift certificate honored at Indigo/Chapters, Tim Hortons, Cineplex or Second Cup}

If you are interested in participating and are over the age of 18 and are fluent in English, you may complete the study on-line at www.copewell.carleton.ca. If you have any questions or would like a paper copy of the study sent to you to complete at home you can contact us at 6135202600 ext. 2692 or apierre2@connect.carleton.ca.

Canadians' Perspective on International Conflicts Study

www.copewell.carleton.ca

Carleton

U N I VER S I T Y 


\section{Appendix B: Presentation of study 1}

\section{Welcome to the Canadians' Perspective on International Conflicts Study}

You've now entered the study about "Canadians' Perspective on International conflicts". We're interested in studying how belonging to various groups within Canadian society influences our views on specific international conflicts occurring today. Given that Canada is comprised of many social groups and individuals with different values and priorities, we believe that it is important to know your attitudes toward specific international conflicts occurring today. The specific international conflicts we will ask you about were selected because they are currently being covered in the Canadian media.

During this study you will be asked to complete questionnaires assessing your views and attitudes toward a specific international conflict. This study is expected to take approximately $45-60$ mins and you will receive $10 \$$ gift certificate as a token of our appreciation for your participation. If you wish, you may pause during the completion of the questionnaire and return at a later time to complete the survey, but you must remember your log in user ID and your password. For privacy purposes if your internet browser is idle on one page for 5 minutes or more you will automatically be redirected from that page to the Carleton home page, and your information on that page will not be saved. You can come back later to complete it, but you need to log in with your user ID and password. We ask that you try to complete the survey within the same day of starting it. In order to be eligible to participate in this study, you MUST be a Canadian aged 18 years and older, fluent in English and currently living in Canada. If you do not meet these criteria, you will not be eligible to receive a gift card for this study.

Please complete all questionnaires truthfully. In order to guarantee the validity of the data, we will be performing validity checks. If the responses are not deemed to be valid, a gift card will not be issued. Thank you!

Ready to begin the study? 


\section{Appendix C: Informed Consent Form for Study 1}

\section{Informed Consent}

The purpose of an informed consent is to ensure that you understand the purpose of the study and the nature of your involvement. The informed consent has to provide sufficient information such that you have the opportunity to determine whether you wish to participate in the study.

Study Title: Canadians' Perspective on International Conflicts

Research Personnel: The following people are involved in this research and may be contacted at any time if you have any questions about the project, what it means, or concerns about how it was conducted:

Andrena Pierre, Researcher, Department of Psychology, (613) 520-2600 ext. 2692

Rachel Oommen, Researcher, Department of Psychology, (613) 520-2600 ext. 2683

Dr. Kim Matheson, Faculty Member, Department of Psychology, (613) 520-2684

Dr. Hymie Anisman, Faculty Member, Department of Psychology, (613) 5202699

If you have any ethical concerns about how this study was conducted, please contact either of the following:

Dr. M. Sénéchal, Chair of the Carleton University Research Ethics Committee for Psychological Research, (613) 520-2600, ext. 1155

Dr. J. Mantler, Chair, Dept. of Psychology, Carleton University, (613) 520-4173

Purpose and Task Requirements: The goal of this study is to assess the different reactions that information on conflict among groups may elicit. In this regard, you will be asked to read a short text about an important conflict between groups. In addition, you will be asked to answer a few questions about yourself in order for us to have an idea of the characteristics of the participants in the study, as well as questionnaires that assess your reactions to the issue presented in the text. This study is expected to take approximately 45-60 minutes and you will receive $10 \$$ gift certificate as a token of our appreciation for your participation.

Potential Risk and Discomfort: There are no physical risks in this study. Some individuals may experience discomfort when asked to respond to personal or sensitive questions, or read about a stressful issue. If you do feel some 
discomfort during the study you can choose to withdraw from the study. If you do feel some discomfort after the study you are encouraged to contact one of the help resources in the debriefing sheet that will be provided to you immediately after the completion of this study.

Benefits: Your honest answers are crucial as they may help us understand how a person's understanding of an issue reported in the media influences their reactions. There are no wrong or good answers; your accurate answer is the one that first comes to your mind.

Anonymity/Confidentiality: The data collected in this study will be kept anonymous and confidential. Your informed consent form will be separated from your questionnaire and kept in a separate and secured file by one of the research investigators. All individual answers will be combined for data analyses, and hence your individual name or responses would not be identifiable in any reports based on the data collected.

Right to Withdraw: Your participation in this study is entirely voluntary. At any point during the study you have the right to choose to not answer any questions, or to withdraw entirely without penalty.

Data Validity: Before sending you the gift card, we will evaluate the validity of your answers to make sure you did not respond at random. Only those participants who have taken the time to read all the questions and provide us with valid responses will be sent a gift card. In the event that an individual has not responded in good faith, we will NOT honor the gift card for that participant. Please note that you are only allowed to participate in this study once.

I have read the above description of the study concerning "Canadians' Perspective on International Conflicts". The data collected will be used in research publications and/or for teaching purposes. By clicking on "Accept", this indicates that I agree to participate in the study, and this in no way constitutes a waiver of my rights.

ACCEPT

DECLINE 


\section{Appendix D: Socio-demographic Characteristics and Engagement with Current News}

\section{Demographic Information}

Please take a few moments to complete some background information about yourself. This kind of information can help to explain certain differences that may be found among people with different perspectives and experiences. Please check the answer that best applies to you or write your answer when appropriate.

1. How did you hear about this study?

2. What is your first language?

English
Other (please specify)

3. Sex: Male French

Female

4. Age:

5. What is your ethnic/racial background? (Please check one) Asian (e.g., Chinese, Japanese, Korean) South Asian (e.g., East Indian, Pakistani, Punjabi, Sri Lankan) South East Asian (e.g., Cambodian, Indonesian, Laotian) Arab/West Asian (e.g., Armenian, Egyptian, Iranian, Lebanese, Moroccan) Black (e.g., African, Haitian, Jamaican, Somali) Latin American/Hispanic Aboriginal White/Euro-Caucasian Other (Please specify): 
Please check the answer that best applies to you or write your answer when appropriate.

6. What is your religious affiliation? (Please check one)

None-Atheist (e.g., belief that there is NO God)

None-Agnostic (e.g., belief that the existence of God cannot be known)

Protestant (e.g., United, Anglican, Baptist, Presbyterian, Lutheran,

Pentecostal, Mennonite,

"Christian")

Catholic (e.g., Roman Catholic, Ukrainian Catholic)

Jewish

Muslim

Other (Please specify):

7.What is your citizenship status?

\begin{tabular}{cll}
\hline Canadian citizen & Since what year? & Country of birth \\
Landed immigrant & Since what year? & Country of birth \\
Temporary visa & Since what year? & Country of birth
\end{tabular}

8. What is your current relationship status?

$\begin{array}{cc}\text { single } & \text { in a dating relationship } \\ \text { engaged } & \text { co-habitating } \\ \text { married } & \text { separated/divorced } \\ \text { widowed } & \end{array}$

9. Is your current partner (boyfriend, girlfriend, spouse) Male

Female ?

Please check the answer that best applies to you or write your answer when appropriate.

10. What is the highest level of education you have completed?

8 years or less of elementary school

some high school but no diploma

high school diploma or equivalent

1 to 3 years of college/university (including study at a technical college or CEGEP)

undergraduate university degree

master's degree

doctoral degree 
professional degree [medicine (M.D.), dentistry (D.D.S.), law, or other similar degrees]

11. Are you currently a student? No Yes, full time

Yes, part-time

12. Academic Major (i.e., Psychology, Sociology, Biology, etc.):

13. Are you currently employed? (please check all that apply)

Full-time Part-time Unemployed Homemaker Disability pension Social assistance ;

What is your current occupation (previous occupation if unemployed)?

14. Are you retired? No

Yes

If yes, what year did you retire in?

What was your previous occupation?

Please check the answer that best applies to you or write your answer when appropriate.

15. What is your total gross family income per annum? (check one)

Under $\$ 15,000$
$\$ 15,000-\$ 24,999$
$\$ 25,000-\$ 34,999$
$\$ 35,000-\$ 44,999$
$\$ 45,000-\$ 54,999$
$\$ 55,000-\$ 64,999$
$\$ 65,000$ or more


16. Which Canadian political party do you most identify with currently? (check one $)^{11}$

Bloc Québécois

Conservative Party of Canada

Green Party of Canada

Liberal Party of Canada

New Democratic Party

Other:

I do not identify with any of them

\section{Engagement with Current News}

\section{Please indicate the extent to which you agree with the following statements.}

1. Most issues discussed in the news don't affect me personally

$\begin{array}{lllllll}1 & 2 & 3 & 4 & 5 & 6 & 7 \\ \text { Strongly } & \text { Moderately } & \text { Mildly } & \text { Neither } & \text { Mildly } & \text { Moderately } & \text { Strongly } \\ \text { Disagree } & \text { Disagree } & \text { Disagree } & \begin{array}{l}\text { Agree Nor } \\ \text { Disagree }\end{array} & \text { Agree } & \text { Agree } & \text { Agree } \\ & & & & & \end{array}$

2. Whatever disaster happens in the United States is too far from Canada for me to be concerned

$\begin{array}{lllllll}1 & 2 & 3 & 4 & 5 & 6 & 7 \\ \text { Strongly } & \text { Moderately } & \text { Mildly } & \text { Neither } & \text { Mildly } & \text { Moderately } & \text { Strongly } \\ \text { Disagree } & \text { Disagree } & \text { Disagree } & \begin{array}{l}\text { Agree Nor } \\ \text { Disagree }\end{array} & \text { Agree } & \text { Agree } & \text { Agree }\end{array}$

3. Whatever disaster happens in South America is too far from Canada for me to be concerned

$\begin{array}{lllllll}1 & 2 & 3 & 4 & 5 & 6 & 7 \\ \text { Strongly } & \text { Moderately } & \text { Mildly } & \text { Neither } & \text { Mildly } & \text { Moderately } & \text { Strongly } \\ \text { Disagree } & \text { Disagree } & \text { Disagree } & \begin{array}{l}\text { Agree Nor } \\ \text { Disagree }\end{array} & \text { Agree } & \text { Agree } & \text { Agree } \\ & & & & & \end{array}$

\footnotetext{
${ }^{11}$ In studies 2 and 3, a yes and no question about voting was added prior to this question: "Did you vote in the last federal election?"
} 
4. Whatever disaster happens in Europe is too far from Canada for me to be concerned

$\begin{array}{lllllll}1 & 2 & 3 & 4 & 5 & 6 & 7 \\ \text { Strongly } & \text { Moderately } & \text { Mildly } & \text { Neither } & \text { Mildly } & \text { Moderately } & \text { Strongly } \\ \text { Disagree } & \text { Disagree } & \text { Disagree } & \begin{array}{l}\text { Agree Nor } \\ \text { Disagree }\end{array} & \text { Agree } & \text { Agree } & \text { Agree } \\ & & & & & \end{array}$

5. Whatever disaster happens in Asia is too far from Canada for me to be concerned.

$\begin{array}{lllllll}1 & 2 & 3 & 4 & 5 & 6 & 7 \\ \text { Strongly } & \text { Moderately } & \text { Mildly } & \text { Neither } & \text { Mildly } & \text { Moderately } & \text { Strongly } \\ \text { Disagree } & \text { Disagree } & \text { Disagree } & \begin{array}{l}\text { Agree Nor } \\ \text { Disagree }\end{array} & \text { Agree } & \text { Agree } & \text { Agree } \\ & & & & & \end{array}$

6. Whatever disaster happens in Africa is too far from Canada for me to be concerned.

$\begin{array}{lllllll}1 & 2 & 3 & 4 & 5 & 6 & 7 \\ \text { Strongly } & \text { Moderately } & \text { Mildly } & \text { Neither } & \text { Mildly } & \text { Moderately } & \text { Strongly } \\ \text { Disagree } & \text { Disagree } & \text { Disagree } & \begin{array}{l}\text { Agree Nor } \\ \text { Disagree }\end{array} & \text { Agree } & \text { Agree } & \text { Agree } \\ & & & & & \end{array}$

7. Public officials don't care much what people like me think.

\begin{tabular}{|c|c|c|c|c|c|c|}
\hline $\begin{array}{c}1 \\
\text { onglv }\end{array}$ & $\begin{array}{c}2 \\
\text { Moderatelv }\end{array}$ & $\begin{array}{r}3 \\
\text { Mildlv }\end{array}$ & $\begin{array}{c}4 \\
\text { Neither }\end{array}$ & $\begin{array}{r}5 \\
\text { Mildlv }\end{array}$ & $\begin{array}{c}6 \\
\text { Moderatelv }\end{array}$ & $\begin{array}{c}7 \\
\text { Stronalv }\end{array}$ \\
\hline agre & Disagree & Disagree & $\begin{array}{l}\text { Agree Nor } \\
\text { Disagree }\end{array}$ & Agree & Agree & Agree \\
\hline
\end{tabular}

8. People like me don't have any say about what the government does.

$\begin{array}{lllllll}1 & 2 & 3 & 4 & 5 & 6 & 7 \\ \text { Strongly } & \text { Moderately } & \text { Mildly } & \text { Neither } & \text { Mildly } & \text { Moderately } & \text { Strongly } \\ \text { Disagree } & \text { Disagree } & \text { Disagree } & \begin{array}{l}\text { Agree Nor } \\ \text { Disagree }\end{array} & \text { Agree } & \text { Agree } & \text { Agree }\end{array}$

9. Canada should give humanitarian aid like food and medicine to foreign countries even if they don't stand for the same things we do.

$\begin{array}{lllllll}1 & 2 & 3 & 4 & 5 & 6 & 7 \\ \text { Strongly } & \text { Moderately } & \text { Mildly } & \text { Neither } & \text { Mildly } & \text { Moderately } & \text { Strongly } \\ \text { Disagree } & \text { Disagree } & \text { Disagree } & \begin{array}{l}\text { Agree Nor } \\ \text { Disagree }\end{array} & \text { Agree } & \text { Agree } & \text { Agree }\end{array}$


10. The best way to insure peace is military strength.

$\begin{array}{lllllll}1 & 2 & 3 & 4 & 5 & 6 & 7 \\ \text { Strongly } & \text { Moderately } & \text { Mildly } & \text { Neither } & \text { Mildly } & \text { Moderately } & \text { Strongly } \\ \text { Disagree } & \text { Disagree } & \text { Disagree } & \begin{array}{l}\text { Agree Nor } \\ \text { Disagree }\end{array} & \text { Agree } & \text { Agree } & \text { Agree }\end{array}$

11. Diplomacy is the best way to ensure peace.

123

Strongly Moderately Mildly

Disagree Disagree Disagree $\begin{array}{cr}4 & 5\end{array}$

Agree Nor Agree Disagree 5

\begin{tabular}{cc}
\multicolumn{1}{c}{6} & 7 \\
Moderately & Strongly \\
Agree & Agree
\end{tabular}




\section{Appendix E: List of Questionnaires}

1) Socio-demographic characteristics

2a) Interpersonal reactivity index (Davis, 1980) Study 1

2b) Perception of Humanity (Luke \& Maio, 2009) Study 2

3a) Identity (group identification; modified Cameron, 2004)

3b) General Perception (based the Inventory of global social responsibility scales of Starrett, 1996) Study 2 and Study 3

4) Engagement with current news (based on Gizzi, Gladstone-Sovell, \& Wilkerson, 2007) and general knowledge on the situation in Darfur

5) Emotional reactions to the plight of the people of Darfur (18 emotional adjectives (modified version of the PANAS; Watson, Clark, \& Tellegen, 1988)) Study 1 and 22 emotional adjectives (including adjectives from Iyer, Schmader, \& Lickel (2007)) Study

\section{2 and Study 3}

6a) infrahumanization scale to characterize Darfurians (based on Cuddy et al., 2007)

\section{Study 1}

6b) Group-based anger and shame (adapted from Brown \& Cehajic, 2008; Brown et al., 2008; Pagano \& Huo, 2007). Study 2 and Study 3

7) Prototypicality (developed for study conducted in the lab) Study1

8) Infrahumanization scale (based on Cuddy et al., 2007) to characterize participants

\section{Study 1}

9) Threat and personal vulnerability (adapted from the Stress Appraisal measure (SAM) of Peacock \& Wong (1990) and previous studies on perceptions of international conflicts conducted in the lab and from the image threat literature (Iyer et al., 2007)) 
10) Collective guilt questionnaire (adapted from Branscombe, Slugoski, \& Kappen (2004)

11) Endorsement of government intervention and collective action (based on the recommendations of the MIGS (2009) and the literature on collective action (e.g., Louis, Duck, Terry, Schuller, \& Lalonde, 2007))

12) Cost-benefit of prosocial action (based on the literature on collective action (Louis 2009; Louis, Taylor, \& Neil, 2004; Miller, Cronin, Garcia, \& Branscombe, 2009; van Zomeren, Postmes, \& Spears, 2008; van Zomeren, Spears, \& Leach, 2008)) Study 2 and

\section{Study 3}

13) Efficacy (based on questions used in previous studies conducted in the lab and from van Zomeren, Spears, Fischer, \& Leach (2004), van Zomeren, Postmes, \& Spears (2008) and van Zomeren, Spears, \& Leach (2008)) Study 2 and Study 3 


\section{Appendix F: Manipulation of Levels of Social Categorization}

\section{This study is designed to assess your views and attitudes toward this specific international conflict.}

\section{1) Individual identity}

The region of Darfur in Sudan of Africa is home to communities or tribes of settled farmers who identify as African, alongside tribes of nomadic herders who identify as Arabic. In 2003, the African residents of Darfur accused the government of ethnic discrimination and of ignoring the economical development of their region. They start to rebel against the government. In response, the Sudanese government has sponsored the Janjaweed, an Arab militia on horseback, who use rape, displacement, organized starvation, and mass murder to terrorize innocent African civilians in Darfur. Despite talk on taken action to stop the violence in Darfur, the international community has not yet taken action to end the mass killings of Africans. As a result, more than 300,000 African Darfurians have died and more than 2.5 millions have fled their homes. This conflict is still ongoing today.

Hasan Al-Fashir is one more innocent African citizen who has been murdered in Darfur, leaving behind family who continue to live in fear. There is evidence that the perpetrators of his murder are supported by the Sudanese government. Several organizations are asking the international Criminal court to do justice and make the government of Sudan accountable for heinous crimes committed against specifics individuals in Darfur.

\section{2) Outgroup identity}

The region of Darfur in Sudan of Africa is home to communities or tribes of settled farmers who identify as African, alongside tribes of nomadic herders who identify as Arabic. In 2003, the African residents of Darfur accused the government of ethnic discrimination and of ignoring the economical development of their region. They start to rebel against the government. In response, the Sudanese government has sponsored the Janjaweed, an Arab militia on horseback, who use rape, displacement, organized starvation, and mass murder to terrorize innocent African civilians in Darfur. Despite talk on taken action to stop the violence in Darfur, the international community has not yet taken action to end the mass killings of Africans. As a result, more than 300,000 African Darfurians have died and more than 2.5 millions have fled their homes. This conflict is still ongoing today.

Hundreds of thousands of innocent citizens have been murdered in Darfur because of their ethnicity among other things. There is evidence that the perpetrators of these murders are supported by the Sudanese government. Several organizations are asking the international Criminal court to do justice and 
make the government of Sudan accountable for heinous crimes committed against specifics groups in Darfur.

\section{3) Common ingroup identity}

The region of Darfur in Sudan of Africa is home to communities or tribes of settled farmers who identify as African, alongside tribes of nomadic herders who identify as Arabic. In 2003, the African residents of Darfur accused the government of ethnic discrimination and of ignoring the economical development of their region. They start to rebel against the government. In response, the Sudanese government has sponsored the Janjaweed, an Arab militia on horseback, who use rape, displacement, organized starvation, and mass murder to terrorize innocent African civilians in Darfur. Despite talk on taken action to stop the violence in Darfur, the international community has not yet taken action to end the mass killings of Africans. As a result, more than 300,000 African Darfurians have died and more than 2.5 millions have fled their homes. This conflict is still ongoing today.

Hundreds of thousands of innocent citizens have been murdered in countries around the world because of their ethnicity among other things. There is evidence that the perpetrators of these murders are supported by the government of the state. Several organizations are asking the international Criminal Court to do justice and make governments of states accountable for heinous crimes committed against citizens of their countries. 


\section{Appendix G: Measures}

\section{General knowledge on the situation in Darfur}

1. How familiar are you with this issue?

Not at all

123

3

4

5

6

7

Extremely

2. How important is this issue to you?

Not at all

12

3

4

5

6

7

Extremely

3. How important do you think this issue is to most Canadians?

Not at all

1

2

3

4

5

6

$7 \quad$ Extremely 


\section{Emotional reactions to the plight of the people of Darfur}

How do you feel when you think about the conflict in Darfur?

\begin{tabular}{|c|c|c|c|c|c|c|c|c|c|}
\hline Angry........ & Not at all & 1 & 2 & 3 & 4 & 5 & 6 & 7 & Extremely \\
\hline Anxious... & Not at all & 1 & 2 & 3 & 4 & 5 & 6 & 7 & Extremely \\
\hline Ashamed... & Not at all & 1 & 2 & 3 & 4 & 5 & 6 & 7 & Extremely \\
\hline Contempt................ & Not at all & 1 & 2 & 3 & 4 & 5 & 6 & 7 & Extremely \\
\hline Disgust.................... & Not at all & 1 & 2 & 3 & 4 & 5 & 6 & 7 & Extremely \\
\hline Enraged.. & Not at all & 1 & 2 & 3 & 4 & 5 & 6 & 7 & Extremely \\
\hline Fearful.... & Not at all & 1 & 2 & 3 & 4 & 5 & 6 & 7 & Extremel \\
\hline Frustrated. & Not at all & 1 & 2 & 3 & 4 & 5 & 6 & 7 & Extremel \\
\hline Guilty.................... & Not at all & 1 & 2 & 3 & 4 & 5 & 6 & 7 & Extremely \\
\hline Hopeful................. & Not at all & 1 & 2 & 3 & 4 & 5 & 6 & 7 & Extremely \\
\hline Helpless.... & Not at all & 1 & 2 & 3 & 4 & 5 & 6 & 7 & Extremely \\
\hline Indifferent.. & Not at all & 1 & 2 & 3 & 4 & 5 & 6 & 7 & Extremel \\
\hline Infuriated................ & Not at all & 1 & 2 & 3 & 4 & 5 & 6 & 7 & Extremely \\
\hline Moral Outrage.. & Not at all & 1 & 2 & 3 & 4 & 5 & 6 & 7 & Extremel \\
\hline Remorse............. & Not at all & 1 & 2 & 3 & 4 & 5 & 6 & 7 & Extremel \\
\hline Sad..... & Not at all & 1 & 2 & 3 & 4 & 5 & 6 & 7 & Extremel \\
\hline Upset..................... & Not at all & 1 & 2 & 3 & 4 & 5 & 6 & 7 & Extreme \\
\hline Worried.... & Not at all & 1 & 2 & 3 & 4 & 5 & 6 & 7 & Extreme \\
\hline
\end{tabular}




\section{Appraisals*}

Please indicate how much you agree or disagree with each of the following statements.

1. Canada has its own concerns, and so realistically, does not have the moral authority to intercede on behalf of the people of Sudan.

$\begin{array}{llllllllll}\text { Strongly Disagree } & 1 & 2 & 3 & 4 & 5 & 6 & 7 & \text { Strongly Agree }\end{array}$

*2. If Canada does not intercede on behalf of the people of Sudan, we become complicit in the genocide of the people of Darfur.

$\begin{array}{lllllllll}\text { Strongly Disagree } & 1 & 2 & 3 & 4 & 5 & 6 & 7 & \text { Strongly Agree }\end{array}$

3. I have my own concerns, and so realistically, I do not feel any urge to intercede on behalf of the people of Darfur.

$\begin{array}{llllllllll}\text { Strongly Disagree } & 1 & 2 & 3 & 4 & 5 & 6 & 7 & \text { Strongly Agree }\end{array}$

*4. If I don't take action on behalf of the people of Darfur, I become complicit in the genocide of the people of Darfur.

$\begin{array}{lllllllll}\text { Strongly Disagree } & 1 & 2 & 3 & 4 & 5 & 6 & 7 & \text { Strongly Agree }\end{array}$ 


\section{Accountability AND Collective Guilt*}

We are interested in knowing what your beliefs are regarding responsibility for the Canadian government to protect innocent civilians in the situation in Darfur. Please indicate how much you agree or disagree with each of the following statements.

1. The world has benefited at the expense of Black African countries for generations.

$\begin{array}{lllllllll}\text { Strongly Disagree } & 1 & 2 & 3 & 4 & 5 & 6 & 7 & \text { Strongly Agree }\end{array}$

2. It upsets me that Black African countries have been exploited by the western world throughout history.

$\begin{array}{llllllllll}\text { Strongly Disagree } & 1 & 2 & 3 & 4 & 5 & 6 & 7 & \text { Strongly Agree }\end{array}$

3. Darfurians are entitled to concessions for past wrongs that have been done to Black Africans.

$\begin{array}{lllllllll}\text { Strongly Disagree } & 1 & 2 & 3 & 4 & 5 & 6 & 7 & \text { Strongly Agree }\end{array}$

4. Because many nations have chosen to ignore or perpetrate the oppression of Black Africans, they now owe Darfurians their support.

$\begin{array}{llllllllll}\text { Strongly Disagree } & 1 & 2 & 3 & 4 & 5 & 6 & 7 & \text { Strongly Agree }\end{array}$

5. It distresses me that Darfurians suffer today because of the wrongs perpetrated against them throughout history.

$\begin{array}{lllllllll}\text { Strongly Disagree } & 1 & 2 & 3 & 4 & 5 & 6 & 7 & \text { Strongly Agree }\end{array}$

6. It distresses me that Darfurians suffer today because of the violence against them.

$\begin{array}{lllllllll}\text { Strongly Disagree } & 1 & 2 & 3 & 4 & 5 & 6 & 7 & \text { Strongly Agree }\end{array}$

*7. If the inaction of Canadian government harms members of a group, then all Canadians should feel guilty.

Strongly Disagree

*8. All Canadians ought to be held responsible for the inaction of their government.

Strongly Disagree

${ }^{*} 9$. I can see holding all Canadians responsible for the measures against genocide that their government has not taken.

$\begin{array}{lllllllll}\text { Strongly Disagree } & 1 & 2 & 3 & 4 & 5 & 6 & 7 & \text { Strongly Agree }\end{array}$

*10. Society, like individuals, ought to be held accountable for their actions or inactions.

$\begin{array}{lllllllll}\text { Strongly Disagree } & 1 & 2 & 3 & 4 & 5 & 6 & 7 & \text { Strongly Agree }\end{array}$ 
*11. I think that all Canadians are accountable for what their government does or does not do.

$\begin{array}{lllllllll}\text { Strongly Disagree } & 1 & 2 & 3 & 4 & 5 & 6 & 7 & \text { Strongly Agree }\end{array}$

*12. I feel regret for Canada's inactions toward the Darfurians.

$\begin{array}{lllllllll}\text { Strongly Disagree } & 1 & 2 & 3 & 4 & 5 & 6 & 7 & \text { Strongly Agree }\end{array}$

*13. I feel guilty about the inaction of Canada toward the Darfurians.

$\begin{array}{lllllllll}\text { Strongly Disagree } & 1 & 2 & 3 & 4 & 5 & 6 & 7 & \text { Strongly Agree }\end{array}$

*14. I feel regret for the inaction of Canada to stop the mass killing in Darfur.

$\begin{array}{lllllllll}\text { Strongly Disagree } & 1 & 2 & 3 & 4 & 5 & 6 & 7 & \text { Strongly Agree }\end{array}$

15. I believe that the Canadian government should repair the damage caused by the Sudanese government.

$\begin{array}{lllllllll}\text { Strongly Disagree } & 1 & 2 & 3 & 4 & 5 & 6 & 7 & \text { Strongly Agree }\end{array}$

*16. I can easily feel guilty for the bad outcomes brought in Darfur by the inaction of Canada.

$\begin{array}{lllllllll}\text { Strongly Disagree } & 1 & 2 & 3 & 4 & 5 & 6 & 7 & \text { Strongly Agree }\end{array}$




\section{Measures of Prosocial Actions}

Governments of any powerful country are often confronted with making decisions regarding how to position themselves with regard to specific international conflicts. We are interested in how you perceive the treatment of Darfurians, and the Canadian government's actions to deal with it. For each of the following questions, please indicate the extent to which you agree or disagree with the statement.

1. Canada should encourage the international community to punish those responsible of the mass killing in Darfur.

\begin{tabular}{|c|c|c|c|c|c|c|}
\hline 1 & 2 & 3 & 4 & 5 & 6 & 7 \\
\hline Strongly & Moderately & Mildly & Neither & Mildly & Moderately & Strongly \\
\hline Disagree & Disagree & Disagree & $\begin{array}{l}\text { Agree Nor } \\
\text { Disagree }\end{array}$ & Agree & Agree & Agree \\
\hline
\end{tabular}

2. Canada should pressure the United Nation Security Council to send military troops to Darfur.

$\begin{array}{lllllll}1 & 2 & 3 & 4 & 5 & 6 & 7 \\ \text { Strongly } & \text { Moderately } & \text { Mildly } & \text { Neither } & \text { Mildly } & \text { Moderately } & \text { Strongly } \\ \text { Disagree } & \text { Disagree } & \text { Disagree } & \begin{array}{l}\text { Agree Nor } \\ \text { Disagree }\end{array} & \text { Agree } & \text { Agree } & \text { Agree } \\ & & & & & \end{array}$

3. If international military action is taken in Darfur, then Canada should participate.

\begin{tabular}{|c|c|c|c|c|c|c|}
\hline 1 & 2 & 3 & 4 & 5 & 6 & 7 \\
\hline Strongly & Moderately & Mildly & Neither & Mildly & Moderately & Strongly \\
\hline Disagree & Disagree & Disagree & $\begin{array}{l}\text { Agree Nor } \\
\text { Disagree }\end{array}$ & Agree & Agree & Agree \\
\hline
\end{tabular}

4. Canada should participate in diplomatic talks aiming at stopping the mass killing in Darfur.

$\begin{array}{lllllll}1 & 2 & 3 & 4 & 5 & 6 & 7 \\ \text { Strongly } & \text { Moderately } & \text { Mildly } & \text { Neither } & \text { Mildly } & \text { Moderately } & \text { Strongly } \\ \text { Disagree } & \text { Disagree } & \text { Disagree } & \begin{array}{l}\text { Agree Nor } \\ \text { Disagree }\end{array} & \text { Agree } & \text { Agree } & \text { Agree } \\ & & & \text { aree }\end{array}$

5. Canada should create a genocide prevention center that will monitor and react to early signs in order to prevent mass atrocities in countries over the world. 


\begin{tabular}{|c|c|c|c|c|c|c|}
\hline 1 & 2 & 3 & 4 & 5 & 6 & 7 \\
\hline Strongly & Moderately & Mildly & Neither & Mildly & Moderately & Strongly \\
\hline Disagree & Disagree & Disagree & $\begin{array}{l}\text { Agree Nor } \\
\text { Disagree }\end{array}$ & Agree & Agree & Agree \\
\hline
\end{tabular}

6. If a state is unwilling or unable to protect its own citizens against gross violations of internationally recognized human rights, the international community must assume the responsibility to protect them.

\begin{tabular}{|c|c|c|c|c|c|c|}
\hline 1 & 2 & 3 & 4 & 5 & 6 & 7 \\
\hline Strongly & Moderately & Mildly & Neither & Mildly & Moderately & Strongly \\
\hline Disagree & Disagree & Disagree & $\begin{array}{l}\text { Agree Nor } \\
\text { Disagree }\end{array}$ & Agree & Agree & Agree \\
\hline
\end{tabular}

7. The purpose of Canadian foreign policy should be to take action to save lives and to prevent the loss of life around the world

\begin{tabular}{|c|c|c|c|c|c|c|}
\hline 1 & 2 & 3 & 4 & 5 & 6 & 7 \\
\hline Strongly & Moderately & Mildly & Neither & Mildly & Moderately & Strongly \\
\hline Disagree & Disagree & Disagree & $\begin{array}{l}\text { Agree Nor } \\
\text { Disagree }\end{array}$ & Agree & Agree & Agree \\
\hline
\end{tabular}

8. The international community should actively protect civil populations against war crime, ethnic cleansing, crime against humanity and genocide.

\begin{tabular}{|c|c|c|c|c|c|c|}
\hline 1 & 2 & 3 & 4 & 5 & 6 & 7 \\
\hline Strongly & Moderately & Mildly & Neither & Mildly & Moderately & Strongly \\
\hline Disagree & Disagree & Disagree & $\begin{array}{l}\text { Agree Nor } \\
\text { Disagree }\end{array}$ & Agree & Agree & Agree \\
\hline
\end{tabular}

9. Prevention of mass atrocities needs to be integrated into Canada Foreign Policy

\begin{tabular}{|c|c|c|c|c|c|c|}
\hline 1 & 2 & 3 & 4 & 5 & 6 & 7 \\
\hline Strongly & Moderately & Mildly & Neither & Mildly & Moderately & Strongly \\
\hline Disagree & Disagree & Disagree & $\begin{array}{l}\text { Agree Nor } \\
\text { Disagree }\end{array}$ & Agree & Agree & Agree \\
\hline
\end{tabular}

10. To lower the likelihood of mass atrocities, it is important to take a preventive approach and address the structural elements of endemic poverty and inequality

$\begin{array}{llllccc}1 & 2 & 3 & 4 & 5 & 6 & 7 \\ \text { Strongly } & \text { Moderately } & \text { Mildly } & \text { Neither } & \text { Mildly } & \text { Moderately } & \text { Strongly } \\ \text { Disagree } & \text { Disagree } & \text { Disagree } & \begin{array}{l}\text { Agree Nor } \\ \text { Disagree }\end{array} & \text { Agree } & \text { Agree } & \text { Agree }\end{array}$


The citizens of any powerful country are themselves confronted with making a decision regarding how to respond to a conflict between groups. We are interested in how you perceive the treatment of Darfurians, and your own actions to deal with it. For each of the following questions, please indicate the extent to which you agree or disagree with the statement.

1
Strongly

2

3

4

5

6

7

Disagree

Strongly

Agree

1. I Would be willing to call the 1-800-GENOCID line to ask the Canadian government to prevent and protect populations of other countries from mass atrocities.

2. I follow the media coverage regarding the Canadian government involvement in the Darfur conflict.

3. I support the Darfurian in their plight.

4. I'm willing to write letters to politicians to encourage them to take action to stop the atrocities in Darfur

5. I'm willing to get involved with groups who are lobbying for appropriate action to be taken to stop the atrocities in Darfur.

6. I'd be willing to join a protest march to bring peace and reconciliation in Darfur.

7. l'd be willing to donate money to organizations or events aimed at getting justice and fair treatment for the innocent civilians in Darfur. 


\section{Appendix H- Feel Good Statement}

Please think of a positive interaction you had with another person of another ethnicity that make you feel good about yourself. Please write it down. 


\section{Appendix I: Debriefing and Contact Information for Study 1}

The following two pages should be printed and kept for future reference. The responsibility to protect refers to the idea that sovereign states have a responsibility to protect their own citizens from avoidable catastrophe such as mass murder, rape, and starvation. However, when States are unwilling or unable to protect their own citizens, that responsibility must be taken by the wider international community. The inaction of the international community to stop the genocide that occurred in Rwanda in 1994 or to prevent the massacre of civilians in Bosnia in 1995 has shown the horror of inaction.

The region of Darfur in Sudan of Africa is home to communities or tribes of settled farmers who identify as African, alongside tribes of nomadic herders who identify as Arabic. In 2003, the African residents of Darfur accused the government of ethnic discrimination and of ignoring the economical development of their region. They start to rebel against the government. In response, the Sudanese government has sponsored the Janjaweed, an Arab militia on horseback, who use rape, displacement, organized starvation, and mass murder to terrorize innocent civilians in Darfur. Despite talk on taken action to stop the violence in Darfur, the international community has not yet taken action to end the mass killings. As a result, more than 300,000 Darfurians have died and more than 2.5 millions have fled their homes. This conflict is still ongoing today. In the present investigation, our objective was to assess the reactions of Canadians on the genocide that is occurring in Darfur. More specifically, we wanted to assess the factors that may influence reactions to this conflict. Thus, in our study we have included numerous measures assessing emotional reactions, how close to the conflict you feel, and your views on the issue on the inaction of the Canadian Government and on actions that you will be willing to support in order to stop the genocide.

Our hope is that studies like this will help guide Canadian foreign policy, including our involvement in preventing and stopping genocide or other atrocities. Taken together, we believe that our results will provide important information that can be taken into consideration in the formulation of foreign policies that recognize the needs and priorities of Canadians. We appreciate the time you have taken to participate.

If you know of anyone who might be interested in participating in our study, we would greatly appreciate it if you could let them know about our website address, www.copewell.carleton.ca. Or if you think they would be more comfortable completing a hard copy version of the questionnaire, we will gladly mail it to them if they email us at life_experiences@carleton.ca or phone us at (613) 520-2600 ext. 2692. 


\section{Contacts}

The following people are involved in this research project and may be contacted at any time if you have any further questions about the project, what it means, or concerns about how it was conducted:

Andrena Pierre

Phone: (613) 520-2600 \# 2692

Email: apierre2@connect.carleton.ca

Rachel Oommen

Phone: (613) 520-2600 \# 2683

Email: life_experiences@carleton.ca

Dr. Kim Matheson

Phone: (613) 520-3570

Email: kim_matheson@carleton.ca

Dr. Hymie Anisman

Phone: (613) 520-2699

Email: hymie_anisman@carleton.ca

If you have any ethical concerns about how this study was conducted, please contact

Dr. M. Sénéchal, Chair of the Carleton University Research Ethics

Committee for Psychological Research, (613) 520-2600, ext. 1155

If you have any other concerns about this study or how it was conducted, please contact

Dr. J. Mantler, Chair, Dept. of Psychology, Carleton University, (613) 520 4173

Some participants may feel sadness or distress as a result of this study. If any distress you experience is more than temporary, or if you would like to speak to someone about this distress, then you may want to contact your family physician. Your family physician will usually be able to help you or to refer you to someone who can. If you do not have a family physician, then contact any of the following:

\section{Hospital Directories:}

Alberta: http://www.health.alberta.ca/ http://www.fsnhospitals.com/Canada-Hospitals/Alberta-Hospitals/

British Colombia: http://www.health.gov.bc.ca/socsec/pdf/hospitallist.pdf http://www.fsnhospitals.com/Canada-Hospitals/British-Columbia-Hospitals/

Saskatchewan: http://www.fsnhospitals.com/Canada-Hospitals/SaskatchewanHospitals/Saskatoon-Hospitals/

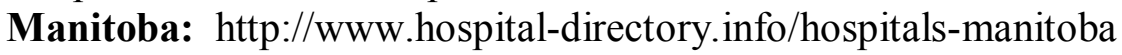
http://www.fsnhospitals.com/Canada-Hospitals/Manitoba-Hospitals/

Ontario: http://www.health.gov.on.ca/english/public/contact/hosp/hosploc_mn.html http://www.fsnhospitals.com/Canada-Hospitals/Ontario-Hospitals/ 
Quebec: http://www.fsnhospitals.com/Canada-Hospitals/Quebec-Hospitals/QuebecHospitals/

New Brunswick: http://nb.finditincanada.ca/app/search/cat-12014

http://www.fsnhospitals.com/Canada-Hospitals/New-Brunswick-Hospitals/

Nova Scotia: http://www.fsnhospitals.com/Canada-Hospitals/Nova-Scotia-Hospitals/

Prince Edward Island: http://www.fsnhospitals.com/Canada-Hospitals/Prince-EdwardIsland-Hospitals/

Newfoundland: http://www.fsnhospitals.com/Canada-Hospitals/Newfoundland-

Hospitals/

Yukon: http://www.fsnhospitals.com/Canada-Hospitals/Yukon-Territory-Hospitals/

Nunavut: http://www.ementalhealth.ca/site/nu-baffin/index.php?m=2\&ID=992

Northwest Territories: http://www.fsnhospitals.com/Canada-Hospitals/NorthwestTerritory-Hospitals/

Thank you for your participation in this survey! 


\section{Appendix J: Announcement for Recruitment for Study $2^{12}$}

\section{Interested in completing an online study?}

Researchers at Carleton University are currently conducting a community survey, assessing Canadians' perspective on various international conflicts. If you are a Canadian citizen, are over the age of 18 and are currently residing in Canada, you have a chance to receive a $\$ 5.00$ gift card to Tim Hortons by completing a 30 minute survey on “Canadians' Perspective on International Conflicts ” online at:

https://www.psychdata.com/s.asp?SID=140843

This study has been approved by the Carleton University Ethics Committee for Psychological Research (Ethics \# 11-163).

12 Note that Study 2 was conducted under the title Canadians' Perspective on International Conflicts Study III 
MTurk letter of information

Canadians' Perspective on International Conflicts Study III

Duration: 30 minutes, Reward: $\$ 1.00$

The study will be completed online at a secure site (psychdata.com)

TO BE ELIGIBLE FOR THIS HIT, YOU MUST BE A CANADIAN CITIZEN AGED 18 YEARS AND OLDER, FLUENT IN ENGLISH, CURRENTLY LIVING IN CANADA, AND YOU MUST HAVE NOT PARTICIPED IN ANY STUDIES THAT CONTAIN CANADIANS' PERSPECTIVE ON INTERNATIONAL CONFLICTS IN THE TITLE

We're interested in studying how belonging to various groups within Canadian society influences our views on specific international conflicts occurring today. Given that Canada is comprised of many social groups and individuals with different values and priorities, we believe that it is important to know your attitudes toward specific international conflicts occurring today. The specific international conflicts we will ask you about were selected because they were covered in the Canadian media.

Your participation in this study is entirely voluntary. During this study you will be asked to complete questionnaires assessing your views and attitudes toward a specific international conflict. This study is expected to take approximately 30 minutes and you will receive $\$ 1.00$ in appreciation of your participation. To complete the survey, copy and paste this link in a new window or click on this
link: https://www.psychdata.com/s.asp? $S I D=151243$ (The link will open in a new window)

At the end of the survey you will be given a code. Enter the correct code below and your hit will be approved.

Enter survey completion code here:

This study has received clearance by the Carleton University Psychology Research Ethics Board (Reference \# 11-163) 


\section{Appendix K: Presentation of Study 2}

\section{Welcome to the Canadians' Perspective on International Conflicts Study III}

You've now entered the study about "Canadians' Perspective on International conflicts III". We're interested in studying how belonging to various groups within Canadian society influences our views on specific international conflicts occurring today. Given that Canada is comprised of many social groups and individuals with different values and priorities, we believe that it is important to know your attitudes toward specific international conflicts occurring today. The specific international conflicts we will ask you about were selected because they were covered in the Canadian media.

During this study you will be asked to complete questionnaires assessing your views and attitudes toward a specific international conflict. This study is expected to take approximately 30 mins and you will receive $5 \$$ gift certificate as a token of our appreciation for your participation. If you wish, you may pause during the completion of the questionnaire and return at a later time to complete the survey, but you must remember your login user ID and your password. For privacy purposes if your internet browser is idle on one page for 5 minutes or more you will automatically be redirected from that page to the Carleton home page, and your information on that page will not be saved. You can come back later to complete it, but you need to log in with your user ID and password. We ask that you try to complete the survey within the same day of starting it.

In order to be eligible to participate in this study, you MUST BE A CANADIAN

CITIZEN AGED 18 YEARS AND OLDER, FLUENT IN ENGLISH, CURRENTLY LIVING IN CANADA, AND YOU MUST HAVE NOT PARTICIPED IN ANY STUDIES THAT CONTAIN CANADIANS' PERSPECTIVE ON INTERNATIONAL CONFLICTS IN THE TITLE. If you do not meet all of these criteria, you will not be eligible to receive a gift card for this study. Please complete all questionnaires truthfully. In order to guarantee the validity of the data, we will be performing validity checks (e.g., answers to 9 preselected pair of questions and 3 single questions will be examined). Only those participants who have taken the time to read all the questions and provided valid responses to the preselected questions will be sent a gift card. Thank you! 


\section{Appendix L- Informed Consent Form for Study 2}

\section{Informed Consent}

The purpose of an informed consent is to ensure that you understand the purpose of the study and the nature of your involvement. The informed consent has to provide sufficient information such that you have the opportunity to determine whether you wish to participate in the study.

Study Title: Canadians' Perspective on International Conflicts III

Research Personnel: The following people are involved in this research and may be contacted at any time if you have any questions about the project, what it means, or concerns about how it was conducted:

Andrena Pierre, Principal Investigator, Department of Psychology, (613) 520-2600 ext. 2692, apierre2@connect.carleton.ca

Dr. Tracey Cronin, Postdoctoral Research Fellow, Department of Psychology, (613) 5202684, tracey_cronin@carleton.ca

Dr. Kim Matheson, Faculty Sponsor, Department of Psychology, (613) 520-3570, kim_matheson@carleton.ca

Dr. Hymie Anisman, Faculty Sponsor, Department of Psychology, (613) 520-2699, hymie_anisman@carleton.ca

\section{Ethical concerns: If you have any ethical concerns about how this study was} conducted, please contact:

Dr. M. Sénéchal, Chair of the Carleton University Research Ethics Committee for Psychological Research, (613) 520-2600, ext. 1155, monique_senechal@carleton.ca

Any other concerns: If you have any other concerns about how this study was conducted, please contact:

Dr. A. Bowker, Chair, Department of Psychology, Carleton University, (613) 520-8218, psychchair@carleton.ca

Purpose and Task Requirements: The goal of this study is to assess the different reactions that information on conflict among groups may elicit. In this regard, you will be asked to carefully read a short text about an important conflict between groups. In 
addition, you will be asked to answer a few questions about yourself in order for us to have an idea of the characteristics of the participants in the study, as well as questionnaires that assess your reactions to the issue presented in the text. This study is expected to take approximately 30 minutes and you will receive $5 \$$ gift certificate as a token of our appreciation for your participation.

Potential Risk and Discomfort: There are no physical risks in this study. Some individuals may experience discomfort when asked to respond to personal or sensitive questions, or read about a stressful issue. If you do feel some discomfort during the study you can choose to withdraw from the study by clicking on the withdraw button, located at the bottom of each questions' page. When you click on the withdraw button, you will get access to the debriefing and contact resources. If you do feel some discomfort after the study you are encouraged to contact one of the help resources in the debriefing sheet that will be provided to you immediately after the completion of this study.

Benefits: Your truthful answers are crucial as they may help us understand how a person's understanding of an issue reported in the media influences their reactions. There are no wrong or good answers; your truthful answer is the one that first comes to your mind.

Anonymity/Confidentiality: The data collected in this study will be kept confidential, and is associated only with a numeric code. All individual answers will be combined for data analyses, and hence your individual responses would not be identifiable in any reports based on the data collected. Your personal information will be stored in a computer file separate from the information provided in the questionnaires. Your data (identified by code and not your name) will be stored in secured files that will only be accessible by the researchers involved in this study.

Right to Withdraw: Your participation in this study is entirely voluntary. At any point during the study you have the right to choose to not answer any questions, or to withdraw entirely without penalty. If you choose to withdraw you would not be able to complete the study at a later time. 
Data Validity: Before sending you the gift card, we will evaluate the validity of your answers to make sure you did not respond at random. Only those participants who have taken the time to read all the questions and provided valid responses to the preselected questions ( 9 pair of questions and 3 single questions) will be sent a gift card. Please note that you are only allowed to participate in this study once. You will not receive a gift card if you participate more than once.

I have read the above description of the study concerning "Canadians' Perspective on International Conflicts III". The data collected will be used in research publications and/or for teaching purposes. By clicking on "Accept", this indicates that I agree to participate in the study, and this in no way constitutes a waiver of my rights.

ACCEPT

DECLINE

This study has received clearance by the Carleton University Psychology Research Ethics Board (Ethics \# 11-163). 


\section{Appendix M: Humanity-Esteem}

\section{Perception of Humanity}

The following statements ask about your beliefs and perceptions of human beings in general, regardless of religion, ethnicity, or gender. That is, what are your thoughts about the average human being? Please rate the extent to which you agree or disagree with each of the following statements using the scale:

$1=$ strongly disagree $\quad 2=$ moderately disagree $\quad 3=$ slightly disagree

$4=$ neither agree or disagree $5=$ slightly agree $\quad 6=$ moderately agree

$7=$ strongly agree

1. I feel that the human species is very valuable, at least on equal plane with other species in the universe.

2. I feel that human beings have a number of very good qualities.

3. All in all, I am inclined to regard the human species as a failure

4. Human beings are able to prosper as well as any other species in the universe.

5. I feel that human beings do not have much to be proud of.

6. I take a positive attitude toward humanity.

7. On the whole, I am satisfied with the evolution of humanity

8. I wish I could have more respect for humanity in general.

9. Human beings are useless at times

10. At times I think that human beings are no good at all 


\section{Appendix N: Manipulation of Levels of Social Categorization for Study 2}

\section{This study is designed to assess your views and attitudes toward this specific international conflict. Please read carefully what follow as you will be asked questions about what you remember of it.}

The region of Darfur in Sudan of Africa is home to communities or tribes of settled farmers who identify as African, alongside tribes of nomadic herders who identify as Arabic. In 2003, the African residents of Darfur accused the government of ethnic discrimination and of ignoring the economical development of their region. They start to rebel against the government. In response, the Sudanese government has sponsored the Janjaweed, an Arab militia on horseback, who use rape, displacement, organized starvation, and mass murder to terrorize innocent African civilians in Darfur. As a result, more than 300,000 African Darfurians have died and more than 2.5 millions have fled their homes. This conflict is still ongoing today.

1) Outgroup identity

Hundreds of thousands of Sudanese citizens have been murdered in Darfur, because of their ethnicity among other things, leaving behind families who continue to live in fear. There is evidence that the perpetrators of these murders are supported by the Sudanese government. Several organizations are asking the international Criminal court to do justice and make the government of Sudan accountable for heinous crimes committed against specifics groups in Darfur.

2) Common ingroup identity

Hundreds of thousands of humans have been murdered in countries around the world, because of their ethnicity among other things, leaving behind families who continue to live in fear. There is evidence that the perpetrators of these murders are supported by governments of states. Several organizations are asking the international Criminal Court to do justice and make governments of states accountable for heinous crimes committed against humans in our planet. 


\section{Appendix O: Debriefing for Study 2}

\section{Debriefing}

\section{The following pages should be printed and kept for future reference.}

This research survey draws on the emerging theoretical and empirical literature on third party interventions in conflict situations, including the Responsibility to Protect (R2P) norm, in which Canada played a leading role (International Commission on Intervention and State Sovereignty [ICISS], 2001) and the mobilization of a collective will to intervene following R2P (Chalk, Dallaire, Matthews, Barqueiro, \& Doyle, 2010; Montreal Institute for Genocide and Human Rights Studies [MIGS], 2009). Based on various theoretical models, in this study we consider how people evaluate, feel and behave depending on the salience of their group identity in this instance as Canadians. In addition, we are interested in whether emotions (in this instance, collective guilt, anger, and shame) for actions taken by other members of their ingroup (i.e., the Canadian government) are linked to mobilizing collective action. Finally, we are testing the notion of whether these effects vary depending on whether the scenario read included a description of a single, but identifiable, victim or it described the plight of a large number of victims.

To assess our hypotheses, we wanted to examine reactions to real-world situations, where it was feasible to consider different factors that might come into play to influence support for third party interventions. The conflict in Darfur was used in this study because of the existed body of literature delineating factors being brought into play in this conflict (Badescu \& Berghom, 2009; Booker, 2008; de Waal, 2007, Slim, 2004; Williams \& Bellamy, 2005).

The region of Darfur in Sudan of Africa is home to communities or tribes of settled farmers who identify as African, alongside tribes of nomadic herders who identify as Arabic. In 2003, the African residents of Darfur accused the government of ethnic discrimination and of ignoring the economical development of their region. They start to rebel against the government. In response, the Sudanese government has sponsored the Janjaweed, an Arab militia on horseback, who use rape, displacement, organized 
starvation, and mass murder to terrorize innocent civilians in Darfur. As a result, more than 300,000 Darfurians have died and more than 2.5 million have fled their homes.

It is important to note that since 2006 Canada has been contributing humanitarian assistance and development aid in Sudan, and has been involved in the process of peacebuilding. Due to the continued effort of Canada and other members of the United Nations, a ceasefire was signed between Sudan's president and the leader of the Liberation and Justice Movement (LJM) on July 2011. Hence, it is important to keep in mind that any reference to the inaction of Canada in this conflict was hypothetical. As stated by the Canadian government,

\footnotetext{
"Canada takes every appropriate opportunity to raise its concerns for the humanitarian and security situation in Sudan as well as to promote Canada's foreign policy priorities of freedom, democracy, human rights and the rule of law. Several regions such as Darfur, South Kordofan, Blue Nile and Abyei are severely affected by ongoing conflict. [...] Canada has implemented a number of national measures against Sudan in response to the government's role in the country's conflicts, and in support of Canada's policy for peace in this country"
}

(http://www.canadainternational.gc.ca/sudan south sudansoudan_soudan_du_sud/sudan-bilateral-soudan.aspx?lang=eng\&view=d, retrieved September 27, 2012). For more information on the involvement of Canada in Sudan, please visit the website of Canada: Active in Sudan:

http://www.canadainternational.gc.ca/sudan_south_sudan$\underline{\text { soudan_soudan_du_sud/index.aspx?lang=eng\&view }=\mathrm{d}}$

We appreciate the time you have taken to participate.

\section{Contacts}

The following people are involved in this research project and may be contacted at any time if you have any further questions about the project, what it means, or concerns about how it was conducted:

Andrena Pierre

Phone: (613) 520-2600 \# 2692

Dr. Tracey Cronin

Phone: (613) 520-2684

Dr. Kim Matheson

Phone: (613) 520-3570
Email: apierre2@connect.carleton.ca

Email: tracey_cronin@carleton.ca

Email: kim_matheson@carleton.ca 
Dr. Hymie Anisman

Phone: (613) 520-2699

Email: hymie_anisman@carleton.ca

If you have any ethical concerns about how this study was conducted, please contact

Dr. Avi Parush, Chair of the Carleton University Research Ethics Committee for

Psychological Research, (613) 520-2600, ext.6026, avi_parush@carleton.ca

\section{If you have any other concerns about this study or how it was conducted, please contact}

Dr. A. Bowker, Chair, Department of Psychology, Carleton University, (613) 520-2600, ext.8218,psychchair@carleton.ca

Some participants may feel sadness or distress as a result of this study. If any distress you experience is more than temporary, or if you would like to speak to someone about this distress, then you may want to contact your family physician. Your family physician will usually be able to help you or to refer you to someone who can. If you do not have a family physician, then contact any of the following:

\section{Hospital Directories:}

Alberta: http://www.health.alberta.ca/ http://www.fsnhospitals.com/Canada-Hospitals/Alberta-Hospitals/

British Colombia: http://www.health.gov.bc.ca/socsec/pdf/hospitallist.pdf http://www.fsnhospitals.com/Canada-Hospitals/British-Columbia-Hospitals/ Saskatchewan: http://www.fsnhospitals.com/Canada-Hospitals/SaskatchewanHospitals/Saskatoon-Hospitals/

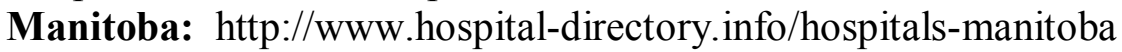
http://www.fsnhospitals.com/Canada-Hospitals/Manitoba-Hospitals/

Ontario: http://www.health.gov.on.ca/english/public/contact/hosp/hosploc_mn.html http://www.fsnhospitals.com/Canada-Hospitals/Ontario-Hospitals/

Quebec: http://www.fsnhospitals.com/Canada-Hospitals/Quebec-Hospitals/QuebecHospitals/

New Brunswick: http://nb.finditincanada.ca/app/search/cat-12014 http://www.fsnhospitals.com/Canada-Hospitals/New-Brunswick-Hospitals/

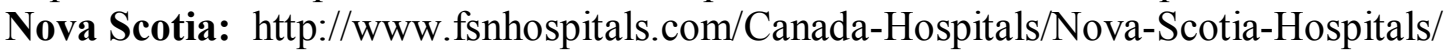

Prince Edward Island: http://www.fsnhospitals.com/Canada-Hospitals/Prince-EdwardIsland-Hospitals/

Newfoundland: http://www.fsnhospitals.com/Canada-Hospitals/NewfoundlandHospitals/ 
Yukon: http://www.fsnhospitals.com/Canada-Hospitals/Yukon-Territory-Hospitals/

Nunavut: http://www.ementalhealth.ca/site/nu-baffin/index.php?m=2\&ID=992

Northwest Territories: http://www.fsnhospitals.com/Canada-Hospitals/Northwest-

Territory-Hospitals/

Thank you for your participation in this survey!

This study has received clearance by the Carleton University Psychology Research Ethics Board (ethics \# 11-163). 


\section{Appendix P: Invitation to Participate in Study $3^{13}$}

\section{Greetings,}

We are writing you because you have participated in one or more online research studies at http://www.copewell.carleton.ca/project22/prod120308/1-indexPro22.php and you have accepted to be contacted for future studies. We are currently conducting a community survey, assessing Canadians' perspective on various international conflicts. If you are interested in participating and are a Canadian citizen aged 18 years and older and are fluent in English, you may complete the study on-line at

http://www.copewell.carleton.ca/project22/prod120308/1-indexPro22.php

Your answers will help provide us with a good idea of some of the factors that influence Canadians'views on specific international conflicts occurring today. As a token of our appreciation for your time, should your answers to our question pass the validity check (e.g., answers to 9 preselected pair of questions and 3 single questions will be examined to check that answers are not given at random), you will receive a $\$ 10 \mathrm{gift}$ certificate honored at Indigo/Chapters, Tim Hortons, Cineplex or Second Cup. If you have already participated in the study Canadians' Perspective on International Conflicts between the month of June 2010 and August 2010, please discard this email and please accept our apology for sending this email. We are only recruiting people who have not participated in our previous study on international conflicts conducted during the year 2010.

If you have any questions or would like a paper copy of the study sent to you to complete at home you can contact us at 613-520-2600 ext. 2692 or apierre2@carleton.ca.

Thank you,

\footnotetext{
${ }^{13}$ Note that Study 3 was conducted under the title "Canadians' Perspective on International Conflicts Study II".
} 
Research team

For Canadians' Perspective on International Conflicts Study II

Please click on this link to enter the study website:

http://www.copewell.carleton.ca/project22/prod120308/1-indexPro22.php

This study has received clearance by the Carleton University Psychology

Research Ethics Board (Ethics \# 11-097). 


\section{Appendix Q - Presentation of study 3}

\section{Welcome to the Canadians' Perspective on International Conflicts Study II}

You've now entered the study about "Canadians' Perspective on International conflicts II". We're interested in studying how belonging to various groups within Canadian society influences our views on specific international conflicts occurring today. Given that Canada is comprised of many social groups and individuals with different values and priorities, we believe that it is important to know your attitudes toward specific international conflicts occurring today. The specific international conflicts we will ask you about were selected because they were covered in the Canadian media.

During this study you will be asked to complete questionnaires assessing your views and attitudes toward a specific international conflict. This study is expected to take approximately 45 mins and you will receive $10 \$$ gift certificate as a token of our appreciation for your participation. If you wish, you may pause during the completion of the questionnaire and return at a later time to complete the survey, but you must remember your log in user ID and your password. For privacy purposes if your internet browser is idle on one page for 5 minutes or more you will automatically be redirected from that page to the Carleton home page, and your information on that page will not be saved. You can come back later to complete it, but you need to log in with your user ID and password. We ask that you try to complete the survey within the same day of starting it.

In order to be eligible to participate in this study, you MUST be a Canadian citizen aged 18 years and older, fluent in English, currently living in Canada, and YOU MUST HAVE NOT PARTICIPED IN THE STUDY CANADIANS'PERSPECTIVE ON INTERNATIONAL CONFLICTS LAST SUMMER. If you do not meet all of these criteria, you will not be eligible to receive a gift card for this study.

Please complete all questionnaires truthfully. In order to guarantee the validity of the data, we will be performing validity checks (e.g., answers to 9 preselected pair of questions and 3 single questions will be examined to check that answers are not given at random). If the responses are deemed to be random, a gift card will not be issued. Thank you! 


\section{Appendix R - Informed Consent Form for Study 3}

\section{Informed Consent}

The purpose of an informed consent is to ensure that you understand the purpose of the study and the nature of your involvement. The informed consent has to provide sufficient information such that you have the opportunity to determine whether you wish to participate in the study.

Study Title: Canadians' Perspective on International Conflicts II

Research Personnel: The following people are involved in this research and may be contacted at any time if you have any questions about the project, what it means, or concerns about how it was conducted:

Andrena Pierre, Researcher, Department of Psychology, (613) 520-2600 ext. 2692, apierre2@connect.carleton.ca

Rachel Oommen, Researcher, Department of Psychology, (613) 520-2600 ext. 2683, rachel_oommen@carleton.ca

Dr. Kim Matheson, Faculty Member, Department of Psychology, (613) 520-3570, kim_matheson@carleton.ca

Dr. Hymie Anisman, Faculty Member, Department of Psychology, (613) 5202699, hymie_anisman@carleton.ca

\section{If you have any ethical concerns about how this study was conducted, please contact either of the following:}

Dr. M. Sénéchal, Chair of the Carleton University Research Ethics Committee for Psychological Research, (613) 520-2600, ext. 1155, monique_senechal@carleton.ca

Dr. J. Mantler, Chair, Department of Psychology, Carleton University, (613) 5204173, janet_mantler@carleton.ca

Purpose and Task Requirements: The goal of this study is to assess the different reactions that information on conflict among groups may elicit. In this regard, you will be asked to carefully read a short text about an important conflict between groups. In addition, you will be asked to answer a few questions about yourself in order for us to have an idea of the characteristics of the participants in the study, as well as questionnaires that assess your reactions to the issue presented in the text. This study is expected to take approximately 45 minutes and you will receive $10 \$$ gift certificate as a token of our appreciation for your participation. 
Potential Risk and Discomfort: There are no physical risks in this study. Some individuals may experience discomfort when asked to respond to personal or sensitive questions, or read about a stressful issue. If you do feel some discomfort during the study you can choose to withdraw from the study. If you do feel some discomfort after the study you are encouraged to contact one of the help resources in the debriefing sheet that will be provided to you immediately after the completion of this study.

Benefits: Your truthful answers are crucial as they may help us understand how a person's understanding of an issue reported in the media influences their reactions. There are no wrong or good answers; your truthful answer is the one that first comes to your mind.

Anonymity/Confidentiality: The data collected in this study will be kept anonymous and confidential. Your informed consent form will be separated from your questionnaire and kept in a separate and secured file by one of the research investigators. All individual answers will be combined for data analyses, and hence your individual name or responses would not be identifiable in any reports based on the data collected.

Right to Withdraw: Your participation in this study is entirely voluntary. At any point during the study you have the right to choose to not answer any questions, or to withdraw entirely without penalty. A "withdraw button" will be provided for you on each questionnaire page should you desire to exit the survey at any time.

Data Validity: Before sending you the gift card, we will evaluate the validity of your answers to make sure you did not respond at random. Only those participants who have taken the time to read all the questions and provide us with valid responses will be sent a gift card. In the event that an individual has responded at random, we will NOT honor the gift card for that participant. Please note that you are only allowed to participate in this study once.

I have read the above description of the study concerning "Canadians' Perspective on International Conflicts II". The data collected will be used in research publications and/or for teaching purposes. By clicking on "Accept", this indicates that I agree to participate in the study, and this in no way constitutes a waiver of my rights.

ACCEPT

DECLINE

This study has received clearance by the Carleton University Psychology Research Ethics Board (11-097), ethics file number will be indicated once obtained). 


\section{Appendix S: Debriefing and Contact Information}

\section{The following two pages should be printed and kept for future reference.}

The responsibility to protect refers to the idea that sovereign states have a responsibility to protect their own citizens from avoidable catastrophe such as mass murder, rape, and starvation. However, when States are unwilling or unable to protect their own citizens, this responsibility must be taken by the wider international community. The inaction of the international community to stop the genocide that occurred in Rwanda in 1994 or to prevent the massacre of civilians in Bosnia in 1995 has shown the horror of inaction.

The region of Darfur in Sudan of Africa is home to communities or tribes of settled farmers who identify as African, alongside tribes of nomadic herders who identify as Arabic. In 2003, the African residents of Darfur accused the government of ethnic discrimination and of ignoring the economical development of their region. They start to rebel against the government. In response, the Sudanese government has sponsored the Janjaweed, an Arab militia on horseback, who use rape, displacement, organized starvation, and mass murder to terrorize innocent civilians in Darfur. Despite talk on taken action to stop the violence in Darfur, the international community has not yet taken action to end the mass killings. As a result, more than 300,000 Darfurians have died and more than 2.5 millions have fled their homes. Although a ceasefire was signed between Sudan's president and the leader of the Justice and Equality Movement (JEM) on February 2010, not all rebel groups were represented. So, the conflict is still not completely ended.

In the present investigation, our objective was to assess the reactions of Canadians when norms about the right to protect are not activated, activated or deactivated. More specifically, we wanted to assess whether the norms that ask Canadians to prevent and stop genocide may influence reactions to the Darfur conflict. Thus, in our study we have included numerous measures assessing emotional reactions, how close to the conflict you feel, and your views on the issue on the inaction of the Canadian Government and on actions that you will be willing to support in order to stop the genocide.

Our hope is that studies like this will help guide Canadian foreign policy, including our involvement in preventing and stopping genocide or other atrocities. Taken together, we believe that our results will provide important information that can be taken into consideration in the formulation of foreign policies that recognize the needs and priorities of Canadians. We appreciate the time you have taken to participate. 


\section{Contacts}

The following people are involved in this research project and may be contacted at any time if you have any further questions about the project, what it means, or concerns about how it was conducted:

Andrena Pierre

Phone: (613) 520-2600 \# 2692

Email: apierre2@connect.carleton.ca

Rachel Oommen

Phone: (613) 520-2600 \# 2683

Email: rachel_oommen@carleton.ca

Dr. Kim Matheson

Phone: (613) 520-3570

Email:kim_matheson@carleton.ca

Dr. Hymie Anisman

Phone: (613) 520-2699

Email: hymie_anisman@carleton.ca

If you have any ethical concerns about how this study was conducted, please contact

Dr. M. Sénéchal, Chair of the Carleton University Research Ethics Committee for

Psychological Research, (613) 520-2600, ext. 1155,

monique_senechal@carleton.ca

If you have any other concerns about this study or how it was conducted, please contact

Dr. J. Mantler, Chair, Department of Psychology, Carleton University, (613) 5204173, janet_mantler@carleton.ca

Some participants may feel sadness or distress as a result of this study. If any distress you experience is more than temporary, or if you would like to speak to someone about this distress, then you may want to contact your family physician. Your family physician will usually be able to help you or to refer you to someone who can. If you do not have a family physician, then contact any of the following:

\section{Hospital Directories:}

Alberta: http://www.health.alberta.ca/

http://www.fsnhospitals.com/Canada-Hospitals/Alberta-Hospitals/

British Colombia: http://www.health.gov.bc.ca/socsec/pdf/hospitallist.pdf http://www.fsnhospitals.com/Canada-Hospitals/British-Columbia-Hospitals/

Saskatchewan: http://www.fsnhospitals.com/Canada-Hospitals/Saskatchewan-

Hospitals/Saskatoon-Hospitals/

Manitoba: http://www.hospital-directory.info/hospitals-manitoba http://www.fsnhospitals.com/Canada-Hospitals/Manitoba-Hospitals/

Ontario: http://www.health.gov.on.ca/english/public/contact/hosp/hosploc_mn.html http://www.fsnhospitals.com/Canada-Hospitals/Ontario-Hospitals/ 
Quebec: http://www.fsnhospitals.com/Canada-Hospitals/Quebec-Hospitals/QuebecHospitals/

New Brunswick: http://nb.finditincanada.ca/app/search/cat-12014

http://www.fsnhospitals.com/Canada-Hospitals/New-Brunswick-Hospitals/

Nova Scotia: http://www.fsnhospitals.com/Canada-Hospitals/Nova-Scotia-Hospitals/

Prince Edward Island: http://www.fsnhospitals.com/Canada-Hospitals/Prince-EdwardIsland-Hospitals/

Newfoundland: http://www.fsnhospitals.com/Canada-Hospitals/Newfoundland-

Hospitals/

Yukon: http://www.fsnhospitals.com/Canada-Hospitals/Yukon-Territory-Hospitals/

Nunavut: http://www.ementalhealth.ca/site/nu-baffin/index.php?m=2\&ID=992

Northwest Territories: http://www.fsnhospitals.com/Canada-Hospitals/NorthwestTerritory-Hospitals/

Thank you for your participation in this survey! 


\section{Appendix T - Manipulation of Norms}

This study is designed to assess your views and attitudes toward this specific international conflict. Please read the following text carefully as you will later be asked to answer question on what you understood and remembered from this text.

\section{1) ACTIVATION OF R2P}

The United Nations' norm Responsibility to Protect (R2P) states that each state has a responsibility to protect its citizens from mass killings and other gross violations of their rights. In the instance that a state is unable or unwilling to carry out that function, the state is considered to have given up its sovereignty, and the responsibility to protect is passed on to the international community.

The region of Darfur in Sudan of Africa is home to communities or tribes of settled farmers who identify as African, alongside tribes of nomadic herders who identify as Arabic. In 2003, the African residents of Darfur accused the government of ethnic discrimination and of ignoring the economical development of their region. They start to rebel against the government. In response, the Sudanese government has sponsored the Janjaweed, an Arab militia on horseback, who use rape, displacement, organized starvation, and mass murder to terrorize innocent African civilians in Darfur. As a result, more than 300,000 African Darfurians have died and more than 2.5 millions have fled their homes. This conflict is still ongoing today.

Adal Khatir is one more innocent African citizen who has been murdered in Darfur, leaving behind family who continue to live in fear. There is evidence that the perpetrators of his murder are supported by the Sudanese government. Several organizations are asking the International Community to intervene in Darfur in order to stop the mass killings.

\section{2) SIMULTANEOUS ACTIVATION OF R2P AND NON-INTERVENTION NORMS}

The United Nations' norm Responsibility to Protect (R2P) states that each state has a responsibility to protect its citizens from mass killings and other gross violations of their rights. In the instance that a state is unable or unwilling to carry out that function, the state is considered to have given up its sovereignty, and the responsibility to protect is passed on to the international community. However, the fundamental principle of international law regarding state sovereignty stipulates that any intervention of the international community into a state is a violation of this state sovereignty and freedom. The region of Darfur in Sudan of Africa is home to communities or tribes of settled farmers who identify as African, alongside tribes of nomadic herders who identify as Arabic. In 2003, the African residents of Darfur accused the government of ethnic discrimination and of ignoring the economical development of their region. They start to rebel against the government. In response, the Sudanese government has sponsored the Janjaweed, an Arab militia on horseback, who use rape, displacement, organized 
starvation, and mass murder to terrorize innocent African civilians in Darfur. As a result, more than 300,000 African Darfurians have died and more than 2.5 millions have fled their homes. This conflict is still ongoing today.

Adal Khatir is one more innocent African citizen who has been murdered in Darfur, leaving behind family who continue to live in fear. There is evidence that the perpetrators of his murder are supported by the Sudanese government. Several organizations are asking the International Community to intervene in Darfur in order to stop the mass killings.

\section{3) CONTROL (no normative information)}

The region of Darfur in Sudan of Africa is home to communities or tribes of settled farmers who identify as African, alongside tribes of nomadic herders who identify as Arabic. In 2003, the African residents of Darfur accused the government of ethnic discrimination and of ignoring the economical development of their region. They start to rebel against the government. In response, the Sudanese government has sponsored the Janjaweed, an Arab militia on horseback, who use rape, displacement, organized starvation, and mass murder to terrorize innocent African civilians in Darfur. As a result, more than 300,000 African Darfurians have died and more than 2.5 millions have fled their homes. This conflict is still ongoing today.

Adal Khatir is one more innocent African citizen who has been murdered in Darfur, leaving behind family who continue to live in fear. There is evidence that the perpetrators of his murder are supported by the Sudanese government. Several organizations are asking the International Community to intervene in Darfur in order to stop the mass killings. 